\title{
HABILIDADES DO DESENVOLVIMENTO EM CRIANÇAS COM HIPOTIREOIDISMO CONGÊNITO: ENFOQUE NA COMUNICAÇÃO
}

Mariana Germano Gejão

\begin{abstract}
Dissertação apresentada à Faculdade de Odontologia de Bauru, da Universidade de São Paulo, como parte dos requisitos para a obtenção do título de Mestre em Fonoaudiologia.
\end{abstract}

BAURU

2006 


\section{HABILIDADES DO DESENVOLVIMENTO EM CRIANÇAS COM HIPOTIREOIDISMO CONGÊNITO: ENFOQUE NA COMUNICAÇÃO}

Mariana Germano Gejão

Dissertação apresentada à Faculdade de Odontologia de Bauru, da Universidade de São Paulo, como parte dos requisitos para a obtenção do título de Mestre em Fonoaudiologia.

Orientadora: Prof $^{\mathrm{a}} \mathrm{Dr}^{\mathrm{a}}$ Dionísia Aparecida Cusin Lamônica

BAURU 2006 
Gejão, Mariana Germano.

G279h Habilidades do desenvolvimento em crianças com hipotireoidismo congênito: enfoque na comunicação / Mariana Germano Gejão. - Bauru, 2006.

148p. : il.; $31 \mathrm{~cm}$.

Dissertação. (Mestrado) - Faculdade de Odontologia de Bauru.

USP.

Orientadora: Prof $^{\mathrm{a}} \mathrm{Dr}^{\mathrm{a}}$ Dionísia Aparecida Cusin Lamônica

Autorizo, exclusivamente para fins acadêmicos e científicos, a reprodução total ou parcial desta dissertação, por processos fotocopiadores e outros meios eletrônicos.

Data de aprovação pelo Comitê de Ética em Pesquisa da FOB: 05 de julho de 2005. Processo n 53/2005. 



\section{Mariana Germano Gejão}

07 de dezembro de 1982

FILIAÇÃO

$2001-2004$

2001-2004

2001-2002

$2005-2006$
Nascimento, Bauru - SP.

Paulo Donizete Gejão.

Luzia Teresa Germano.

Curso de Fonoaudiologia - Faculdade de Odontologia de Bauru - USP.

Membro da Comissão Organizadora da Jornada Fonoaudiológica da Faculdade de Odontologia de Bauru - USP.

Membro do Centro Acadêmico IX de Dezembro do Curso de Fonoaudiologia da Faculdade de Odontologia de Bauru - USP.

Curso de Pós-Graduação em Fonoaudiologia, em nível de Mestrado Faculdade de Odontologia de Bauru, USP. 
"A cada dia que vivo, mais me convenço de que o desperdício da vida está no amor que não damos, nas forças que não usamos, na prudência egoísta que nada arrisca, e que, esquivando-se dos sofrimentos, perdemos também a felicidade" (autor desconhecido) 


\section{DEDICATÓRIA}

DEDICO este trabalho...

... aos meus pais PAULO e LUZIA, que sempre acreditaram nos meus sonhos e me ajudaram a torná-los realidade. Devo esta conquista a vocês!

... às minhas irmãs e amigas DANIELE e NATALIA. Obrigada por serem tão queridas e pela força que recebi de vocês em todos os momentos de minha vida.

... à minha segunda família, SÔNIA e ROBERTO. Obrigada pelo incentivo constante e, principalmente, pelo amor e carinho de pais.

... ao meu namorado, RODRIGO, companheiro e o amor da minha vida. Obrigada pelo apoio e compreensão durante a realização deste estudo. É maravilhoso poder contar com a força e o amor e de alguém tão especial.

AMO VOCÊS!!! 


\section{AGRADECIMENTO ESPECIAL}

À minha querida orientadora Prof ${ }^{\mathrm{a}}$ Dr $^{\mathrm{a}}$ Dionísia Aparecida Cusin Lamônica, exemplo de dedicação a fonoaudiologia e profissionalismo.

Ensinou-me que o papel de um mestre não é apenas transmitir ensinamentos, mas também e, talvez principalmente, despertar o interesse do aprendiz pela busca do conhecimento.

Obrigada por acreditar neste estudo, por me acompanhar desde a Graduação, pelos ensinamentos transmitidos e pelo apoio nos momentos que precisei. $O$ carinho e a dedicação incansável com os quais me orientou tornou este estudo ainda mais prazeroso e especial. Serei eternamente grata!

Agradeço sua amizade que, gentilmente, me permitiu desfrutar.

Agradeço sua energia que, positivamente, muitas batalhas me ajudou a ganhar. Agradeço sua força que, bravamente, conseguiu me emprestar.

Agradeço ao seu coração todo carinho que pôde me dar... (autor desconhecido) 


\section{AGRADECIMENTOS}

À equipe do Laboratório de Screening Neonatal "Teste do Pezinho" da Associação de Pais e Amigos dos Excepcionais de Bauru, por acreditarem neste estudo e pelo carinho com que me receberam durante a coleta de dados.

Às crianças participantes deste estudo, que o tornaram ainda mais especial e, aos seus familiares, pela confiança, disponibilidade e exemplo de força e dedicação.

À minha querida amiga Sushila N. Aguiar, pelo apoio incondicional e auxílio na coleta de dados.

Ao Prof. Dr. José Roberto Lauris, pelo auxílio e orientação na realização da análise estatística deste estudo.

À Valéria Cristina Trindade Ferraz pelas orientações na elaboração e normatização desta dissertação.

Às minhas queridas amigas da $\mathbf{1}^{\text {a }}$ Turma de Mestrado em Fonoaudiologia, Vanessa, Dáphine, Luciana Silva, Simone, Maria Cecília, Isabel, Josilene, Ana Dolores, Daniela e Luciana Merighi, pela amizade e por terem tornado esta jornada, se não menos árdua, com certeza mais prazerosa e alegre.

Aos Professores do Departamento de Fonoaudiologia, pelos conhecimentos científicos e humanos que nos transmitiram e que certamente serão parte de nossas vidas. Obrigada pelo carinho.

Ao Eliton Carlos Galeli de Oliveira e Wlademir da Silva, pela amizade, atenção e auxílio sempre que precisei. 
Aos Funcionários não docentes do Departamento de Fonoaudiologia e da Clínica de Fonoaudiologia, que foram sempre atenciosos nos momentos em que precisei.

Aos Funcionários da Secretaria de Pós-graduação, pelo carinho e atenção dedicados à $1^{\text {a }}$ Turma de Mestrado em Fonoaudiologia.

À FOB/USP, na pessoa de seu Diretor, Prof. Dr. Luiz Fernando Pegoraro. Por seis anos a FOB foi minha segunda casa. Devo minha formação profissional a esta instituição.

À minha "irmãzinha" Laena Teresinha Monteiro, pelo companheirismo tão sincero e por todo o apoio nas horas mais difíceis. Mesmo distante, sei que sempre poderei contar com você.

À minha querida amiga Olivia Machado. Sempre lembrarei com muito carinho de tudo que passamos durante nossa Graduação. Obrigada pela amizade!

Aos meus cunhados Alessandra, Adriano e Juliana, pelo carinho e torcida durante a realização desta etapa de minha vida. 


\section{SUMÁRIO}

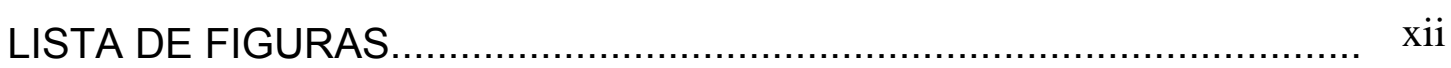

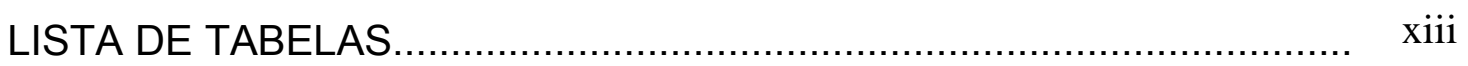

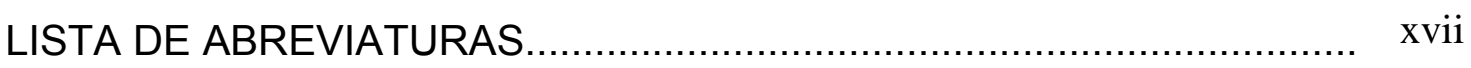

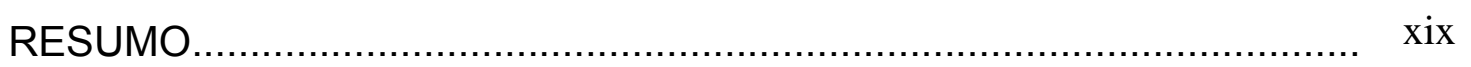

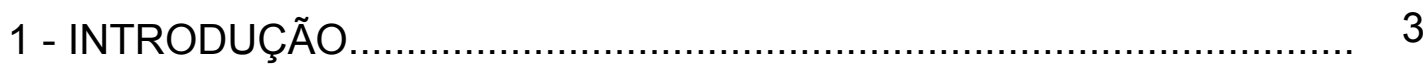

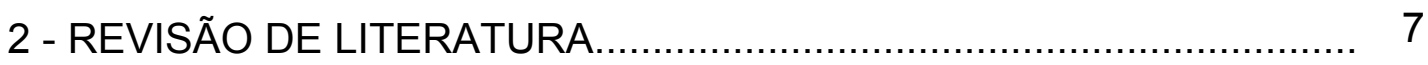

2.1 - Hipotireoidismo congênito e suas formas.................................. 7

2.2 - Hormônios tireoideanos e o sistema nervoso................................. 9

2.3 - Diagnóstico e tratamento do hipotireoidismo congênito..................... 13

2.4 - Desenvolvimento na presença do hipotireoidismo congênito............. 20

3 - HABILIDADES DO DESENVOLVIMENTO NO HIPOTIREOIDISMO 43 CONGÊNITO: ENFOQUE NA COMUNICAÇÃO.................................

4 - PROPOSIÇÃO.................................................................. 49

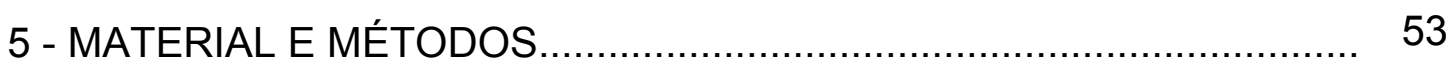

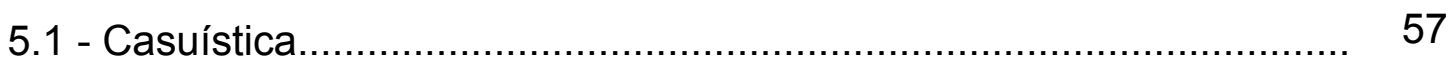

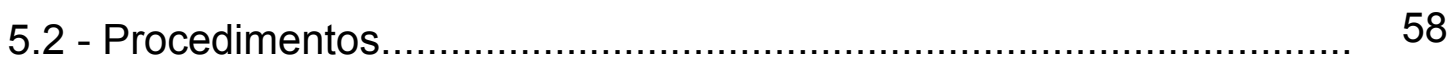

5.3 - Critérios de classificação dos resultados.................................. 64

5.4 - Método estatístico............................................................... 65

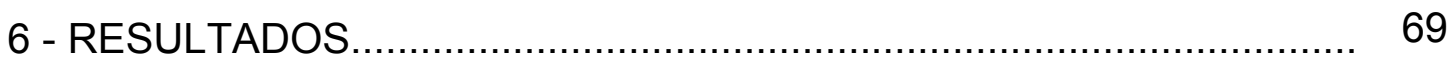

6.1 - Perfil das habilidades do desenvolvimento............................. 69

6.2 - Dados da história clínica........................................................ 73

6.3 - Análise da influência da história clínica no perfil das habilidades do 85

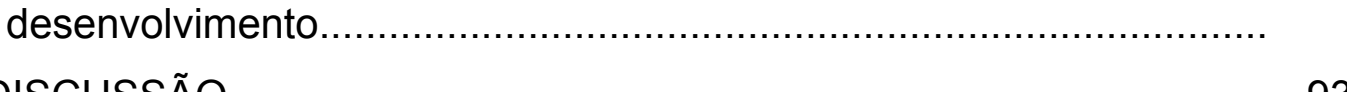

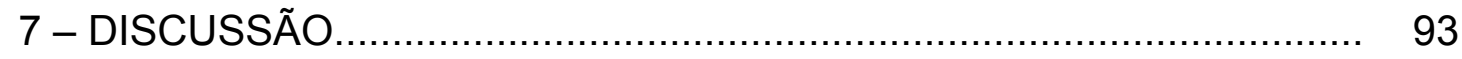


8 - CONCLUSÃO.

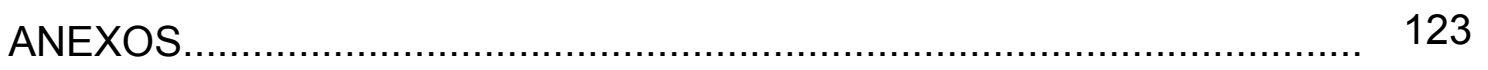

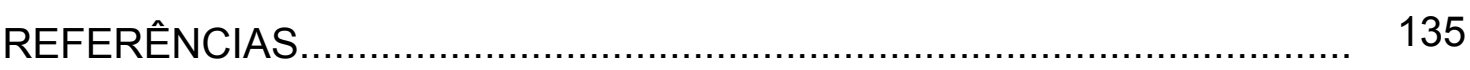

ABSTRACT 


\section{LISTA DE FIGURAS}

FIGURA 1 - Número de crianças nascidas vivas, número de crianças triadas, cobertura populacional da TN, número de diagnósticos de $\mathrm{HC}$ e prevalência do $\mathrm{HC}$ durante o período de 2002 a 2005

FIGURA 2 - Número de itens do IPO a serem realizados por mês em cada área de avaliação de acordo com a faixa etária.

FIGURA 3 - Proposta de LANDIS e KOCH, 1977, para a análise dos resultados da Estatística kappa 


\section{LISTA DE TABELAS}

TABELA 1 - Distribuição da casuística quanto à idade na época da coleta de dados e quanto ao gênero.

TABELA 2 - Distribuição da casuística quanto ao desempenho global obtido na Escala ELM e no IPO ........................................ 70

TABELA 3 - Distribuição da casuística quanto ao desempenho nas funções auditiva expressiva, auditiva receptiva e visual da Escala ELM.

TABELA 4 - Distribuição da casuística quanto aos meses de atraso nas funções auditiva expressiva, auditiva receptiva e visual da Escala ELM...

TABELA 5 - Distribuição da casuística quanto ao desempenho nas áreas autocuidados, socialização, motora, cognição, linguagem, e estimulação infantil do IPO.

TABELA 6 - Distribuição da casuística quanto aos meses de atraso nas áreas autocuidados, socialização, motora, cognição, linguagem e estimulação infantil do IPO.

TABELA 7 - Concordância entre o desempenho da casuística na Escala ELM e o desempenho na área de linguagem do IPO.

TABELA 8 - Caracterização da casuística quanto à idade na coleta de dados, ao peso no nascimento, às idades ao realizar a $\mathrm{TN}$, receber o diagnóstico e iniciar o tratamento para $\mathrm{O}$ $\mathrm{HC}$, ao nível de TSH obtido na TN e à dosagem de levotiroxina no início do tratamento.

TABELA 9 - Distribuição da casuística quanto ao peso no nascimento..

TABELA 10 - Distribuição da casuística quanto à idade ao realizar a TN, à idade ao receber o diagnóstico e à idade ao iniciar o tratamento para o $\mathrm{HC}$ 
TABELA 11 - Distribuição da casuística quanto ao nível de TSH obtido na análise da amostra de sangue coletada na TN.

TABELA 12 - Distribuição da casuística quanto à dosagem de levotiroxina no início do tratamento medicamentoso para $\mathrm{oHC}$

TABELA 13 - Distribuição da casuística quanto à realização do diagnóstico etiológico, ao nível socioeconômico, ao desempenho na EPBD e ao controle dos níveis hormonais durante o tratamento com levotiroxina.

TABELA 14 - Distribuição da casuística quanto aos dados do período gestacional: existência de consangüinidade entre os pais, realização do pré-natal e ocorrência de problemas gestacionais.

TABELA 15 - Distribuição da casuística quanto aos tipos de problemas de saúde da mãe durante a gestação.

TABELA 16 - Distribuição da casuística quanto aos dados do nascimento: tipo de nascimento, tipo de parto e suspeita do HC após o parto

TABELA 17 - Distribuição da casuística quanto à existência de problemas de saúde na época da coleta de dados, após o nascimento e durante a primeira infância.

TABELA 18 - Distribuição da casuística quanto aos tipos de problemas de saúde na época da coleta de dados

TABELA 19 - Distribuição da casuística quanto aos tipos de problemas de saúde ocorridos após o parto.

TABELA 20 - Distribuição da casuística quanto aos tipos de problemas de saúde durante a primeira infância

TABELA 21 - Distribuição da casuística quanto aos dados do desenvolvimento: crescimento físico, desenvolvimento do controle de esfíncteres e alimentação. 
TABELA 22 - Distribuição da casuística quanto à qualidade do sono, à freqüência em instituições de ensino e à existência de queixas do comportamento.

TABELA 23 - Distribuição da casuística quanto ao desenvolvimento comunicativo, à realização de avaliações auditivas e visuais anteriores e à ocorrência de otites de repetição.....

TABELA 24 - Distribuição da casuística quanto aos tipos de problemas de comunicação observados pelos responsáveis legais.....

TABELA 25 - Distribuição da casuística quanto à presença de outros fatores de risco para alterações do desenvolvimento além do $\mathrm{HC}$ e quanto à presença de antecedentes familiares.....

TABELA 26 - Distribuição da casuística quanto aos antecedentes familiares.

TABELA 27 - Comparação da idade na época da coleta de dados e do peso no nascimento entre as crianças com desempenho adequado e alterado na Escala ELM e IPO

TABELA 28 - Comparação das idades ao realizar a TN, receber o diagnóstico e iniciar o tratamento para o $\mathrm{HC}$ entre as crianças com desempenho adequado e alterado na Escala ELM e IPO.

TABELA 29 - Comparação do nível de TSH obtido na análise da amostra de sangue coletada na $\mathrm{TN}$ e da dosagem de levotiroxina no início do tratamento entre as crianças com desempenho adequado e alterado na Escala ELM e IPO.. 86

TABELA 30 - Correlação entre a idade ao realizar a TN e a idade ao receber o diagnóstico de $\mathrm{HC}$, entre a idade ao receber o diagnóstico e a idade ao iniciar o tratamento e entre $\mathrm{O}$ nível de TSH obtido na análise da amostra de sangue coletada na TN e a dosagem de levotiroxina no início do tratamento 
TABELA 31 - Associação entre o nível socioeconômico e 0 desempenho na Escala ELM e IPO................................... 88

TABELA 32 - Associação entre o gênero e o desempenho na Escala ELM e IPO e entre a presença de outros fatores de risco para alterações do desenvolvimento além do $\mathrm{HC}$ e o desempenho na Escala ELM e IPO................................. 88

TABELA 33 - Associação entre a condição dos níveis hormonais durante o tratamento para $\mathrm{O} \mathrm{HC}$ e o desempenho na Escala ELM e IPO

TABELA 34 - Concordância entre o desempenho para a EPBD e o desempenho na Escala ELM e IPO.

TABELA 35 - Concordância entre o julgamento dos responsáveis legais a respeito do desenvolvimento comunicativo das crianças e o desempenho na Escala ELM e área de linguagem do IPO 


\section{LISTA DE ABREVIATURAS}

$A E$ - função auditiva expressiva

APAE - Associação de Pais e Amigos dos Excepcionais

AR - função auditiva receptiva

$\mathrm{dB}$ - decibels

dp - desvio padrão

ELM - Early Language Milstone Scale

EPBD - Escala Passos Básicos do Desenvolvimento

FOB/USP - Faculdade de Odontologia de Bauru da Universidade de São Paulo.

HC - hipotireoidismo congênito

IDM - índice de desenvolvimento mental

IDP - índice de desenvolvimento psicomotor

IMC - índice de massa corporal

IPO - Inventário Portage Operacionalizado

Med - mediana

PC - perímetro cefálico

PNTN - Programa Nacional de Triagem Neonatal

PTN - Programa de Triagem Neonatal

QI - quociente intelectual 
RN - recém-nascido

rTSH - receptor do hormônio tirotrofina

$\mathrm{SN}$ - sistema nervoso

$\mathrm{T}_{3}$ - hormônio triiodotironina

$\mathrm{T}_{4}$ - hormônio tiroxina

TG - tireoglobulina

$\mathrm{TN}$ - triagem neonatal

TPO - tirioperoxidade

TRH - hormônio liberador de tirotrofina

TSH - hormônio tirotrofina

V - função visual

$\bar{x}$ - média 


\section{RESUMO}

O hipotireoidismo congênito, uma das alterações do metabolismo detectadas por meio da triagem neonatal, pode acarretar alterações no desenvolvimento global do indivíduo. O objetivo deste estudo foi traçar o perfil das habilidades do desenvolvimento em crianças com hipotireoidismo congênito e verificar possíveis influências dos dados da história clínica no perfil traçado. Foram avaliadas, por meio da Early Language Milestone Scale e do Inventário Portage Operacionalizado, 35 crianças (23 do gênero feminino e 12 do masculino) com hipotireoidismo congênito detectado pela triagem neonatal. As crianças pertenciam à faixa etária de 2 a 36 meses e realizavam tratamento com reposição hormonal há pelo menos um mês. Os dados da história clínica foram obtidos por meio de entrevista com os responsáveis legais pelas crianças e análise de prontuário. $\mathrm{Na}$ avaliação por meio da Early Language Milestone Scale, 11 crianças apresentaram desempenho alterado na função auditiva expressiva, 2 na função visual e 1 na função auditiva receptiva. $\mathrm{Na}$ avaliação por meio do Inventário Portage Operacionalizado, 7 crianças apresentaram desempenho alterado na área da linguagem, 5 na área cognitiva, 4 nas áreas motora e social e 3 na área de autocuidados. Não foram observadas influências dos dados da história clínica no resultado obtido. Concluiu-se que a maioria das crianças avaliadas neste estudo apresentou desempenho adequado para as habilidades avaliadas. Paras as crianças com desempenho alterado, observou-se maior déficit na área de linguagem, principalmente no que diz respeito aos aspectos expressivos e na área cognitiva. Não ficou provada a influência dos dados da história clínica no perfil traçado para as habilidades do desenvolvimento. Entretanto, observou-se tendência para desempenho adequado nas habilidades avaliadas entre as crianças que realizaram a triagem neonatal, receberam o diagnóstico e iniciaram o tratamento para o hipotireoidismo congênito mais precocemente e que receberam dosagem de levotiroxina mais elevada no início do tratamento.

Palavras-chave: Hipotireoidismo congênito. Desenvolvimento infantil. Desenvolvimento da linguagem. Avaliação. 
1 - INTRODUÇÃO 



\section{1 - INTRODUÇÃO}

O hipotireoidismo congênito $(\mathrm{HC})$ é causado pela produção insuficiente dos hormônios tireoideanos devido à malformação da glândula tireóide ou alteração na biossíntese hormonal. É detectado em 1:4000 recémnascidos e se não tratado precocemente torna-se uma das poucas causas de retardo mental passível de prevenção (MANRÍQUEZ; NAGEL; VIVANCO ${ }^{74}$, 1998, MANGLIK; CHATTERJEE; $\mathrm{CHOSH}^{73}$, 2005).

Durante a vida fetal e ao longo dos primeiros anos de vida, os hormônios tireoidianos exercem grande influência no desenvolvimento do sistema nervoso, especialmente nos processos de mielinização, arborização dendrítica, formação de sinapses, migração neuronal, diferenciação celular e expressão de genes (ROVET ${ }^{101}, 1999$, NUNES $^{82}, 2003$ ).

O desenvolvimento das habilidades cognitivas dos indivíduos diagnosticados com $\mathrm{HC}$ depende principalmente da precocidade do início do tratamento e adequação ao mesmo, além da gravidade da patologia. Crianças tratadas tardiamente, sem controle hormonal e acompanhamento multidisciplinar adequados, tendem a apresentar alterações nas habilidades globais do desenvolvimento, ou seja, nas habilidades motoras, cognitivas, lingüísticas, sociais e de autocuidados.

A Triagem Neonatal (TN), também conhecida como Teste do Pezinho, detecta o HC entre outras alterações congênitas do metabolismo. Deve ser realizada entre o terceiro e sétimo dia de vida permitindo o início do tratamento dentro do primeiro mês de vida e, conseqüentemente, a prevenção das seqüelas nas habilidades do desenvolvimento. 
Em 1990, a Lei Federal $n^{\circ}$. 8069/90 tornou obrigatória a realização da TN para o $\mathrm{HC}$ e fenilcetonúria em todo o país, entretanto, o Programa Nacional de Triagem Neonatal (PNTN) foi criado pelo Ministério da Saúde somente no ano de 2001. Seu objetivo foi estabelecer normas para a realização de um Programa de Triagem Neonatal (PTN).

A Associação de Pais e Amigos dos Excepcionais de Bauru (APAEBauru) possui desde 1998 o PTN implantado no Laboratório e Ambulatório de Screening Neonatal "Teste do Pezinho" (Laboratório do Teste do Pezinho da APAE-Bauru). Este PTN é credenciado pelo Ministério da Saúde e oferece TN, diagnóstico, tratamento e acompanhamento para o $\mathrm{HC}$, fenilcetonúria e hemoglobinopatias. Sua cobertura se estende às crianças nascidas em grande parte da região Centro Oeste Paulista. As crianças triadas e diagnosticadas com HC realizam o tratamento de reposição hormonal com dosagens de levotiroxina e recebem acompanhamento endocrinológico, pediátrico, psicológico, neurológico, além de assistência social.

Embora o PNTN não inclua a atuação fonoaudiológica como parte da rotina de acompanhamento de crianças com $\mathrm{HC}$, estudos têm observado alterações do desenvolvimento da habilidade de linguagem em crianças com início do tratamento tardio e até precoce. Diante do exposto, este estudo objetivou traçar o perfil das habilidades do desenvolvimento de crianças com HC em tratamento no Laboratório do Teste do Pezinho da APAE-Bauru, enfocando a comunicação. 



\section{2 - REVISÃO DE LITERATURA}

\section{1 - Hipotireoidismo congênito e suas formas}

O hipotireoidismo congênito $(\mathrm{HC})$ é um distúrbio do metabolismo sistêmico caracterizado pela produção deficiente dos hormônios tireoideanos devido ao mau funcionamento ou malformação da glândula tireóide. É a principal causa de retardo mental passível de prevenção se diagnosticada e tratada oportunamente (SETIAN ${ }^{108}, 1996$, MANRÍQUEZ; NAGEL; VIVANCO ${ }^{74}$, 1998, ALMACHE ${ }^{3}, 2003$, MANGLIK; CHATTERJEE; $\left.\mathrm{CHOSH}^{73}, 2005\right)$.

Afeta cerca de 1:4000 recém-nascidos (RNs) em regiões iodosuficientes (LAFRANCHI ${ }^{64}, 1999, \quad$ CAMPOS; CAMPOS $^{22}, \quad 2003$ ). A SOCIEDADE BRASILEIRA DE TRIAGEM NEONATAL ${ }^{111}$, 2003, apresentou um estudo sobre a prevalência do $\mathrm{HC}$ no Brasil de 1:3.808 RNs vivos.

Segundo LAFRANCHI ${ }^{64}, 1999$ e ALMACHE ${ }^{3}, 2003$, o HC é mais freqüente no gênero feminino, atingindo a proporção de 2:1 em relação ao gênero masculino. No estudo de CAMPOS; CAMPOS ${ }^{22}$, 2003, a proporção encontrada foi de quatro mulheres para cada homem.

A causa desta alteração metabólica pode ser classificada em primária - quando a falha ocorre na glândula tireóide; secundária - quando ocorre deficiência do hormônio hipofisário tirotrofina (TSH) estimulador da produção dos hormônios tireoidianos; e terciária - quando ocorre deficiência do hormônio hipotalâmico liberador de tirotrofina (TRH) que estimula a produção do TSH. O HC pode ainda ser causado pela resistência periférica à ação dos hormônios tireoidianos (KNOBEL; NOGUEIRA; MEDEIROS-NETO ${ }^{60}$, 2001). 
As causas secundárias e terciárias são mais raras. O HC de causa primária além de ser mais comum pode ser classificado em permanente ou transitório (KNOBEL; NOGUEIRA; MEDEIROS-NETO ${ }^{60}$, 2001). Cerca de $85 \%$ do HC permanente é decorrente da digenesia tireoidiana (caracterizada por agenesia da glândula, ectopia com tecido tireoidiano encontrado desde a base da língua até o mediastino, ou hipoplasia com glândula de tamanho reduzido em posição cervical normal). As disormonogêneses, erros inatos da síntese hormonal, ocorrem em $10 \%$ dos casos de HC permanente. Os $5 \%$ restantes resultam da transferência de anticorpos maternos para a criança (FALEN ${ }^{35}$, 1992, PERONE et al. ${ }^{88}, 2004$, VONO-TONIOLO; KOPP $\left.{ }^{118}, 2004\right)$. O HC permanente pode ainda ser causado pela deficiência de iodo $\left(\mathrm{ALMACHE}^{3}\right.$, 2003).

Todos os erros inatos da síntese hormonal, as disormonogêneses, são considerados autossômicos recessivos, com exceção dos defeitos na ação do receptor do hormônio da tireóide, os quais são considerados autossômicos dominantes (LAFRANCHI $\left.{ }^{64}, 1999\right)$.

As formas transitórias do hipotireoidismo primário são menos freqüentes em relação às permanentes. Podem ser idiopáticas, decorrentes da prematuridade ou principalmente da insuficiência ou excesso de iodo materno, fetal ou no RN. Podem ser causadas ainda pela passagem transplacentária de drogas antitireoidianas ou de anticorpos antitireoidianos maternos, podendo apresentar-se com bócio e ser de curta duração. Normalmente as formas transitórias necessitam de tratamento que deve ser ministrado, via de regra, até os três anos (KNOBEL; NOGUEIRA; MEDEIROS-NETO ${ }^{60}$, 2001, ALMACHE $^{3}$, 2003).

Sendo a tireóide a primeira glândula endócrina a se formar durante o desenvolvimento embrionário, evidências sugerem que os fatores de transcrição gênica FOXE1 (também conhecido como FKHL15, TITF-2 e TTF2), NKX2.1 (também conhecido como TITF-1 e TTF1) e PAX-8, são indispensáveis à evolução glandular do ponto de vista migratório e proliferativo. Vários estudos sugerem que mutações nesses fatores de transcrição gênica acarretam alterações no controle transcricional dos genes da tireoglobulina (TG), da 
tirioperoxidade (TPO) e do receptor de TSH (rTSH) (LAFRANCHI ${ }^{64}, 1999$, VONO-TONIOLO; KOPP ${ }^{118}$, 2004).

Segundo ROVET ${ }^{101}, 1999$, a agenesia da glândula tireóide pode estar relacionada às alterações nos fatores de transcrição TTF1, TTF-2 e PAX8 e acarretar $\mathrm{HC}$ grave de início no terceiro trimestre gestacional. Nos casos de ectopia da glândula tireóide os mesmos fatores de transcrição gênica podem estar alterados, porém o HC é leve e de início após o nascimento. As disormonogêneses podem estar relacionadas às alterações nos genes NIS (natrium-iodide sumporter) e rTSH e acarretar HC moderado com início ao nascimento. Nos casos de hipoplasia glandular nenhum gene foi associado, porém o grau de HC é leve e também de início pós-natal. Também foram associados às digenesias os genes $\mathrm{rTSH}, \mathrm{G}_{\mathrm{s}} \alpha$ (stimulatory $\mathrm{G}$ protein $\alpha$ ) e às disormonogêneses os genes da TG, TPO, THOX2 (thyroid oxidase 2) e pendrina (PARK; CHATTERJEE ${ }^{85}$, 2005).

Tanto fatores genéticos, como ambientais, podem exercer influências no desenvolvimento do $\mathrm{HC}$, tais como: gestação de gêmeos, associação de outros defeitos congênitos, gênero feminino e nascimento em idade gestacional superior a 40 semanas. Entretanto, há uma tendência ao aumento do risco de ocorrência do $\mathrm{HC}$ em famílias com histórico de alterações na glândula tireóide, em crianças grandes para a idade gestacional em que a mãe apresenta diabetes e quando a idade da mãe na gestação é superior a 40 anos (MEDDA et al. $\left.{ }^{76}, 2005\right)$.

\section{2 - Hormônios tireoideanos e o sistema nervoso}

A glândula tireóide se origina durante a quarta semana de gestação e é capaz de concentrar iodo e secretar tiroxina $\left(T_{4}\right)$ e triiodotironina $\left(T_{3}\right)$ a partir da décima semana gestacional. Porém, o eixo hipotálamo-hipofisiário-tireóideo se encontra ativado somente por volta do quarto mês e meio de gestação (PORTERFIELD; HENDRICH ${ }^{92}$, 1993). 
$\mathrm{O}_{4}$ e $T_{3}$ são fundamentais para o crescimento e desenvolvimento de vários órgãos e tecidos. Aproximadamente $90 \%$ do hormônio secretado pela glândula tireóide estão na forma de $T_{4}$ e apenas $10 \%$ na forma de $T_{3}$. A maior parte do $T_{3}$ circulante, hormônio necessário para a atividade de praticamente todos os tecidos do organismo, é derivada do $T_{4}$ por desiodação (ALMACHE ${ }^{3}$, 2003, NUNES ${ }^{82}$, 2003).

Os hormônios tireoidianos têm grande influência no desenvolvimento do sistema nervoso (SN) durante a vida fetal e ao longo dos primeiros anos de vida. Destes hormônios, dependem os processos de vascularização do SN, mielinização, arborização dentrítica, formação de sinapses, migração neuronal, diferenciação celular e expressão de genes. Como estes processos normalmente apresentam um pico a partir do quinto mês de gestação e após o nascimento, dependendo do tipo de processo e sua localização no cérebro, níveis adequados de hormônio tireoidiano são essenciais (NUNES ${ }^{81}, 1984$, BERNAL; NUNES ${ }^{11}, 1995$, LEONARD; FARWELL ${ }^{69}, 1997$, BOTLER ${ }^{16}, 1996$, ROVET ${ }^{101}, 1999$, NUNES $\left.^{82}, 2003\right)$.

$O$ hormônio $T_{3}$ age formando um complexo com o receptor do hormônio da tireóide. Este último funciona como regulador da transcrição de genes produtores das proteínas que dão suporte aos eventos neurodesenvolvimentais. As regiões do núcleo caudado, hipocampo e córtex, regiões responsáveis por atividades cognitivas, possuem receptores da tireóide fazendo com que a ação do $T_{3}$ reflita nas habilidades perceptivas do indivíduo (IGLESIAS et al. ${ }^{53}, 1996$, ROVET $\left.^{101}, 1999\right)$.

PORTERFIELD; HENDRICH ${ }^{92}$, 1993, sugeriram que o papel dos hormônios tireoidianos no desenvolvimento neurológico acontece em três fases:

Fase l: período anterior à síntese dos hormônios tireoidianos pelo feto em que a maior parte do tronco cefálico e uma porção significante da neurogênese cerebral dependem da passagem transplacentária de hormônio tireoidiano sintetizado pela mãe. Esta fase correspondente a décima e décima segunda semana de gestação. 
Fase II: período em que a tireóide do feto é capaz de sintetizar e secretar seus hormônios. Nesta fase, a migração, proliferação e maturação neuronal e o desenvolvimento de sinapses dependem dos hormônios tireoidianos fetais e maternos.

Fase III: período após o parto em que o desenvolvimento neurológico depende exclusivamente dos hormônios tireoidianos secretados pela tireóide do RN. Tanto a mielinização como a gliogênese continuam ocorrendo até os 2 anos de idade, porém em maior atividade nesta fase do que na fase anterior.

Nos casos de $\mathrm{HC}$ em que a mãe tem a função tireoidiana normal e o feto apresenta alguma função tireoidiana durante a gestação, as áreas do SN mais afetadas são aquelas relacionadas ao desenvolvimento pós-natal, ou seja, cerebelo, hipocampo e córtex, principalmente o visual e o auditivo (BOTLER $^{16}$, 1996). Isso ocorre porque os efeitos deletérios da falta dos hormônios tireoideanos durante o período gestacional podem ser evitados pela passagem transplacentária de hormônios da mãe para o feto (BERNAL; NUNES ${ }^{11}, 1995$, WARD et al. ${ }^{120}, 1998$, CALVO et al. ${ }^{20}, 2002$, LAVADOAUTRIC et al. ${ }^{67}, 2003$, ZOELLER $^{126}, 2004$, KEMPERS et al. $\left.{ }^{56}, 2006\right)$.

Porém, a partir do nascimento a transferência de hormônio materno para o feto desaparece e aqueles RNs tratados após o terceiro mês de vida apresentarão geralmente atraso no desenvolvimento físico e cognitivo (WARD et al. ${ }^{120}, 1998$, ZOELLER $\left.{ }^{126}, 2004\right)$.

Exemplificando a importância do hormônio materno para o desenvolvimento do feto, VAN WASSENAER et al. ${ }^{117}$, 2002, observaram seqüelas no desenvolvimento de crianças prematuras, porém sem $\mathrm{HC}$, decorrentes da ausência do hormônio tireoidiano materno após o nascimento. Afirmaram que o sistema hipotálamo-hipofisiário-tireóideo do bebê prematuro não se encontrava totalmente maduro.

Quando a deficiência dos hormônios tireoidianos se inicia no período pré-natal ocorre uma redução numérica das células nervosas. Porém, quando seu início é pós-natal, as fibras nervosas e área de contato das sinapses ficam menores, comprometendo a capacidade de transmissão dos impulsos nervosos 
(BOTLER ${ }^{16}$, 1996). Em ambos os casos, o tratamento com reposição hormonal pode até compensar o número de células nervosas, entretanto, a composição e arquitetura neuronal se manterão alteradas, não sendo possível prevenir totalmente as seqüelas neurológicas (PORTERFIELD; HENDRICH ${ }^{92}, 1993$, BOTLER $\left.{ }^{16}, 1996\right)$.

No córtex, a deficiência hormonal reduz o comprimento e as ramificações dos neurônios piramidais, a densidade das terminações axonais e o número de espinas dendríticas. No cerebelo, ocorrem déficits no número, densidade e ramificações dos dendritos (NUNES ${ }^{81}$, 1984, BERNAL; NUNES ${ }^{11}$, 1995). Portanto, na presença do HC podem ser observadas diminuições do tamanho absoluto do cérebro e do cerebelo, além de atrofia das circunvoluções cerebrais (LUDUEÑA; PRADA; SÂNDI ${ }^{71}$, 2002).

As alterações nas conexões neuronais reduzem a capacidade de transmissão neuronal afetando o funcionamento intelectual. Dependendo do sincronismo da deficiência hormonal, as habilidades cognitivas também são afetadas. Portanto, quanto maior o período pré-natal e pós-natal de hipotireoidismo, maior a extensão dos danos cerebrais (ROVET ${ }^{101}, 1999$ ).

Estes danos irreversíveis no tecido neuronal não acarretam apenas retardo mental e outras alterações neurológicas, mas também alterações metabólicas e maturacionais em todo o organismo, principalmente com relação ao tecido ósseo. Portanto, na deficiência dos hormônios tireoidianos o crescimento também fica comprometido (LUDUEÑA; PRADA; SÂNDI ${ }^{71}$, 2002).

Entre as complicações neurológicas do $\mathrm{HC}$, incluem-se cefaléias, distúrbios dos nervos cranianos e periféricos, alterações sensitivo-motoras, alterações na cognição e no nível de consciência. Nos bebês hipotireóideos, o aumento generalizado acentuado ou hipertrofia dos músculos constitui a síndrome de Kocher-Debré-Sémélaigne que dá origem ao "bebê Hércules". Nestes casos os músculos diminuem de tamanho com a terapia de reposição hormonal (ABRAMS; ZIMMERMAN', 1997). 
Para a síntese dos hormônios tireoidianos é necessário o iodo. Sua falta, quando grave o suficiente para afetar a produção dos hormônios tireoideanos durante o período pré e pós-natal, resulta em $\mathrm{HC}$ e danos cerebrais com retardo mental como conseqüência clínica (DELANGE $\left.{ }^{31}, 2001\right)$.

A alteração cerebral causada pela deficiência de iodo é mais grave do que a causada pelo HC esporádico. Neste último, o hormônio de origem materna pode ser capaz de proteger o cérebro do feto durante toda a vida fetal e o tratamento de reposição hormonal precoce pode prevenir o aparecimento de alterações cerebrais na criança (DELANGE $\left.{ }^{31}, 2001\right)$. Porém, na deficiência grave de iodo, o hipotireoidismo materno também está presente na gravidez contribuindo para o surgimento de alterações neurológicas não revertidas com o início da reposição hormonal, pois se tornaram permanentes já no fim do segundo trimestre de gestação (DELANGE ${ }^{31}, 2001$, LAVADO-AUTRIC et al. ${ }^{67}$, 2003).

O cretinismo, termo utilizado por muito tempo na literatura representando retardo mental severo, é a forma mais grave de alteração cerebral causada pela deficiência de iodo (DIAMENT ${ }^{32}, 1996$ ). É caracterizado por alterações graves e irreversíveis no desenvolvimento cerebral, retardo mental e presença de sinais neurológicos, incluindo surdez, diplegia espástica, rigidez motora e sinais de insuficiência tireoidiana grave como, mixedema, imaturidade sexual e nanismo (DELANGE ${ }^{31}, 2001$ ).

\section{3 - Diagnóstico e tratamento do hipotireoidismo congênito}

Crianças com HC podem apresentar já nos três primeiros meses de vida sinais clínicos sugestivos dessa alteração metabólica. Nestes casos, são observados sinais de letargia, sonolência, hipotonia, hipotermia, icterícia prolongada, edema, olhos empapuçados, fontanelas amplas, distensão abdominal, bócio, macroglossia, "fácies cretínica", choro rouco, obstrução 
nasal, dificuldade para mamar, dificuldade respiratória, constipação intestinal, pele fria, marmorata, pálida, seca, descamativa e carotinêmica e hérnia umbilical. Após o terceiro mês estes sinais tornam-se cada vez mais evidentes e é possível observar atraso do crescimento e do desenvolvimento neuropsicomotor. Estas crianças podem ainda nascer com mais de 40 semanas de gestação e peso elevado, sendo consideradas grandes para a idade gestacional (FALEN ${ }^{35}$, 1992, MANRÍQUEZ; NAGEL; VIVANCO ${ }^{74}, 1998$, UNIVERSIDADE FEDERAL DE MINAS GERAIS ${ }^{116}$, 2005).

Este diagnóstico clínico é difícil e incomum de ser realizado antes do terceiro mês de vida. As características clínicas podem não aparecer devido à proteção relativa e transitória dos hormônios tireoidianos maternos durante a gestação (LUDUEÑA; PRADA; SÂNDI ${ }^{71}$, 2002) e, embora as seqüelas se iniciem antes do primeiro mês, estas crianças podem se desenvolver normalmente até o quarto ou quinto mês (MENABÓ et al. ${ }^{78}, 1990$, SETIAN ${ }^{108}$, 1996, SOUZA; SCHWARTZ; GIUGLIANI ${ }^{112}$, 2002). Por esta razão, a detecção do HC durante a primeira semana de vida é essencial para o início rápido do tratamento e, conseqüentemente, para a prevenção de suas manifestações e seqüelas (FRANÇA; SANDRINI ${ }^{37}, 1997$, WARD et al. ${ }^{120}, 1998$, JONES et al. ${ }^{55}$, 2006, ROSE et al. $\left.{ }^{96}, 2006\right)$.

A TN, também conhecida por Teste do Pezinho, permite a detecção precoce do $\mathrm{HC}$ entre outras alterações congênitas do metabolismo. O primeiro PTN do Brasil foi implantado em 1976 pela APAE de São Paulo e contribuiu para a aprovação da primeira lei no país (Lei Estadual $n^{\circ}$. 3914/73) a tornar obrigatória a realização da TN para todas as crianças nascidas a partir de então. Entretanto, a Lei federal n . 8069/90 somente foi aprovada em 1990 com o objetivo de formalizar a obrigatoriedade da TN para o $\mathrm{HC}$ e fenilcetonúria em todo o território nacional (BRASIL. MINISTÉRIO DA SAÚDE ${ }^{18}$, 2002). Porém, SETIAN ${ }^{108}$, 1996 e FRANÇA; SANDRINI ${ }^{37}$, 1997, afirmaram que muitas crianças ainda nascem no Brasil sem a oportunidade de realizar a TN.

No ano de 1992 a TN foi incorporada ao Sistema Único de Saúde Portaria GM/MS n 22 de 15 de Janeiro de 1992. Em 2001, o Ministério da Saúde, por meio da Secretaria de Assistência à Saúde, criou o PNTN - Portaria 
GM/MS n. 822 de 6 de junho de 2001. Seu objetivo foi incluir também na TN a detecção da anemia falciforme, de outras hemoglobinopatias e da fibrose cística, além de estabelecer normas para a realização de um PTN (BRASIL. MINISTÉRIO DA SAÚDE $\left.{ }^{18}, 2002\right)$.

A realização da TN traz benefícios aos indivíduos com alteração metabólica, aos seus familiares, à sociedade e ao governo, por permitir a prevenção de seqüelas no desenvolvimento, principalmente o retardo mental e, reduzir os gastos com o tratamento e acompanhamento destes indivíduos (GEELHOED et al. ${ }^{40}$, 2005, CARROLL; DOWNS ${ }^{23}$, 2006). Antes do início da realização da $\mathrm{TN}$, o diagnóstico clínico era comumente atrasado e o prognóstico neurodesenvolvimental de crianças com HC pior (CHIOVATO; BARGAGNA $\left.^{25}, 1999\right)$.

Estudos têm mostrado a evolução dos PTN para o HC no Brasil. As coberturas dos PTN descritas foram: 15\% em Sergipe (RAMALHO; VALIDO; AGUIAR-OLIVEIRA ${ }^{93}$, 2000), 81\% em Santa Catarina (NASCIMENTO et al. ${ }^{80}$, 2003), 32,2\% em Campina Grande (RAMOS et al. ${ }^{95}$, 2003), 85\% em Sergipe (RAMALHO et al. $^{94}, 2004$ ) e 94,5\% na Bahia (ALMEIDA et al. ${ }^{4}, 2006$ ).

O exame de TN consiste em coletar uma amostra de sangue em papel filtro ou do cordão umbilical ou por punção do calcanhar para mensuração do nível de TSH ou de $\mathrm{T}_{4}$. Quando um desses hormônios é analisado na TN, o outro é analisado no diagnóstico para confirmação do HC. No Brasil, as duas estratégias são utilizadas (WARD et al. ${ }^{120}, 1998$ ).

Com relação à coleta da amostra de sangue, MENABÓ et al. ${ }^{78}, 1990$, verificaram sensibilidade de $100 \%$ e especificidade e acurácia de $99.4 \%$ ao utilizar sangue do cordão umbilical após o parto. Ao empregar sangue colhido por punção de calcanhar no terceiro dia de vida do bebê, verificaram sensibilidade, especificidade e acurácia de $100 \%$.

A coleta por punção do calcanhar entre o $3^{\circ}$ e $5^{\circ}$ dia de vida permite a pesquisa do $\mathrm{HC}$ e da fenilcetonúria na mesma amostra, porém suas desvantagens são a permanência dos RNs e das mães por tempo prolongado 
no hospital, a menor quantidade de sangue colhido e a necessidade de enfermeiras e material especializado (MENABÓ et al. ${ }^{78}, 1990$, MEIRELLES et al. $\left.{ }^{77}, 1991\right)$. As vantagens da coleta de sangue do cordão umbilical são: manter a rotina de alta ao $\mathrm{RN}$ de parto natural entre o primeiro e segundo dia de vida, não elevar os custos pela manutenção hospitalar da mãe e do $\mathrm{RN}$ e não expor os RNs a riscos de infecção hospitalar pela permanência prolongada no berçário. Sua desvantagem refere-se à impossibilidade de obtenção concomitante de material para a pesquisa de fenilcetonúria, cuja coleta deve ser realizada a partir do terceiro dia de vida (MEIRELLES et al. ${ }^{77}, 1991$ ).

Com relação à análise da amostra de sangue, MEIRELLES et al. ${ }^{77}$, 1991, afirmaram que a dosagem de TSH forneceu menos resultados falsopositivos, pois as concentrações de $\mathrm{T}_{4}$ podem estar baixas nos bebês prematuros, de baixo peso, doentes e na deficiência de TBG ( $T_{4}$ binding globulin). Posteriormente, SOUZA; SCHWARTZ; GIUGLIANI ${ }^{112}, 2002$, verificaram que a dosagem de $\mathrm{T}_{4}$ apresentou $10 \%$ de casos falso-negativos, enquanto a dosagem de TSH nas primeiras 48 horas poderia levar a um aumento de casos falso-positivos.

TYLEK-LEMÁNSKA; KUMOROWICZ-KOPIEC; STARZYKK ${ }^{115}, 2005$, observaram que nos neonatos de baixo ou muito baixo peso, níveis normais de TSH entre $\circ 3^{\circ}$ e $6^{\circ}$ dia de vida não excluem a disfunção tireoidiana, devendo ser repetido o exame após a $4^{\text {a }}$ semana de vida. LAFRANCHI ${ }^{64}, 1999$, considerou que os PTN que medem as concentrações de TSH conseguem detectar apenas as crianças com HC primário, já os PTN que medem primeiramente o nível de $\mathrm{T}_{4}$ têm o potencial de detectar crianças com $\mathrm{HC}$ hipotalâmico-putuitário.

A técnica referida pelo PNTN para a realização da TN consiste em obter uma amostra de sangue coletada por punção do calcanhar, em papel filtro, e efetuar a mensuração primária do $\mathrm{TSH}$. A dosagem de $\mathrm{T}_{4}$ é realizada no exame confirmatório em amostra de sangue em soro, quando o nível de TSH na TN for maior que $20 \mathrm{mUI} / \mathrm{L}$. A coleta deve ocorrer entre o quinto e sétimo dia de vida, quando a função hormonal do recém-nascido já se encontra estabilizada. Este período possibilita o diagnóstico e início do tratamento 
precoce dos casos positivos para o $\mathrm{HC}$ que não deve ultrapassar os 30 dias de vida (BRASIL. MINISTÉRIO DA SAÚDE ${ }^{18}, 2002$ ). O diagnóstico do HC é confirmado por concentrações elevadas de TSH e reduzidas de $\mathrm{T}_{4}$ (CAMPOS; CAMPOS $\left.^{22}, 2003\right)$.

PARK; CHATTERJEE ${ }^{85}$, 2005, destacaram a importância do diagnóstico etiológico e genético do HC. Afirmaram que os resultados das análises genéticas podem ajudar no aconselhamento genético quanto ao risco de recorrência do $\mathrm{HC}$ na família, além de sugerir a melhor opção de tratamento. HANUKOGLU et al. ${ }^{47}, 2001$, observaram que durante o primeiro ano de vida, os casos de agenesia da glândula tireóide necessitaram de tratamento com doses maiores de levotiroxina e acompanhamento hormonal mais freqüente. Nas demais digenesias e nas disormonogêneses esse tipo de atenção pode ser necessária após o primeiro ano de vida.

Os casos diagnosticados com $\mathrm{HC}$ devem receber tratamento $\mathrm{e}$ acompanhamento de equipe multidisciplinar composta ao menos por médico endocrinologista ou endocrinologista-pediátra, psicólogo e assistente social. O acompanhamento hormonal por meio de exames laboratoriais também faz parte da rotina destes indivíduos (BRASIL. MINISTÉRIO DA SAÚDE ${ }^{18}, 2002$ ).

$\mathrm{O}$ tratamento do $\mathrm{HC}$ é realizado por meio da reposição hormonal com levotiroxina ( $T_{4}$ sintético). Sua dosagem deve ser individualizada e adequar-se à necessidade do indivíduo para que os níveis hormonais sejam mantidos dentro da normalidade (ROSE et al. $^{96}, 2006$ ). Existem dúvidas quanto à dosagem ideal, pois a ineficácia de doses inferiores às recomendadas foi comprovada, porém não se tem certeza se doses superiores resultariam em menores comprometimentos decorrentes do $\mathrm{HC}$, principalmente quanto aos déficits intelectuais (HINDMARSH ${ }^{52}, 2002$ ). Entretanto, LAFRANCHI ${ }^{64}, 1999$, afirmou que overdoses medicamentosas podem acarretar fusão prematura das suturas do crânio, aceleração do crescimento e da maturação óssea e problemas de comportamento. 
Durante a reposição hormonal são necessárias reavaliações periódicas dos níveis de TSH e de $\mathrm{T}_{4}$ livre, que devem ser mantidos abaixo de $5 \mathrm{mU} / \mathrm{L}$ e dentro do intervalo de 10 e $16 \mathrm{mg} / \mathrm{dl}$, respectivamente, durante o primeiro ano de vida. Estes exames devem ser realizados a cada quatro ou seis semanas nos primeiros seis meses de vida, a cada dois meses entre seis e dezoito meses de vida e a cada três e seis meses após este período (BRASIL. MINISTÉRIO DA SAÚDE ${ }^{18}, 2002$, ROSE et al. ${ }^{96}, 2006$ ). Durante os seis primeiros meses de idade as crianças com $\mathrm{HC}$ devem ser acompanhadas com mais freqüência, pois este é um período crítico de desenvolvimento neurológico, de formação dendrítica e de rápido crescimento e mudanças no corpo (HINDMARSH ${ }^{52}$, 2002). Assim, as avaliações periódicas do desenvolvimento neuropsicomotor e do crescimento pondero-estatural ajudam garantir a adequação constante da terapia de reposição hormonal (ROVET ${ }^{101}$, 1999, SOUZA; SCHWARTZ; GIUGLIANI ${ }^{112}$, 2002, UNIVERSIDADE FEDERAL DE MINAS GERAIS $\left.{ }^{116}, 2005\right)$.

$\mathrm{Na}$ década de 70 , com o surgimento dos principais PTN para o $\mathrm{HC}$ no mundo, acreditava-se que os três primeiros meses de vida correspondiam à fase crítica para o início do tratamento. Desde então, tem-se mostrado a importância do início do tratamento o mais próximo ao nascimento, considerando que mesmo com intervenção precoce podem ocorrer alterações cerebrais mínimas (BOTLER ${ }^{16}, 1996$, ROVET$\left.^{101}, 1999\right)$. ROVET; EHRLICH; SORBARA $^{97}, 1987$, consideraram que apesar dos avanços com a TN em relação à prevenção do retardo mental, faz-se necessário o desenvolvimento de procedimentos de diagnóstico alternativos para a detecção do $\mathrm{HC}$ ainda mais precoce, ou seja, durante a gestação. GHAZI et al. ${ }^{41}, 2005$, observaram que o diagnóstico e o início do tratamento para o $\mathrm{HC}$ durante a vida fetal pode diminuir a mortalidade perinatal e otimizar o desenvolvimento físico e intelectual da criança.

Devido a grande participação dos hormônios tireoidianos no desenvolvimento cerebral, quanto maior o período de insuficiência hormonal, maior a gravidade e extensão dos danos cerebrais e quanto antes se iniciar a reposição hormonal com levotiroxina, menos a criança será afetada 
$\left(\right.$ ROVET$\left.^{101}, 1999, \mathrm{ALMACHE}^{3}, 2003\right)$. A este respeito, $\mathrm{ALMACHE}^{3}, 2003$ e ROSE et al. ${ }^{96}, 2006$, propõem o início do tratamento antes do $15^{\circ}$ dia de vida, especialmente para os casos de deficiência grave dos hormônios tireoidianos.

Crianças com diagnóstico e tratamento tardio (idade superior a 30 dias) apresentam desenvolvimento neuropsicomotor atrasado. No entanto, conseguem recuperar o ritmo de ganho pôndero-estatural e normalizar os parâmetros metabólicos alterados como freqüência cardíaca, hábitos intestinais, hábitos de sono, temperatura e umidade da pele (BRASIL. MINISTÉRIO DA SAÚDE ${ }^{18}$, 2002).

Os fatores de risco para alterações no desenvolvimento em crianças com HC tratado precocemente referem-se à concentração de $T_{4}$ antes do tratamento, à maturação óssea, à etiologia do $\mathrm{HC}$, à idade no início do tratamento, à dose inicial de levotiroxina, à adequação do tratamento nos primeiros 2 anos de vida e após, e o nível socioeconômico da família (CHIOVATO; BARGAGNA ${ }^{25}$, 1999).

Para que não ocorram comprometimentos neurológicos decorrentes de reposição hormonal irregular é extremamente importante garantir a aderência das famílias ao tratamento principalmente nos primeiros 3 anos de vida. A equipe multiprofissional deve estar sempre atenta e aconselhar os familiares da necessidade de tratamento regular, contínuo, sem esquecimentos, exatamente para que a criança permaneça com crescimento e desenvolvimento normais (UNIVERSIDADE FEDERAL DE MINAS GERAIS ${ }^{116}$, 2005).

Atenção deve ser oferecida também à família da criança com $\mathrm{HC}$, uma vez que o sentimento de culpa dos pais e a frustração da perda da criança "perfeita" podem levar a atitudes incorretas em relação à criança. Nestes casos durante o acompanhamento da criança com $\mathrm{HC}$, devem ser realizadas avaliações da relação afetiva entre os pais e a criança (CHIOVATO; BARGAGNA $^{25}$, 1999). 


\section{4 - Desenvolvimento na presença do hipotireoidismo congênito}

KLEIN; MELTZER; KENNY ${ }^{58}$, 1972, avaliaram o quociente intelectual (QI) de 31 crianças com $\mathrm{HC}$, aos 3 anos de idade, divididas em grupos, considerando a variável idade no início do tratamento. $\mathrm{O}$ grupo $\mathrm{A}$ iniciou $\mathrm{O}$ tratamento antes dos 3 meses, o grupo $B$ entre 3 e 5 meses, o grupo $C$ entre 5 e 7 meses e o Grupo D após 7 meses. A média do QI de todas as crianças foi de 72 pontos. A média do QI do grupo A, B, C e D foi 89, 70, 71 e 54 pontos, respectivamente. $O$ grupo $A$ obteve pontuação média significantemente superior aos outros grupos e, $78 \%$ de suas crianças apresentaram QI acima do limiar de normalidade. Os autores concluíram que o tratamento para o $\mathrm{HC}$ deve começar o mais cedo possível permitindo a prevenção de alterações intelectuais.

GLEISNER et al. ${ }^{42}, 1986$, observaram alterações no desenvolvimento neuropsicomotor de 22 crianças em tratamento para o $\mathrm{HC}$, com idade superior a 7 anos. O grau de alteração estava relacionado à idade da criança no diagnóstico do HC. Crianças diagnosticadas antes dos 6 meses de vida iniciaram a marcha e a fala por volta de 2 anos de idade. Crianças diagnosticadas após os 2 anos, iniciaram a marcha aos 2 anos e 6 meses e a fala por volta dos 3 anos e 6 meses, com exceção de três crianças que iniciaram a fala depois dos 6 anos de idade. Em todas as crianças foram observadas alterações neurológicas, entre elas: atraso na inibição de reflexos primitivos, incoordenação motora grossa e fina, transtornos da linguagem, sincinesias, hipotonia e transtornos de conduta. Quanto ao QI, foram observados escores de normalidade em 2 crianças, escores limítrofes em 5 crianças, retardo leve em outras 5 crianças e retardo mental de moderado a severo em 10 crianças.

ROVET; EHRLICH; SORBARA ${ }^{97}$, 1987, acompanharam longitudinalmente, até os 5 anos de idade, um grupo de 80 crianças (23 meninas e 57 meninos) com HC detectado na TN, por meio da avaliação do desenvolvimento neuropsicomotor. As crianças foram divididas em: grupo com 
atraso na idade óssea (45 crianças com idade óssea no diagnóstico $\leq 36$ semanas) e grupo sem atraso na idade óssea (35 crianças com idade óssea no diagnóstico $\geq 37$ semanas). Os grupos não se diferenciavam quanto ao peso no nascimento, níveis hormonais, nível de instrução familiar e socioeconômico, porém a maioria das crianças com agenesia da glândula tireóide fazia parte do grupo com atraso na idade óssea. As crianças de ambos os grupos demonstraram desempenho dentro da normalidade em todas as avaliações. No primeiro ano de vida não foram observadas diferenças entre os grupos, entretanto, as crianças com atraso na idade óssea apresentaram pior desempenho nas habilidades auditivas, de fala e motora fina aos 2 anos de idade e nas habilidades de locomoção, sociais, perceptivas e motora fina aos 3 anos de idade. Aos 4 anos, estas crianças apresentaram alterações nas habilidades verbais, de compreensão da linguagem e aritmética e, aos 5 anos, nas habilidades motoras, de vocabulários, compreensão da linguagem, aritmética, no QI total e de execução. Não foram observadas diferenças entre os grupos quanto à avaliação do comportamento. Segundo os autores, estes achados sugerem que o início do $\mathrm{HC}$ para as crianças com atraso na idade óssea ocorreu durante a gestação, acarretando atraso no desenvolvimento do $\mathrm{SN}$ e do sistema esquelético.

ARASON et al. ${ }^{6}, 1990$, acompanharam o crescimento de 52 crianças com HC (41 meninas e 15 meninos) até os 9 anos de idade, quanto à altura, peso, perímetro cefálico (PC), idade óssea e altura adulta prevista e as compararam com o percentil da população inglesa. Observaram que a média do percentil para a altura e PC foi maior do que a média da população. Após o primeiro ano de vida, os valores para o peso foram significantemente inferiores ao da população. Mesmo com idade óssea maior, a previsão da altura adulta não foi diferente da média de seus pais e da população. Por fim, verificaram que quanto maior o tempo de hipotireoidismo pós-natal, menor a altura atingida até os 9 anos de idade.

BAZÁN; PASTERI; CHAIL $^{10}, 1990$, avaliaram o crescimento e desenvolvimento neuropsicomotor de 29 crianças com HC de 2 a 4 anos de idade, divididas em grupos de acordo com a idade no diagnóstico. O grupo $\mathrm{A}$ 
foi diagnosticado antes dos 3 meses, o grupo $B$ entre o $3^{\circ}$ e $6^{\circ}$ mês, o grupo $C$ entre $\circ 6^{\circ}$ e $24^{\circ}$ mês e o grupo $D$ após o $24^{\circ}$ mês. Observaram redução na velocidade de crescimento e maior diferença entre a idade cronológica e idade óssea conforme aumentava a idade das crianças no diagnóstico. Com o tratamento para o $\mathrm{HC}$ houve redução nas concentrações de TSH em todos os casos. Quanto à evolução neuropsicomotora o grupo A se mostrou normal, o grupo $B$ apresentou atraso leve, o grupo $C$ apresentou déficit leve a moderado e o grupo $D$ apresentou desempenho extremamente abaixo do esperado. $A$ avaliação eletroencefalográfica nos grupos $A$ e $B$ foi normal e nos grupos $C$ e $D$ revelou alteração do traçado relacionado à freqüência e amplitude com poucas respostas. Concluíram que a idade no diagnóstico do HC é determinante do grau de desenvolvimento dessas crianças.

ROVET $^{98}, 1990$, avaliou as habilidades intelectuais de 107 crianças com $\mathrm{HC}$ dos $1^{\circ}$ ao $6^{\circ}$ ano de idade. Todas as crianças iniciaram o tratamento com levotiroxina por volta do $13^{\circ}$ dia de vida, entretanto, 58 foram alimentadas por leite materno e 49 por meio de fórmulas. As crianças apresentaram desempenho intelectual semelhante. $O$ nível de $T_{4}$ durante $01^{\circ}$ e $2^{\circ}$ mês de vida foi significantemente maior nas crianças alimentadas com leite materno, porém o mesmo não foi observado nos meses seguintes. $\mathrm{O}$ autor concluiu que as crianças alimentadas com leite materno alcançaram níveis hormonais dentro da normalidade mais rapidamente, porém os níveis de $T_{4}$ observados na primeira infância não refletiram, necessariamente, em posteriores melhoras no funcionamento intelectual, uma vez que todas as crianças estavam em tratamento com reposição hormonal.

FUGGLE et al. ${ }^{39}, 1991$ avaliaram aos 5 anos de idade as habilidades cognitivas, motoras e o comportamento de 57 crianças com $\mathrm{HC}$ tratado precocemente e as compararam com 51 crianças controle pareadas quanto à idade, gênero, nível socioeconômico e repertório de linguagem. Observaram pequenas diferenças, porém não significantes, no Ql e no comportamento dos dois grupos. Déficits significantes nas habilidades motoras principalmente quanto ao equilíbrio e destreza foram observados nas crianças com $\mathrm{HC}$ em comparação ao grupo controle. As crianças com HC grave no diagnóstico (nível 
muito baixo de $\mathrm{T}_{4}$ ) apresentaram QI inferior e habilidades motoras piores em comparação as crianças com HC menos grave.

HEYERDAHL; KASE; LIE ${ }^{50}$, 1991, avaliaram o desenvolvimento cognitivo aos 2 e 6 anos de idade de 46 crianças com HC identificado na TN. As crianças com níveis de $\mathrm{T}_{4}$ mais elevados durante o segundo ano de vida apresentaram melhores índices de desenvolvimento mental (IDM) e aquelas com níveis de $\mathrm{T}_{4}$ mais elevados durante o sexto ano apresentaram QI verbal melhor. Com relação ao gênero, os meninos apresentaram IDM inferiores aos 2 anos.

GLORIEUX; DUSSAULT; VAN VLIET ${ }^{43}$, 1992, avaliaram aos 12 anos de idade o desenvolvimento cognitivo de 27 crianças com HC e as compararam com seus irmãos alteração metabólica. Doze crianças apresentaram HC grave no diagnóstico (nível muito baixo de $\mathrm{T}_{4}$ e idade óssea reduzida) e quinze apresentaram $\mathrm{HC}$ moderado (nível baixo de $\mathrm{T}_{4} \mathrm{e}$ idade óssea adequada). As crianças com HC grave apresentaram QI verbal e não-verbal significantemente inferior às crianças com $\mathrm{HC}$ moderado. Metade das crianças com $\mathrm{HC}$ grave apresentou QI total inferior ao grupo controle e a outra metade apresentou QI total semelhante. Das crianças com HC moderado, 4 apresentaram QI total superior ao grupo controle e 5 apresentaram QI total inferior. Segundo os autores estes resultados sugerem que os déficits cognitivos persistirão até a idade adulta.

BRAGATTI-WINCKLER; ROTTA ${ }^{17}$, 1994, relataram o caso de um menino de 5 anos de idade com $\mathrm{HC}$ e histórico materno de alcoolismo e desvios de conduta na gravidez. Na época do diagnóstico e início do tratamento com levotiroxina a criança tinha um 1 ano e 28 dias. A mesma dosagem medicamentosa foi utilizada sem controle médico até os 5 anos de idade. Com relação ao desenvolvimento neuropsicomotor, a criança sentou com apoio aos 7 meses, sem apoio aos 12 meses, engatinhou com 1 ano e 6 meses, iniciou marcha aos 2 anos e até os 5 anos não apresentava controle de esfíncter. A família relatou hipotonia muscular intensa desde bebê. Com 3 anos de idade, foi realizada avaliação auditiva mostrando hipoacusia neurossensorial severa à esquerda e moderada à direita. Aos 4 anos e 6 meses de idade, a 
família procurou atendimento médico devido a hiperatividade intensa, agressividade e auto-agressão. Nesta época foram observados episódios de "ausência", marcha em círculos e sem movimentos conjugados dos membros superiores, interação pobre com o meio e emissão de vogais. O exame físico mostrou robustez, hipoma posterior à esquerda, genitália com micropênis e testículo retrátil à esquerda. Após adequação do tratamento e acompanhamento endocrinológico a criança apresentou melhoras quanto ao uso de brinquedo, simbolizações, interação com outras crianças, tentativa de comunicação gestual e resposta ao nome. Não apresentava auto-agressão e o padrão da marcha vinha se modificando com esboço de movimentos associados dos membros superiores.

CORRÊA et al. ${ }^{30}, 1994$, relataram o caso de uma menina com 3 anos e 7 meses de idade apresentando atraso no crescimento e no desenvolvimento neuropsicomotor. A criança apresentava rosto inexpressivo, olhar vago, choro inarticulado, sucção voluntária, ausência de preensão palmar voluntária, abasia, estasia, hipotonia muscular e ausência de controle cervical. No exame clínico observou-se estatura de 64 centímetros (< que percentil 2,5), peso de 6550 gramas (< que percentil 2,5), perímetro cefálico de 40 centímetros (< que percentil 2,5), cabelos finos e secos, pele marmorata, seca e descamativa, base nasal rasa, micrognatia discreta, ausência de dentes, língua espessa, dificuldade de suç̧ão e refluxo gastroesofágico. O raio-x de crânio mostrou fontanela anterior ampla com diástese de suturas cranianas, além de estruturas ósseas com densidade aumentada, alteração também encontrada nos raios- $X$ de coluna torácico-lombar, sacro e de mãos e punho. Constatou-se então, idade óssea compatível com 3 meses. A cintilografia da glândula tireóide com iodo 131 indicou ausência de atividade captante sugerindo HC por provável mecanismo auto-imune. Com a confirmação do $\mathrm{HC}$, a criança iniciou a reposição hormonal com levotiroxina.

FRANÇÓIS et al ${ }^{38}, 1994$, avaliaram a audição de 42 indivíduos com HC tratado com levotiroxina e os compararam com 42 indivíduos controle pareados quanto à idade e gênero. Para a avaliação de 13 crianças com idade entre 12 e 30 meses utilizou-se a impedanciometria e a audiometria de reforço 
visual. Para a avaliação de 29 indivíduos com idade entre 4 e 21 anos utilizouse a impedanciometria e a audiometria tonal liminar. Em nenhum caso foram relatadas queixas auditivas, zumbido ou vertigem, fatores de risco ou antecedentes familiares. Das crianças, 11 apresentaram limiares auditivos $\leq 20$ decibels $(\mathrm{dB})$ e 2 apresentaram limiares entre 30 e $40 \mathrm{~dB}$. Dos indivíduos com idade superior a 4 anos, 4 apresentaram perda auditiva condutiva com limiares auditivos até $30 \mathrm{~dB}$, outros 4 apresentaram perda auditiva neurossensorial de 20 a 25 dB nas freqüências da fala e 12 apresentaram perda auditiva neurossensorial de 20 a $50 \mathrm{~dB}$ nas altas freqüências. Os tipos e graus de perda auditiva não se correlacionaram com a etiologia do $\mathrm{HC}$ ou com os níveis dos hormônios tireoidianos ao iniciar o tratamento. Quando os limiares auditivos dos indivíduos com $\mathrm{HC}$ foram comparados com os limiares do grupo controle, não foram observadas diferenças significantes.

GOTTSCHALK; RICHMAN; LEWANDOWSKI ${ }^{44}$, 1994, avaliaram as habilidades cognitivas, motoras, adaptativas e de fala em 16 crianças com HC (10 meninas e 6 meninos) entre 5 anos e 1 mês e 9 anos e 3 meses de idade. A média de idade no início de tratamento foi 15,6 dias. Não foram observados déficits cognitivos e adaptativos nas crianças avaliadas, porém as alterações motoras e de articulação da fala foram significantes. As crianças com menor idade óssea no diagnóstico foram piores em quase todas as avaliações. Os autores afirmaram que crianças com atraso na idade óssea são de risco para alterações no desenvolvimento cognitivo e motor, devendo ser acompanhadas mais de perto mesmo.

GRANT $^{45}$, 1994, avaliou o crescimento de 361 crianças com HC identificado na TN. As avaliações quanto à altura, peso, índice de massa corporal (IMC) e PC foram realizadas do nascimento até os 4 anos de idade. $O$ PC foi significantemente maior nas crianças com HC grave (nível muito baixo de $\mathrm{T}_{4}$ no diagnóstico) do que nas crianças com $\mathrm{HC}$ menos grave (nível baixo de $\mathrm{T}_{4}$ no diagnóstico). A altura das crianças com $\mathrm{HC}$ grave no primeiro e segundo ano de vida foi menor do que o esperado para a idade cronológica, porém no $3^{\circ}$ e $4^{\circ}$ ano de vida todas as crianças com HC apresentaram altura maior ou igual ao esperado. Em todas as idades, o peso dos meninos com $\mathrm{HC}$ menos 
grave foi maior do que o esperado para a idade cronológica, o mesmo aconteceu para os meninos com $\mathrm{HC}$ grave aos 3 e 4 anos. O IMC em todas as crianças com HC foi maior do que o esperado para a idade cronológica, com exceção dos meninos no primeiro ano de vida.

KOOISTRA et al. ${ }^{62}, 1994$ avaliaram as habilidades motoras e cognitivas de 72 crianças com HC tratado precocemente e as compararam com 35 crianças controle pareadas quanto à idade, gênero e nível socioeconômico. As crianças foram avaliadas aos 7 anos e 6 meses e posteriormente aos 9 anos e 6 meses de idade. Observaram que apesar do tratamento ter sido iniciado no $23^{\circ}$ dia de vida, as crianças com $\mathrm{HC}$ grave (nível muito baixo de $\mathrm{T}_{4}$ no diagnóstico) apresentaram alterações motoras significantes e habilidades cognitivas muito próximas ao limite inferior na idade de 9 anos e 6 meses. Estas alterações foram observadas particularmente nas crianças com agenesia da glândula tireóide. A coordenação motora grossa e o equilíbrio pioraram com o aumento da idade, enquanto a linguagem e memória se mantiveram.

PIZARRO; PASKULIN; OLIVEIRA ${ }^{90}$, 1994, relataram o caso clínico de uma menina de 8 anos de idade com HC por agenesia da glândula tireóide apresentando sinais de puberdade precoce. A criança foi diagnosticada aos 3 anos de idade e tratada irregularmente desde então. No exame físico, observou-se altura de 120 centímetros, 24,4 quilogramas, aparecimento de mamas pré-puberal bilateralmente (mamas Tanner II), ausência de pêlos pubianos e axilares e presença de odor androgênico. O exame neurológico revelou lesão cerebral do tipo atáxica e desenvolvimento neuropsicomotor compatível com a idade de três a quatro anos. A tomografia computadorizada do encéfalo não mostrou alterações, já o raio-x de mãos e punho revelou atraso na idade óssea de 2 anos em relação à idade cronológica. O quadro de puberdade precoce conseqüente ao $\mathrm{HC}$ foi caracterizado pela constatação de ovários estimulados bilateralmente, com secreção estrogênica pós-puberal na presença de atraso da idade óssea. A puberdade pode ter sido desencadeada pela presença de estímulo discreto, porém constante, de secreção hipofisária decorrente dos níveis moderadamente elevados de TSH durante o desenvolvimento da criança. 
CAMPOS et al. ${ }^{21}$, 1995, avaliaram O QI, comportamento e crescimento de 23 crianças (11 meninas e 12 meninos) com HC identificado na TN. As crianças foram acompanhadas do diagnóstico até os 59 meses de idade. A idade média no início do tratamento foi 14,5 dias e a maioria das crianças apresentaram nível socioeconômico médio. Quanto à etiologia, 12 crianças apresentaram glândula tireóide ectópica, 6 apresentaram agenesia de glândula e 5 apresentaram disormonogênese. A avaliação do QI total, verbal e de execução, do comportamento e do crescimento indicou normalidade. As crianças com idade óssea superior a 32 semanas e níveis menos baixo de T4 na TN apresentaram QI verbal significantemente superior. Não foram observadas correlações significantes entre as variáveis: QI total, QI de execução, comportamento, idade óssea, níveis de $\mathrm{T}_{4}$ na $\mathrm{TN}$, idade no início do tratamento e valores de $\mathrm{T}_{4}$ durante o tratamento.

ROVET; EHRLICH ${ }^{99}$, 1995, avaliaram as habilidades cognitivas e o comportamento de 94 crianças com HC até os 8 anos de idade. Observaram efeitos positivos de doses altas de levotiroxina nas avaliações das habilidades cognitivas (QI total, QI verbal, QI de execução, compreensão verbal, aritmética e memória) com exceção da memória verbal e compreensão da leitura. Entretanto, verificaram que quanto maior a dosagem de levotiroxina, maiores os problemas de comportamento no final da infância, tais como reclusão social, ansiedade, problemas sociais, de conduta e hiperatividade. Seus resultados sugeriam que o período crítico dos efeitos dos hormônios tireoidianos para as habilidades verbais e de memória encontra-se por volta dos dois meses de idade. Em contraste, o período pré-natal pareceu ser crítico para as habilidades visoespaciais e visomotoras. Ressaltaram ainda que crianças com alterações de memória tenderam a apresentar problemas escolares e dificuldade para 0 acompanhamento de instruções apresentadas oralmente.

SALERNO et al. ${ }^{104}$, 1995, avaliaram aos 7 anos de idade, 47 crianças com HC detectado na TN e as compararam com 40 crianças controle. Todas as crianças com $\mathrm{HC}$ ou iniciaram o tratamento dentro do $1^{\circ}$ mês de vida, ou entre o $23^{\circ}$ e $53^{\circ}$ dia. A média do Ql das crianças com HC ficou dentro da normalidade e foi muito semelhante ao grupo controle. A idade no início do 
tratamento e a dosagem inicial de levotiroxina não influenciaram no desempenho das crianças. As crianças com nível baixo de $T_{4}$ no diagnóstico apresentaram QI inferior às crianças com nível muito baixo de $T_{4}$. A etiologia do HC não influenciou significantemente no QI das crianças e embora dois meses de tratamento tenha sido capaz de normalizar as concentrações de $T_{4}$ em todas as crianças, a concentração de TSH normalizou-se em apenas $50 \%$ das crianças.

KOOISTRA et al. ${ }^{63}, 1996$ avaliaram a atenção sustentada de 48 crianças com HC tratado precocemente (idade média de 7,9 anos) e as compararam com 35 crianças controle pareadas quanto à idade, gênero e nível socioeconômico. As crianças com HC foram divididas em dois grupos: 38 crianças com nível muito baixo de $T_{4}$ no diagnóstico e início do tratamento aos 24 dias de vida ( 23 com agenesia da tireóide e 15 com digenesia) e 10 crianças com nível baixo de $T_{4}$ no diagnóstico e início do tratamento aos 37 dias de vida (todas com digenesia da tireóide). $\mathrm{O}$ tratamento das crianças com $\mathrm{HC}$ foi adequado e $\circ$ Ql significantemente inferior ao grupo controle. Observou-se maior declínio do tempo de atenção nas crianças com nível muito baixo de $T_{4}$ no diagnóstico, sugerindo que estas apresentaram dificuldades para manter a atenção. Não foi observada correlação entre a idade no início do tratamento e a atenção sustentada, entretanto, o início do tratamento mais cedo nas crianças com nível muito baixo de $T_{4}$ pareceu não ter sido suficiente para prevenir os problemas de atenção. Os autores consideraram que a alteração na atenção sustentada possa influenciar as futuras atividades escolares e profissionais.

ROVET; ALVAREZ ${ }^{100}, 1996$, avaliaram as habilidades intelectuais, vocabulário, memória e atenção de 86 crianças com HC identificado na TN. As crianças foram avaliadas aos 7 e 9 anos de idade e divididas em grupos quanto aos níveis hormonais durante o tratamento: nível de $\mathrm{T}_{4}$ e TSH elevados $(\mathrm{HH})$, nível de $T_{4}$ elevado e TSH normal (HM) e nível de $T_{4}$ elevado e TSH baixo $(H L)$. Observaram que os grupos não se diferenciaram quanto ao $Q$ I total, verbal ou de execução. Aos 7 anos de idade, o grupo $\mathrm{HH}$ obteve os melhores resultados em vocabulário e os piores em memória de dígitos e atenção. Aos 9 anos, o grupo $\mathrm{HH}$ novamente obteve os piores resultados em atenção, porém estas 
crianças não foram as mesmas do grupo $\mathrm{HH}$ aos sete anos. Independente da razão dos níveis hormonais elevados, a habilidade de atenção encontrou-se defasada enquanto algumas habilidades verbais encontraram-se adequadas. Os autores concluíram que níveis elevados de $\mathrm{T}_{4}$ e TSH durante o tratamento contribuem para alterações atencionais.

SIRAGUSA et al. ${ }^{110}, 1996$ avaliaram a altura, o peso e o PC durante os 6 primeiros anos de vida em 35 crianças com HC detectado na TN e as compararam com 54 crianças com HC diagnosticado clinicamente. A média de idade das crianças na TN foi 32 dias e no diagnóstico clínico 141 dias. O grupo com HC detectado na TN apresentou: comprimento significantemente menor antes de iniciarem o tratamento hormonal; aumento normal do peso e altura nos seis primeiros anos de vida, com exceção dos casos de agenesia tireoidiana; aumento significante do PC durante o segundo ano e atraso na maturação óssea, apesar do crescimento normal. As crianças diagnosticadas por critérios clínicos também apresentaram recuperação do crescimento, porém somente após dez meses de terapia medicamentosa.

HEYERDAHL et al. ${ }^{51}, 1997$, avaliaram o crescimento de 103 crianças com $\mathrm{HC}$ desde o nascimento até o $6^{\circ}$ ano, considerando os níveis de $T_{4}, T_{3}$, e TSH e a altura. No $1^{\circ}$ ano de vida, observaram comprimento inferior aos valores de referência e idade média de início do crescimento atrasada. Os níveis baixos dos hormônios tireoidianos durante o $1^{\circ}$ mês de vida pareceram ter influenciado na idade de início do crescimento. Entre o $6^{\circ}$ e $12^{\circ}$ mês de vida, o padrão de crescimento foi linear, porém reduzido. A partir de então, houve aumento na velocidade de crescimento.

MANRÍQUEZ; NAGEL; VIVANCO ${ }^{74}$, 1998, avaliaram a evolução neurológica de 37 crianças com $\mathrm{HC}$ até $\circ 1^{\circ}$ ano de vida e a correlacionaram com o tratamento e gravidade do HC. Observaram alterações neurológicas e idade óssea atrasada em 9 casos e algumas das características físicas comumente associadas ao $\mathrm{HC}$ como icterícia, hérnia umbilical, constipação e temperatura corporal mais baixa. Das 9 crianças com alteração neurológica, 7 apresentaram $\mathrm{HC}$ grave, mostrando relação significante entre a gravidade do $\mathrm{HC}$ e as alterações neurológicas. 
ROVET $^{101}, 1999$, avaliou as habilidades neuropsicolingüísticas até os 13 anos de idade em 48 crianças com HC identificado na TN e os comparou com um grupo controle. Os adolescentes com menor idade óssea apresentaram alterações visoespaciais, indicando que o hipotireoidismo intrauterino pode influenciar nesta habilidade. Quanto mais baixo o nível de $T_{4}$ no diagnóstico maior $\mathrm{o}$ atraso observado nas habilidades visoespaciais, visomotoras, de atenção, leitura, memória narrativa, velocidade de nomeação e sintáticas. Os adolescentes com início tardio do tratamento, apresentaram maiores dificuldades nas habilidades de discriminação e reconhecimento de objetos familiares. $O$ autor sugeriu a necessidade de avaliações neuropsicolingüísticas em indivíduos com $\mathrm{HC}$ em todas as idades, além de estudos envolvendo procedimentos de neuroimagem estrutural e funcional que possibilitem a identificação dos sítios de perda hormonal seletiva e das bases das habilidades visoespacial e visomotora.

SALERNO et al. ${ }^{105}, 1999$, avaliaram o QI de 40 crianças com HC e as compararam com seus irmãos sem a alteração metabólica (40 crianças). A idade média das crianças com HC foi de 12 anos e de seus irmãos 12,25 anos. Das crianças com HC, 24 apresentaram glândula tireóide ectópica, 8 apresentaram agenesia e 8 disormonogênese. A média do QI das crianças dos dois grupos não se diferenciou significantemente. As crianças com nível muito baixo de $T_{4}$ no diagnóstico apresentaram $Q$ inferior. As crianças com agenesia obtiveram QI total, verbal e de execução inferiores às crianças com glândula ectópica, às crianças com disormonogênese e aos seus irmãos. Este resultado sugeriu que a transferência hormonal materna durante a gestação é insuficiente para as necessidades do feto em casos de $\mathrm{HC}$ grave.

BARGAGNA et al. $^{7}, 2000$, avaliaram as habilidades cognitivas, lingüísticas e motoras de 24 crianças (18 meninas e 6 meninos) com HC diagnosticado e tratado precocemente e as compararam com 25 crianças controle pareadas quanto ao gênero, idade e nível socioeconômico. Aos 3, 5 e 7 anos de idade, as crianças com HC não se diferenciaram das crianças controle quanto às habilidades cognitivas. Aos 7 anos, não foram observadas diferenças significantes no desempenho motor dos dois grupos, porém aos 3 
anos algumas crianças com $\mathrm{HC}$ apresentaram alterações motoras finas, de equilíbrio, de qualidade do movimento e movimentos associados e aos 5 anos todas apresentaram habilidades motoras inferiores às crianças controle. Com relação à linguagem aos 3 anos de idade, $50 \%$ das crianças com $\mathrm{HC}$ apresentaram desempenho em provas de compreensão da linguagem, vocabulário e fonologia considerados dentro dos padrões normais, $29 \%$ apresentaram alterações fonológicas e $21 \%$ apresentaram alterações fonológicas e morfossintáticas (linguagem expressiva). Aos 5 anos, $50 \%$ das crianças com HC apresentaram desempenho em provas de compreensão gramatical, vocabulário e fonologia considerados dentro dos padrões normais, $37,5 \%$ apresentaram alterações fonológicas e 12,5\% apresentaram alterações fonológicas e morfossintáticas. Aos 7 anos, $71 \%$ das crianças apresentaram desempenho em provas de compreensão gramatical, vocabulário e fonologia considerados dentro dos padrões normais e $29 \%$ alterações fonológicas. As crianças com HC grave apresentaram alterações cognitivas, lingüísticas e motoras com mais freqüência do que as crianças com $\mathrm{HC}$ menos grave. Todas as crianças com alterações fonológicas e morfossintáticas realizaram procedimentos terapêuticos e apresentaram bons resultados.

BONGERS-SCHOKKING et al. ${ }^{12}, 2000$, avaliaram o desenvolvimento cognitivo de 61 crianças com $\mathrm{HC}$ aos 10 e 30 meses de idade. As crianças foram divididas em dois grupos: $\mathrm{HC}$ grave e $\mathrm{HC}$ moderado. $\mathrm{O}$ IDM e o índice de desenvolvimento psicomotor (IDP) das crianças dos dois grupos ficaram dentro da normalidade. A média do IDM e IDP para o grupo com HC grave foi inferior em relação ao grupo com HC moderado. Dentro do grupo com HC grave, as crianças com início do tratamento precoce (antes do $13^{\circ}$ dia de vida) e altas doses de levotiroxina obtiveram os melhores IDM e IDP. Dentro do grupo com $\mathrm{HC}$ moderado, as crianças com início do tratamento tardio e com baixas doses de levotiroxina obtiveram os piores IDM. Observou-se correlação entre o IDM e o nível socioeconômico e entre o IDP e a idade na época da avaliação. Os autores afirmaram que embora os primeiros meses de vida sejam cruciais para o desenvolvimento das funções cognitivas (como fala e compreensão), este período se estende para todo $01^{\circ}$ ano quando são consideradas as funções de execução (como habilidade motora grosseira e fina). 
SALERNO et al. ${ }^{106}, 2000$, avaliaram o efeito de diferentes doses iniciais de levotiroxina no QI de crianças de 4 anos de idade com HC detectado na TN. As 83 crianças foram divididas em três grupos: grupo A (42 crianças tratadas com doses iniciais de 6 a $8 \mu \mathrm{g} / \mathrm{kg} / \mathrm{dia}$ ), grupo $\mathrm{B}$ (21 crianças tratadas com dose inicial de 8 a $10 \mu \mathrm{g} / \mathrm{kg} / \mathrm{dia}$ ) e grupo $\mathrm{C}$ (20 crianças tratadas com dose inicial de 10 a $15 \mu \mathrm{g} / \mathrm{kg} / \mathrm{dia}$ ). O QI no grupo $C$ foi significantemente maior quando comparado ao grupo A, mas não ao grupo B. Não foram observados sinais e sintomas clínicos de superdosagem no tratamento das crianças do grupo $C$, como também não foram observadas diferenças significantes no peso, na altura e na idade óssea entre os três grupos.

SALERNO et al. ${ }^{107}, 2001$, avaliaram o crescimento, desenvolvimento puberal e altura final de 55 crianças com HC detectado na TN. A média de idade das crianças no início do tratamento foi 25 dias. As crianças foram avaliadas trimestralmente até os 12 meses, a cada três ou seis meses até os 3 anos e anualmente após os 3 anos. $O$ início da puberdade ocorreu em idades típicas e a média total de crescimento puberal foi normal nos meninos e ligeiramente inferior nas meninas. Todas as crianças atingiram altura adulta média dentro dos valores esperados, porém o IMC esteve acima do percentil 95 até os 6 anos de idade e variou entre o percentil 50 e 85 nos anos subseqüentes. A idade óssea das crianças esteve atrasada nos primeiros anos de vida, porém se normalizou até os 5 anos. A etiologia do HC, a gravidade no diagnóstico, a idade no início do tratamento e a dose medicamentosa não influenciaram no crescimento longitudinal, no desenvolvimento puberal e na altura final das crianças. Os autores concluíram que como o tratamento precoce levou ao desenvolvimento puberal e altura final normais, o principal fator determinante da altura dessas crianças foi o potencial genético de crescimento da família.

RUIBAL-FRANCISCO et al. ${ }^{103}, 2001$, avaliaram o desenvolvimento puberal de 15 mulheres com $\mathrm{HC}$ e 26 mulheres controle a cada 6 meses. As mulheres com HC foram diagnosticadas com idade média de 1,64 anos e desde então, passaram a receber o tratamento hormonal substitutivo de maneira ininterrupta. Inicialmente a reposição hormonal foi realizada com 
preparado farmacológico de $90 \%$ de $\mathrm{T}_{4}$ e $10 \%$ de $\mathrm{T}_{3}$ e posteriormente com levotiroxina exclusivamente. $\mathrm{O}$ crescimento e desenvolvimento puberal das mulheres com $\mathrm{HC}$ foi normal em relação às mulheres do grupo controle, porém seu início foi tardio, seu desenvolvimento mais rápido e o crescimento no período pós-menarca foi maior.

FIGUEIREDO; SCHERMANN ${ }^{36}, 2001$, examinaram a interação mãecriança e o comportamento em crianças com $\mathrm{HC}$ tratadas precocemente de 4 a 6 anos de idade e, as compararam com um grupo de crianças sem a alteração metabólica. Não foram observadas diferenças significantes na interação e no comportamento das crianças dos dois grupos. Os autores concluíram que o fato das crianças com $\mathrm{HC}$ terem sido tratadas precocemente, com boa adesão ao tratamento e serem provenientes de famílias com nível socioeconômico médio, possa ter servido como fator preventivo para o não aparecimento de distúrbios no desenvolvimento social e comportamental na idade pré-escolar. Entretanto, a combinação de situações (gravidade do $\mathrm{HC}$ e o contexto social) pode revelar risco adicional para o desenvolvimento de problemas emocionais e comportamentais, visto que a criança passa por procedimentos de controle e reposição hormonal que diferem da rotina de uma criança saudável podendo levar a família a tratá-la como doente.

LUDUEÑA; PRADA; SÂNDI ${ }^{71}$, 2002, relataram o caso de uma menina com 11 dias de vida apresentando icterícia prolongada, sonolência, sucção fraca, distensão abdominal, constipação intestinal, fontanela posterior ampla e presença de hérnia umbilical. Com a suspeita de $\mathrm{HC}$, solicitou-se a determinação do nível de TSH confirmando a alteração metabólica. O tratamento com levotiroxina foi iniciado imediatamente após o diagnóstico. A cintilografia da tireóide demonstrou tecido tireoidiano hipoplásico. A criança apresentou evolução favorável com normalização do nível de TSH aos quarenta e cinco dias de vida e das características físicas e neurológicas por volta dos dois meses.

OERBECK et al. ${ }^{83}, 2003$, avaliaram as habilidades intelectuais, motoras e de aprendizagem em 49 adultos com $\mathrm{HC}$ identificado até o $3^{\circ}$ ano de idade e os compararam com seus irmãos sem a alteração metabólica. A média 
da idade do grupo com HC foi 20 anos e do grupo de irmãos foi 21 anos. Em todas as habilidades avaliadas, os adultos com $\mathrm{HC}$ apresentaram desempenho inferior aos seus irmãos. Foram observadas diferenças significantes quanto à habilidade motora global, coordenação motora, habilidade de nomeação e aritmética, porém os grupos não se diferenciaram quanto à velocidade motora, fluência verbal, leitura e escrita. Com relação à escolaridade, $6 \%$ dos adultos controle e $24 \%$ dos adultos com HC não completaram o ensino médio. Os adultos com nível baixo de $\mathrm{T}_{4}$ no diagnóstico apresentaram desempenho nas habilidades motoras melhor do que aqueles com nível muito baixo. $O$ desempenho nas habilidades verbais e aritméticas dos indivíduos que iniciaram o tratamento com dosagens de levotiroxina mais elevadas e demonstraram nível menos baixo de $T_{4}$ nos 6 primeiros anos de vida, também foi melhor. Os adultos que iniciaram o tratamento com dosagens de levotiroxina menores foram os que não completaram os estudos.

TINELLI et al. ${ }^{113}, 2003$, avaliaram o comportamento de 12 crianças e 18 adolescentes com HC com idade média de 10 anos e 4 meses e 13 anos e 5 meses respectivamente e os compararam com 58 crianças e 58 adolescentes controle pareados quanto à idade. $\mathrm{O}$ tratamento para $\mathrm{O} \mathrm{HC}$ foi iniciado entre $\mathrm{O}$ $20^{\circ}$ e $30^{\circ}$ dia de vida. Foram observados problemas comportamentais mais freqüentes no grupo com $\mathrm{HC}$ do que no grupo controle. No grupo com $\mathrm{HC}$, as crianças apresentaram comportamentos delinqüentes e os adolescentes demonstraram isolamento, ansiedade, depressão, agressividade, problemas atencionais e de raciocínio. $\mathrm{Na}$ avaliação psiquiátrica $44 \%$ dos adolescentes com HC apresentaram sintomas de ansiedades e fobia, $16 \%$ apresentaram depressão e $11 \%$ apresentaram déficits de atenção.

ANDROVANDI; NUNES ${ }^{5}, 2004$, avaliaram o QI de 22 crianças com $\mathrm{HC}$, na faixa etária de 6 anos a 12 anos e 9 meses. Todas as crianças haviam iniciado o tratamento ante do $3^{\circ}$ mês de vida. Observou-se QI total, QI verbal e QI de execução acima de 90 (resultados classificados na média ou acima) em 17, 18 e 18 participantes, respectivamente. Escores inferiores a 90, foram observados em 5 crianças na avaliação do Ql total e em 4 crianças na 
avaliação do QI verbal e QI de execução. As crianças cujas famílias apresentavam renda maior obtiveram melhores escores.

SIMONS et al. ${ }^{109}$, 2004, avaliaram os aspectos educacionais, comportamentais e as habilidades motoras de 59 crianças aos 10 anos de idade, com HC identificado na TN. O grupo controle foi composto de 59 crianças estudantes nas mesmas salas de aula pareadas quanto à idade, gênero, nível socioeconômico e linguagem expressiva. As crianças com HC foram divididas em: grupo 1 (tratamento com níveis de $T_{4} \leq 40 \mathrm{nmol} / \mathrm{L}$ ) e grupo 2 (tratamento com níveis de $\mathrm{T}_{4}>40 \mathrm{nmol} / \mathrm{L}$ ). As crianças com $\mathrm{HC}$ do grupo 1 apresentaram pior desempenho em todos os aspectos avaliados. A taxa de leitura, sua precisão e compreensão foram semelhantes nos três grupos, porém as habilidades matemáticas e habilidades motoras foram significantemente inferiores no grupo 1 de crianças com HC. Problemas comportamentais foram observados com maior freqüência nos grupos com HC principalmente quanto à intranqüilidade e dificuldade em acalmar-se. Os autores concluíram que problemas comportamentais de grau leve são comuns em indivíduos com $\mathrm{HC}$ tratado precocemente e que as alterações educacionais observadas foram de baixa significância.

TORRES et al. ${ }^{114}, 2004$, avaliaram a atenção sustentada de três grupos de crianças com idade entre 7 e 13 anos. O grupo 1 foi composto de 35 crianças com queixas de distúrbio de aprendizagem, sem alterações neurológicas ou uso de medicamentos. O grupo 2 foi composto de 37 crianças com HC tratado desde o sétimo dia de vida, apresentando QI normal. O Grupo 3 foi composto de 40 crianças do ensino fundamental, sem queixas de problemas de aprendizagem e sem alterações metabólicas para o HC. A avaliação da atenção sustentada foi realizada por meio de uma bateria computadorizada (SESH 1.0) desenvolvida especificamente para o diagnóstico das alterações atencionais de pacientes com $\mathrm{HC}$ e seu acompanhamento. As crianças do grupo 1 apresentaram atenção sustentada inferior ao grupo 3 e as crianças do grupo 2 apresentaram rendimento intermediário. Segundo os autores, as alterações atencionais no grupo com $\mathrm{HC}$ foram relativamente independentes do rendimento intelectual e da precocidade do tratamento. 
BONGERS-SCHOKKING; DE MUINCK KEIZER-SCHRAMA ${ }^{13}, 2005$, avaliaram o desenvolvimento cognitivo e neuropsicomotor de 45 crianças com $\mathrm{HC}$ em idade escolar e as compararam com 37 crianças controle. O QI total das crianças de ambos os grupos foi semelhante. $O$ desempenho nas habilidades visomotoras e verbais foi inferior nas crianças com $\mathrm{HC}$ e o índice de alterações comportamentais foi superior. Observou-se que quanto menor a dosagem de levotiroxina no início do tratamento maiores os índices de alterações comportamentais e quanto maior a dosagem de levotiroxina no início do tratamento melhor o desenvolvimento cognitivo aos 5 e 7 anos de idade.

GHAZI et al. ${ }^{41}, 2005$, relataram o caso de uma família com três filhos afetados pelo $\mathrm{HC}$ e sem histórico anterior. A mãe eutireóidea casou com o primo e teve na primeira gravidez uma menina com sinais clínicos do $\mathrm{HC}$ que foi a óbito devido à obstrução nas vias aéreas superiores e asfixia, ocorridas após o nascimento. A necropsia revelou glândula tireóidea grande na região anterior do pescoço, comprimindo a traquéia. Na segunda gravidez, de um menino, o diagnóstico ultra-sonográfico realizado na $20^{\mathrm{a}}$ semana gestacional, revelou massa na região anterior do pescoço. O menino nasceu na $38^{\mathrm{a}}$ semana de gestação de parto cesariana de emergência e também apresentou os sinais clínicos de HC. O diagnóstico foi confirmado no $3^{\circ}$ dia de vida por meio de níveis elevados de TSH e baixos de $\mathrm{T}_{4}$. $\mathrm{O}$ tratamento com levotiroxina foi iniciado imediatamente, os níveis hormonais foram mantidos dentro da normalidade e o crescimento físico e desempenho escolar estavam aparentemente normais. Na terceira gestação, de uma menina, foi realizada a ultra-sonografia na $33^{a}$ semana de gestação com indicativos de aumento da glândula tireóide. Amniocentese foi realizada para avaliar os níveis de $\mathrm{TSH}_{\mathrm{H}} \mathrm{T}_{4}$ e $500 \mu \mathrm{g}$ de levotiroxina foi injetada na cavidade amniótica semanalmente a partir da $35^{\text {a }}$ semana de gestação. Várias ultra-sonografias foram realizadas e observaram redução do tamanho da massa na região do pescoço. A menina nasceu de parto cesariana na $37^{\text {a }}$ semana de gestação, com Apgar 9 no primeiro minuto e 10 no quinto. O peso, cumprimento e PC foram 3700 gramas, 51 e 26 centímetros respectivamente. Não foram observados problemas respiratórios e icterícia, porém a criança apresentou hérnia umbilical e precisou 
ser internada devido à distensão abdominal e vômitos freqüentes. Níveis de $\mathrm{TSH}$ e $\mathrm{T}_{4}$ alterados confirmaram o diagnóstico de $\mathrm{HC}$ e $\mathrm{o}$ tratamento com levotiroxina foi iniciado no $3^{\circ}$ dia de vida quando a criança começou a se alimentar oralmente.

OERBECK et al. ${ }^{84}, 2005$, avaliaram 49 adultos (idade média de 20 anos) com $\mathrm{HC}$ tratado precocemente, quanto à memória, atenção e comportamento e os compararam com 41 adultos do grupo controle pareados pela idade e gênero. Observou-se desempenho nos testes de memória verbal e atenção significantemente inferior nos adultos com HC. Estes também apresentaram alterações de comportamento com mais freqüência. Doses iniciais altas de levotiroxina, níveis menos baixo de $\mathrm{T}_{4}$ durante os seis primeiros anos de vida e na época da avaliação não apresentaram efeitos prejudiciais para os resultados encontrados. Os resultados sugeriram melhores desempenhos com doses de levotiroxina elevadas no início do tratamento.

ROVET $^{102}$, 2005, avaliou o desempenho cognitivo de 42 crianças com $\mathrm{HC}$ e as comparou com seus irmãos sem a alteração metabólica. Todas as crianças com $\mathrm{HC}$ foram identificadas pela TN. As crianças com HC apresentaram QI significantemente inferior aos seus irmãos e essa diferença foi maior nas crianças com agenesia e ectopia da glândula tireóide. As crianças tratadas com dosagem inicial mais elevada de levotiroxina tiveram QI mais próximo de seus irmãos. Ao se comparar os dois grupos não foram percebidas influências da idade óssea, do nível de $\mathrm{T}_{4}$ no diagnóstico e da idade de início do tratamento nos resultados das avaliações. Para o autor, não ficou claro se doses mais elevadas de levotiroxina permitiriam o desenvolvimento normal de crianças com $\mathrm{HC}$ de início intra-uterino, pois provavelmente, os déficits cognitivos existirão uma vez que o desenvolvimento cerebral depende dos hormônios tireoidianos.

BARGAGNA et al. $^{8}, 2006$, avaliaram 52 crianças com HC tratadas precocemente quanto às habilidades motoras, cognitivas e lingüísticas. Foram observados déficits motores e lingüísticos nas crianças avaliadas, porém a cognição esteve dentro dos padrões de normalidade. As crianças com níveis muito baixos de $\mathrm{T}_{4}$ antes do início do tratamento para o $\mathrm{HC}$ e níveis 
socioeconômicos menos privilegiados apresentaram maiores alterações no desempenho das habilidades avaliadas.

DLUHOLUCKY; HOMOVA; LUKAC ${ }^{33}$, 2006, realizaram acompanhamento longitudinal de uma criança com $\mathrm{HC}$ tratado desde a $4^{\mathrm{a}}$ semana de vida e sua irmã gêmea homozigótica sem a alteração metabólica. 0 desenvolvimento das duas crianças foi muito semelhante. Nos primeiros anos do ensino fundamental, a criança com $\mathrm{HC}$ apresentou desempenho nas habilidades de memória e raciocínio lógico inferior à sua irmã. Porém, ao receber acompanhamento em escola especial durante a adolescência, seu desempenho nestas habilidades melhorou, mostrando que déficits cognitivos em crianças com HC tratado precocemente podem não ser graves e variam durante o desenvolvimento do indivíduo.

HATIPOGLU et al. ${ }^{48}$, 2006, relataram dois casos de crianças com HC. O primeiro descreveu um menino de 7 meses de idade com choro rouco, sonolência e histórico de icterícia prolongada durante o período neonatal. $\mathrm{Na}$ avaliação clínica observou-se língua pequena e alargada, depressão da base do nariz, voz rouca e atraso neuropsicomotor. Os exames laboratoriais referentes aos hormônios tireoidianos mostraram-se alterados. Após um mês de tratamento para o HC observou-se queda de cabelo, normalizando-se após 4 meses de tratamento por meio de reposição hormonal. O segundo caso descreveu uma menina de 16 meses de idade com atraso no desenvolvimento e ausência de marcha. O tratamento para o $\mathrm{HC}$ foi iniciado aos 2 meses de idade e suspenso aos 4 meses devido à queda de cabelo. No exame clínico, foram observadas letargia, rouquidão e pele seca.

HEPWORTH; PANG; ROVET ${ }^{49}$, 2006, avaliaram os potenciais evocados durante o reconhecimento de palavras e faces em 9 crianças com $\mathrm{HC}$ de 11 a 13 anos de idade e em 9 crianças controle pareadas pela idade. Os grupos não se diferenciaram quanto a acurácia e o tempo de reação aos estímulos apresentados, entretanto, observou-se resposta neurofisiológica alterada durante provas de repetição de estímulo verbal nas crianças com $\mathrm{HC}$. Os autores inferiram que tais dificuldades podem estar associadas a alterações da memória de curto prazo. 
KEMPERS et al. $^{56}, 2006$, avaliaram as habilidades cognitivas e motoras de 70 adultos jovens com HC identificado na TN e os compararam com 66 adultos participantes do grupo controle. Os adultos avaliados apresentaram idade média de 21 anos e 6 meses, entretanto, 49 deles já haviam sido avaliados aos 9 anos e 6 meses de idade. A idade média no início do tratamento para $\circ \mathrm{HC}$ foi 28 dias. Os adultos com $\mathrm{HC}$ apresentaram alterações motoras significantes quando comparados ao grupo controle e QI significantemente inferior à média da população. O Ql total e de execução dos adultos com $\mathrm{HC}$ grave (nível muito baixo de $\mathrm{T}_{4}$ no diagnóstico) foi inferior aos obtidos pelos adultos com $\mathrm{HC}$ leve e moderado. Os autores concluíram que déficits cognitivos e motores persistiram nos adultos jovens com $\mathrm{HC}$ tratados precocemente principalmente, no que diz respeito aos domínios verbais, de execução, equilíbrio e habilidade motora fina. Estes déficits foram mais pronunciados nos adultos com HC grave e não tiveram correlação com a idade de início do tratamento, uma vez que a média da idade no início do tratamento dos adultos com $\mathrm{HC}$ leve, moderado e grave foi a mesma.

MARTI et al. ${ }^{75}, 2006$, avaliaram os potenciais evocados auditivos $\mathrm{N} 100$ e N200 em 15 crianças de 5 anos de idade e as compararam com 33 crianças controle. $\mathrm{O}$ tratamento para o $\mathrm{HC}$ foi iniciado em média no $14^{\circ}$ dia de vida e as crianças foram divididas em grupo com $\mathrm{HC}$ grave e grupo com $\mathrm{HC}$ moderado, de acordo com a maturação óssea observada no diagnóstico. Não foram observadas diferenças entre as crianças com $\mathrm{HC}$ e as crianças do grupo controle e entre as crianças com $\mathrm{HC}$ moderado e $\mathrm{HC}$ grave, quanto organização anatômico-funcional do sistema auditivo. Porém, a latência N200 foi maior nas crianças com $\mathrm{HC}$, principalmente naquelas com dosagem elevada de levotiroxina no tratamento e QI verbal mais reduzido. A amplitude da onda N200 não se correlacionou com a dosagem inicial de levotiroxina no tratamento. Desta forma, os autores inferiram que a diferença sutil observada nos potenciais evocados auditivos entre as crianças com $\mathrm{HC}$ e crianças controle esteve relacionada à adequação do tratamento para o $\mathrm{HC}$.

PNIEWSKA-SIARK et al. ${ }^{91}, 2006$, acompanharam longitudinalmente, dos 4 anos e 8 meses aos 14 anos e 2 meses, o desenvolvimento físico e 
cognitivo de 102 crianças com HC diagnosticado pela TN. A idade média no início do tratamento foi 19 dias. As crianças foram divididas em três grupos quanto à etiologia: agenesia, hipoplasia, e ectopia da glândula tireóide. Observou-se desenvolvimento físico e cognitivo adequado nos três grupos, entretanto, o grupo com agenesia apresentou índices de crescimento e QI significantemente inferiores aos outros grupos. 
3 - HABILIDADES DO DESENVOLVIMENTO NO HIPOTIREOIDISMO CONGÊNTIO: ENFOQUE NA COMUNICAÇÃO 



\section{3 - HABILIDADES DO DESENVOLVIMENTO NO HIPOTIREOIDISMO CONGÊNITO: ENFOQUE NA COMUNICAÇÃO}

A deficiência dos hormônios tireoidianos durante a vida fetal e nos primeiros anos de vida pode acarretar retardo mental e alterações do desenvolvimento (BARGAGNA et al. ${ }^{7}, 2000$, LUDUEÑA; PRADA; SÂNDI ${ }^{71}$, 2002). Mesmo com o início precoce do tratamento para o HC algumas seqüelas podem não ser prevenidas e até se tornarem irreversíveis (BOTLER $^{16}$, 1996, SIMONS et al. ${ }^{109}$, 2004, GEELHOED et al. ${ }^{40}$, 2005, ROVET $^{102}$, 2005).

A literatura tem referido alterações nas habilidades do desenvolvimento (habilidades motoras, cognitivas, lingüísticas, sociais e de autocuidados) em crianças com HC, mesmo quando o diagnóstico foi precoce e tratamento adequado. A magnitude de tais alterações depende de alguns fatores como a etiologia do $\mathrm{HC}$, época de seu início (pré ou pós-natal), gravidade da deficiência hormonal e idade da criança ao iniciar o tratamento de reposição hormonal (ROVET ${ }^{101}$, 1999, SALERNO et al. ${ }^{105}$, 1999, ALMACHE $^{3}$, 2003, OERBECK et al. ${ }^{83}, 2003$, ROVET $\left.{ }^{102}, 2005\right)$.

A criança nasce equipada com habilidades pré-programadas para produzir numerosos padrões interativos e sensórios-motores, possibilitando o controle essencial à sua sobrevivência e segurança sobre o corpo, motricidade e simultaneamente sobre suas emoções, habilidades lingüísticas e cognitivas $\left(\right.$ CLARK $^{26}$, 2004). Quando as habilidades motoras se desenvolvem com atraso, costuma seguir uma seqüência própria dependente da etiologia específica que levou a este atraso (WEBSTER et al. ${ }^{121}$, 2005).

O desenvolvimento neuropsicomotor alterado pode interferir na maturidade do desenvolvimento global da criança em função da qualidade de exploração ambiental e das possibilidades interativas. Nestas circunstâncias, a criança pode perder oportunidades concretas de ampliar seu repertório, ocasionando lacunas nas áreas perceptivas, cognitivas, lingüísticas, sociais e 
de autocuidados (LAMÔNICA ${ }^{65}, 2004, \mathrm{KENDAL}^{57}, 2005$ ). A exploração do ambiente, manipulação de objetos, repetição de ações, domínio do controle do esquema corporal e relações estabelecidas em situações vivenciadas possibilitam a aquisição do conhecimento, mostrando que os processos cognitivos estão integrados na atividade motora (LAMÔNICA ${ }^{65}, 2004$, KENDAL ${ }^{57}, 2005$, WEBSTER et al. $\left.{ }^{121}, 2005\right)$.

A aquisição e desenvolvimento da linguagem dependem das condições e da interação de fatores orgânicos, psíquicos e sociais (CASTAÑO ${ }^{24}$, 2003, PERISSINOTO; ISOTANI ${ }^{87}$, 2003). Como sua aquisição ocorre por meio do intercâmbio, exploração ativa e relações estabelecidas com o ambiente, o desenvolvimento motor atrasado pode acarretar alterações no desenvolvimento da linguagem que serão refletidas nas atividades do dia a dia, influenciando, portanto, no desenvolvimento das habilidades sociais e de autocuidados (LAMÔNICA ${ }^{65}, 2004$, WEBSTER et al. ${ }^{121}$, 2005). Estas últimas habilidades podem ainda sofrer influências do protecionismo advindo da cultura brasileira que faz com que pais de crianças com alteração do desenvolvimento ou consideradas doentes, não ofereçam oportunidades para que seus filhos realizarem tarefas do cotidiano mesmo tendo capacidades para tal (MANCINI et al. $\left.{ }^{72}, 2002\right)$.

Por meio da linguagem a criança tem acesso a valores, crenças e regras de sua cultura, antes mesmo de aprender a falar. À medida que se desenvolve seu sistema sensorial, incluindo visão e audição, torna-se mais refinado, seu nível lingüístico aumenta e seu campo de socialização se estende, principalmente com o egresso escolar oferecendo oportunidades de interação com outras crianças. Em suas relações e interações com adultos ocorrem trocas de experiências e conhecimentos estabelecendo relações recíprocas e bidirecionais, contribuindo para o desenvolvimento lingüístico (BORGES; SALOMÃO ${ }^{14}$, 2003).

MENDES; MOURA ${ }^{79}, 2004$, afirmaram que na brincadeira conjunta, a criança e a mãe interagem num contexto que promove o desenvolvimento emocional e das capacidades sociocognitivas. Os gestos, as expressões 
faciais, o olhar do bebê (primeiras formas de comunicação intencional) e as vocalizações com entonações marcadas são respondidos pela mãe que, por sua vez, encoraja a criança a usar a linguagem de forma mais elaborada e funcionalmente correta.

Por volta de 1 ano de idade, a maioria das crianças fala ao menos uma palavra, é compreendida por estranhos $25 \%$ das vezes, acata uma ordem simples não acompanhada por gestos e apontam para objetos desejados. Sua comunicação oral consiste basicamente de balbucios e sua brincadeira é quase restrita à exploração sensorial de objetos. Ao longo do $2^{\circ}$ ano, as crianças utilizam palavras mais espontaneamente, formam frases de duas palavras, utilizam fala telegráfica, são compreendidas por estranhos $50 \%$ das vezes, acatam duas ordens dadas e brincam com objetos por meio de ações explanatórias funcionais e concretas. Aos 3 anos de idade, a maioria das crianças é fluente em sentenças no presente, passa a produzir gradativamente palavras representativas de objetos e eventos próprios ao seu ambiente, é compreendida por estranhos $75 \%$ das vezes e começa a apresentar brincadeira simbólica. Posteriormente, a tendência para representação mental do mundo aumenta tanto na linguagem quanto na brincadeira e sua fala é $100 \%$ compreendida por estranhos (COPLAN ${ }^{28}, 1985$, ZORZI $^{127}, 1994$, BORNSTEIN et al. ${ }^{15}, 1999$, ZORZI $\left.^{128}, 2002\right)$.

Segundo WETHERBY; YONCLAS; BRYAN ${ }^{122}, 1989$, embora as primeiras palavras surjam entre doze e dezoito meses de idade, as alterações no desenvolvimento da linguagem são detectadas muitas vezes somente na pré-escola. Entretanto, já no início do desenvolvimento comunicativo destas crianças pode-se observar padrão de comunicação tipicamente gestual e diferenças nas funções comunicativas como regulação do comportamento, interação social e atenção conjunta. Desta forma, é de extrema importância o acompanhamento do desenvolvimento lingüístico de crianças com idade inferior a 36 meses (WALKER et al. ${ }^{119}$, 1989).

$\operatorname{COPLAN}^{28}, 1985$, afirmou que retardo mental afeta $3 \%$ das crianças e constitui a alteração do desenvolvimento mais comum entre crianças com 
atraso no desenvolvimento da fala e da linguagem. Este atraso global da linguagem é acompanhado por alterações do comportamento adaptativo (capacidade de vestir-se, alimentar-se e ir ao banheiro sozinho) e da capacidade de resolver problemas. Desta forma, a observação de atrasos no desenvolvimento da linguagem é provavelmente uma das melhores formas de triagem do retardo mental.

De acordo com o DSM.IV ${ }^{34}, 2006$, o retardo mental é caracterizado como:

"funcionamento intelectual significativamente inferior à média, acompanhado de limitações significativas no funcionamento adaptativo em pelo menos duas das seguintes áreas de habilidades: comunicação, autocuidados, vida doméstica, habilidades sociais/interpessoais, uso de recursos comunitários, auto-suficiência, habilidades acadêmicas, trabalho, lazer, saúde e segurança".

LAMÔNICA ${ }^{65}, 2004$, afirmou que sendo a linguagem a expressão dos processos mentais, pode-se inferir que quanto maior a capacidade de inteligência maior a capacidade de compreender conceitos, elaborar frases e expressar-se, principalmente quando o funcionamento do SN, do sistema sensorial e perceptual encontra-se íntegro. Assim, considerando-se que a "gravidade do retardo mental na aquisição de linguagem é inversamente proporcional ao Ql" os deficientes mentais sempre apresentarão desenvolvimento da linguagem compatível com a idade mental $\left(\mathrm{CLARK}^{26}\right.$, 2004). Estes indivíduos podem ainda apresentar alterações nas habilidades de autocuidados, socialização e auto-orientação, além de dificuldades em atividades escolares e profissionais (DSM.IV4, 2006, KNOBLOCK; PASSAMANICK $\left.{ }^{61}, 2000\right)$.

Crianças acompanhadas com procedimentos de estimulação, quando identificados precocemente os sinais de anormalidade e/ou desvios desenvolvimentais, demonstram melhoria na condição de respostas e rearranjos na plasticidade cerebral, capazes de minimizar o impacto no desenvolvimento estrutural e funcional (PIOVESANA ${ }^{89}$, 2001, HAHNE; ECKSTEIN; FRIEDERIC ${ }^{46}$, 2004). Desta forma, o diagnóstico precoce associado aos procedimentos de intervenção interdisciplinares, é fundamental para a melhora do desenvolvimento físico, cognitivo, percepto-sensorial e afetivo da criança. 
4 - PROPOSIÇÃO 



\section{4 - PROPOSIÇÃO}

Considerando as possíveis alterações no desenvolvimento de indivíduos com hipotireoidismo congênito, este estudo foi delineado com os objetivos de:

Traçar o perfil das habilidades do desenvolvimento de crianças com hipotireoidismo congênito diagnosticado e tratado precocemente, enfocando as habilidades comunicativas;

$>$ Verificar influências da história clínica nas habilidades do desenvolvimento na presença do hipotireoidismo congênito. 

5 - MATERIAL E MÉTODOS 



\section{5 - MATERIAL E MÉTODOS}

Inicialmente o projeto de estudo foi submetido ao Comitê de Ética em Pesquisa em Seres Humanos da Faculdade de Odontologia de Bauru da Universidade de São Paulo (FOB/USP), protocolo número 53/2005 de 5 de junho de 2005. Após aprovação, o projeto foi encaminhamento para a APAEBauru para ciência.

O presente estudo foi desenvolvido no Departamento de Fonoaudiologia da FOB/USP em parceria com PTN do Laboratório e Ambulatório de Screening Neonatal "Teste do Pezinho" da Associação de Pais e Amigos dos Excepcionais de Bauru (Laboratório do Teste do Pezinho da APAE-Bauru).

A equipe do Laboratório do Teste do Pezinho da APAE-Bauru demonstrou interesse na proposta do estudo por não contar com acompanhamento fonoaudiológico dos casos com alterações do metabolismo atendidos e, pela possibilidade de avaliação da efetividade deste PTN na prevenção de seqüelas do desenvolvimento decorrentes do HC. Cabe ressaltar que este estudo é parte de um projeto maior intitulado "Acompanhamento fonoaudiológico de crianças que apresentam alterações no Teste do Pezinho: Hiperfenilalaninemias e Hipotireoidismo Congênito". O objetivo deste projeto é acompanhar longitudinalmente crianças com risco para atraso do desenvolvimento por alterações metabólicas congênitas.

Serão apresentadas a seguir, informações referentes à rotina de atendimento do PTN realizado pelo Laboratório do Teste do Pezinho da APAEBauru, visando à compreensão do estudo.

Implantado e credenciado pelo Ministério da Saúde em 1998 como Serviço de Referência em Triagem Neonatal, o Laboratório do Teste do Pezinho da APAE-Bauru estende sua cobertura à população de grande parte 
da região Centro Oeste Paulista. Ao todo são aproximadamente 371 postos de coleta em 206 cidades com distância máxima de $350 \mathrm{~km}$ da cidade de Bauru. Suas atividades englobam a realização da TN, diagnóstico, tratamento e acompanhamento para o HC e fenilcetonúria desde 1998 e das hemoglobinopatias desde 2001. Anteriormente à sua implantação, as crianças nascidas nessa região com suspeita de alterações do metabolismo eram encaminhadas para confirmação diagnóstica e tratamento na APAE-SP.

Sua equipe multidisciplinar é composta por endocrinologista-pediátra, pediatra, psicólogo, nutricionista, neuropediatra, assistente social, hematologista e bioquímico. Em março de 2005 foi firmada parceria com o Departamento de Fonoaudiologia da FOB/USP. O objetivo dessa parceria foi caracterizar as habilidades comunicativas das crianças diagnosticas, tratadas e acompanhadas com $\mathrm{HC}$, fenilcetonúria e hemoglobinopatias, estabelecer estratégias de intervenção fonoaudiológica necessárias e acompanhar o desenvolvimento das habilidades comunicativas.

Como o HC é a alteração metabólica de interesse deste estudo serão descritos apenas os procedimentos realizados pelo PTN do Laboratório do Teste do Pezinho da APAE-Bauru referentes à TN, diagnóstico, tratamento e acompanhamento desta entidade clínica.

Para a realização da TN são coletadas amostras de sangue em papel filtro por punção do calcanhar e analisado o nível de TSH. O Laboratório do Teste do Pezinho da APAE-Bauru realiza a coleta e sua análise e/ou orienta as equipes dos postos de coleta da cidade de origem da criança sobre as técnicas de coleta, armazenamento da amostra coletada e a idade ideal para a realização da TN correspondente ao período de 3 a 7 dias de vida. Nestes casos a amostra de sangue coletada deve ser enviada por correio ao Laboratório do Teste do Pezinho da APAE-Bauru para análise. Níveis de TSH entre 6 e $9 \mu \mathrm{Ul} / \mathrm{ml}$ são considerados suspeitos de HC. Nestes casos há a necessidade de nova coleta em papel filtro. Crianças com níveis de TSH acima de $9 \mu \mathrm{Ul} / \mathrm{ml}$ são convocadas para exame diagnóstico. 
Para a realização do exame diagnóstico são coletadas amostras de sangue em soro e analisados os níveis de TSH e $\mathrm{T}_{4}$ Livre. São considerados confirmatórios do $\mathrm{HC}$ níveis de TSH acima de $10 \mu \mathrm{UI} / \mathrm{ml}$ e de $\mathrm{T}_{4}$ Livre abaixo de 0,75 ng/dl. Quando a alteração metabólica não é detectada, a família recebe o resultado da TN e/ou do exame diagnóstico e a criança não é elegível para o programa de tratamento e acompanhamento para o $\mathrm{HC}$ do Laboratório do Teste do Pezinho da APAE-Bauru.

O tratamento e acompanhamento das crianças com diagnóstico confirmado são realizados no Laboratório do Teste do Pezinho da APAE-Bauru às terças-feiras. $O$ período ideal adotado para o início do tratamento corresponde ao primeiro mês de vida da criança. As famílias são encorajadas a realizar o tratamento e acompanhamento de suas crianças no próprio Laboratório do Teste do Pezinho da APAE-Bauru, entretanto podem optar pela realização do tratamento e acompanhamento em suas cidades de origem. Nesta circunstância, o responsável legal pela criança deve assinar um termo se responsabilizando pelo tratamento em sua cidade, para que a criança seja referenciada ao serviço público oficializado pelo município de origem.

Na primeira consulta, a família é esclarecida quanto ao resultado do exame confirmatório, à patologia, à forma de tratamento e possíveis conseqüências decorrentes da sua não adesão e/ou adesão inadequada. Neste momento é realizado o aconselhamento genético e estabelecido o cronograma de tratamento e acompanhamento mais adequado para cada criança.

O tratamento do HC é realizado por meio da reposição hormonal com dosagem de levotiroxina de acordo com os níveis de TSH e $\mathrm{T}_{4}$ Livre de cada criança. O Laboratório do Teste do Pezinho da APAE-Bauru, por meio do Sistema Único de Saúde do Ministério da Saúde, oferece o medicamento gratuitamente. O acompanhamento clínico e laboratorial é realizado mensalmente para as crianças com até seis meses de idade, bimestralmente para as crianças com seis a dezoito meses e trimestralmente para as crianças com idade superior aos dezoito meses. Durante o tratamento, o nível de TSH deve ficar entre 0,49 e 4,67 $\mu \mathrm{Ul} / \mathrm{ml}$ e o nível de $T_{4}$ Livre entre 0,71 e 1,85 ng/dl. 
Todas as crianças do programa de tratamento e acompanhamento para o HC são avaliadas por assistente social quanto ao nível socioeconômico e por psicólogo por meio de uma escala de desenvolvimento intitulada "Escala Passos Básicos do Desenvolvimento" (EPBD), adaptação PÉREZ-RAMOS ${ }^{86}$, 1975. Nesta escala são avaliados o nível cognitivo (em anos e meses), o desempenho funcional nas atividades acadêmicas e os níveis de apoio para autonomia, autocuidados e habilidades sociais. Sua classificação numérica propicia o número de meses de atraso da idade mental com relação à idade cronológica. Porém, no Laboratório do Teste do Pezinho da APAE-Bauru, a análise do cálculo da idade mental é realizada somente para as crianças que apresentam atraso global do desenvolvimento. As crianças que apresentam desenvolvimento considerado dentro de padrões típicos são classificadas como apresentando "desenvolvimento adequado". Quando há a suspeita ou evidências de alterações no desenvolvimento, a criança é encaminhada para avaliação neurológica e atendimentos multidisciplinares em programas da rede pública de sua cidade de origem.

A Figura 1 apresenta o número de crianças nascidas vivas na região de cobertura do PTN, o total de crianças triadas, a porcentagem de cobertura populacional da TN, o número de diagnóstico efetuado e a prevalência do HC durante o período de 2002 a 2005.

\begin{tabular}{|cccccc|}
\hline Ano & $\begin{array}{c}\text { Nascidas } \\
\text { vivas } \\
(\mathbf{n})\end{array}$ & $\begin{array}{c}\text { Triadas } \\
(\mathbf{n})\end{array}$ & $\begin{array}{c}\text { Cobertura } \\
(\mathbf{\%})\end{array}$ & $\begin{array}{c}\text { Diagnóstico } \\
(\mathbf{n})\end{array}$ & Prevalência \\
\hline $\mathbf{2 0 0 2}$ & 53.018 & 34.303 & $64,70 \%$ & 7 & $1: 7.574$ \\
$\mathbf{2 0 0 3}$ & 56.019 & 54.535 & $97,35 \%$ & 14 & $1: 4.001$ \\
$\mathbf{2 0 0 4}$ & 56.007 & 54.764 & $97,78 \%$ & 20 & $1: 2.800$ \\
$\mathbf{2 0 0 5}$ & 56.608 & 55.850 & $98,66 \%$ & 19 & $1: 2.979$ \\
\hline Total & $\mathbf{2 2 1 . 6 5 2}$ & $\mathbf{1 9 9 . 4 5 2}$ & $\mathbf{8 9 , 9 9 \%}$ & $\mathbf{6 0}$ & $\mathbf{1 : 3 6 9 4}$ \\
\hline
\end{tabular}

Observação: a estatística referente ao ano de 2006 será efetuada somente após o término do corrente ano.

FIGURA 1 - Número de crianças nascidas vivas, número de crianças triadas, cobertura populacional da TN, número de diagnósticos de $\mathrm{HC}$ e prevalência do HC durante o período de 2002 a 2005 


\section{1 - Casuística}

A seleção e caracterização da casuística foram realizadas por meio da análise dos prontuários e Banco de Dados do PTN do Laboratório do Teste do Pezinho da APAE-Bauru seguindo os critérios de inclusão:

a) Possuir o diagnóstico de HC;

b) Apresentar idade entre 2 a 36 meses;

c) Realizar tratamento e acompanhamento para o HC no PTN do Laboratório do Teste do Pezinho da APAE-Bauru, com adesão adequada segundo os critérios das diretrizes nacionais;

d) Estar em tratamento medicamentoso para o $\mathrm{HC}$ por um período superior a um mês;

e) Não apresentar outras alterações congênitas ou adquiridas e síndromes genéticas ou neurológicas comprovadas as quais não fazem parte do quadro do HC.

$\mathrm{Na}$ época da coleta de dados, constavam no Banco de Dados do referido laboratório 57 crianças na faixa etária de 2 a 36 meses. Foram excluídas da casuística 16 crianças $(28,07 \%)$ que realizavam tratamento e acompanhamento para o $\mathrm{HC}$ em suas cidades de origem e 6 crianças (10,53\%) que apresentavam adesão inadequada ao programa.

Desta forma, a casuística foi composta por 35 crianças, 23 (65,71\%) do gênero feminino e 12 (34,29\%) do masculino, na faixa etária de 2 a 36 meses. Todas as crianças possuíam diagnóstico de $\mathrm{HC}$ e realizavam o tratamento no Laboratório do Teste do Pezinho da APAE-Bauru há pelo menos um mês. Dezesseis crianças $(45,72 \%)$ pertenciam à faixa etária de 2 a 12 meses, dez $(28,57 \%)$ à faixa etária de 13 a 24 meses e nove $(25,71 \%)$ à faixa etária de 25 a 36 meses. 


\section{2 - Procedimentos}

A coleta de dados foi realizada no próprio Laboratório do Teste do Pezinho da APAE-Bauru entre janeiro e agosto de 2006. Anteriormente aos procedimentos de coleta de dados, os responsáveis legais pelas crianças foram esclarecidos a respeito da parceria do Curso de Pós-Graduação em Fonoaudiologia nível de Mestrado, com o Laboratório do Teste do Pezinho da APAE-Bauru e dos objetivos propostos neste estudo. Em seguida, os responsáveis pelas crianças foram orientados a realizar a leitura do Termo de Consentimento Livre e Esclarecido (Anexo 1) e, após esclarecimentos de dúvidas e concordância, assinaram o referido termo.

Para traçar o perfil das habilidades do desenvolvimento das crianças com HC foram utilizados os seguintes procedimentos:

- Aplicação da Escala ELM - "Early language Milestone Scale" (Anexo 2), com o objetivo de avaliar as habilidades lingüísticas.

A Escala ELM (“Early Language Milestone Scale”) é considerada um instrumento resumido de avaliação de linguagem. COPLAN et al. ${ }^{27}$, 1982, realizaram avaliações mensais da linguagem em recém-nascidos saudáveis, pertencentes à classe socioeconômica média e baixa durante os 36 meses de vida. A partir deste estudo transversal, foram selecionados 41 marcos de linguagem, aos quais foram atribuídos valores normativos na referida faixa etária.

Os marcos de linguagem foram agrupados em função auditiva expressiva (AE), função auditiva receptiva (AR) e função visual (V). Dispostos na forma de gráfico em uma única folha foram ainda divididos em 36 meses de maneira que se possa localizar cada item e o mês no qual determinada habilidade teve seu início. O gráfico indica os valores de $25 \%, 50 \%, 75 \%$ e 90\% como representativo da porcentagem de crianças de determinada faixa 
etária que atingiram a habilidade testada durante o processo de validação da escala. O tempo de aplicação depende da idade e do nível de habilidade do indivíduo avaliado (COPLAN et al. ${ }^{27}, 1982$, COPLAN ${ }^{29}, 1993$ ).

Estudos têm relatado a efetividade do uso da Escala ELM na avaliação da linguagem de crianças com até três anos de idade $\left(\operatorname{LIMA}^{70}, 1997\right.$, LEIRIÃO ${ }^{68}$, 2003). Para KLEIN ${ }^{59}, 1991$, a Escala ELM apresenta sensibilidade e especificidade adequadas para identificar crianças com idade inferior a três anos com risco para alterações de linguagem.

Neste estudo, a forma de aplicação e análise dos resultados da Escala ELM seguiu o proposto pelo instrumento. Inicialmente, traçou-se uma linha vertical ao longo de todo o protocolo de resposta, exatamente na idade cronológica em meses da criança. Todos os itens que entrecruzassem esta linha vertical nas funções $A E, A R$ e $V$ foram avaliados.

A determinação do sucesso ou fracasso em cada item foi realizada mediante a consideração do histórico relatado pelo responsável legal da criança, do teste direto do comportamento ou ainda da observação espontânea do comportamento em questão.

Os resultados foram analisados em nível de teto, ou seja, obtenção de sucesso em três itens consecutivos mais altos. Para finalizar a aplicação da escala, considerou-se necessário obter fracasso em três itens consecutivos, conforme referência prevista neste instrumento.

O desenvolvimento da linguagem foi considerado dentro dos padrões típicos quando o valor do teto nas três funções avaliadas ( $A E, A R$ e $V$ ) correspondia à idade cronológica da criança. O mesmo foi considerado para as três funções separadamente, o que possibilitou avaliar o desempenho da linguagem auditiva expressiva, auditiva receptiva e visual de modo independente. 
- Aplicação do Inventário Portage Operacionalizado - IPO (Anexo 3), com o objetivo de avaliar as habilidades motoras, cognitivas, lingüísticas, sociais e autocuidados.

O Inventário Portage Operacionalizado (IPO) faz parte de um sistema amplo que tem sido utilizado como instrumento de diagnóstico e intervenção do desenvolvimento infantil. Apresenta proposta de procedimentos de treino domiciliar, currículo para avaliação e ensino de crianças pré-escolares e/ou com necessidades educacionais especiais e 0 inventário para pais. (WILLIAMS; AIELLO ${ }^{123}, 2001$ ).

Este instrumento apresenta as seguintes áreas de desenvolvimento: estimulação infantil, específica para avaliação de bebês de zero a quatro meses de idade ou de crianças com tal nível de funcionamento; desenvolvimento motor, envolvendo não somente marcos do desenvolvimento, mas também os atos motores coordenados por pequenos e grandes grupos musculares; linguagem, englobando comportamentos comunicativos verbais, não verbais, receptivos e expressivos; socialização, enfatizando comportamentos e habilidades relevantes na interação da criança nos diferentes ambientes; autocuidados, revisando atividades para independência nas situações de vida diária e cognição, com atenção para atividades nas quais há o estabelecimento de relações de semelhanças e diferenças, compreensão, entre outras (WILLIAMS; AIELLO ${ }^{123}$, 2001). Segundo as autoras, os inventários comportamentais são relativamente fáceis de serem aplicados e seus resultados facilitam a programação de atividades individualizadas e fornecem uma visão global do desenvolvimento da criança.

A aplicação do IPO foi realizada mediante relato do responsável legal pela criança e observação dos comportamentos alvos. Foram utilizados materiais lúdicos e pedagógicos organizados de acordo com a exigência do IPO e seu protocolo de respostas (WILLIAMS; AIELLO ${ }^{123}, 2001$ ).

Todas as crianças foram avaliadas na abrangência do inventário nas áreas motoras, lingüísticas, cognitivas, sociais e autocuidados, considerando sua faixa etária. Para as crianças que apresentavam idade cronológica 
variando de zero a um ano, aplicou-se inicialmente, a avaliação considerando as cinco áreas de desenvolvimento propostas no IPO. Cabe ressaltar que a área estimulação infantil foi também aplicada para as crianças que apresentaram funcionamento do desenvolvimento inferior a quatro meses.

Primeiramente, foram avaliados os itens da faixa etária correspondente à idade cronológica da criança e quando a criança apresentava desempenho insuficiente à sua faixa etária era aplicado o inventário da faixa etária anterior. Assim, se uma crianças de 2 anos e 5 meses não cumprisse os itens referentes à faixa de 2 a 3 anos era aplicado o inventário da faixa de 1 a 2 anos.

Para a determinação dos resultados foram realizadas adaptações. Com a aplicação da regra de três determinou-se, em cada área do desenvolvimento, o número de itens que deveriam ser realizados pela criança para cada mês dentro de cada faixa etária (Anexo 4).

Para a coleta dos dados da história clínica das crianças com HC foram utilizados os seguintes procedimentos:

- Análise de prontuário, com o objetivo de coletar as seguintes informações:

Gênero;

Peso no nascimento (superior a 2.500 gramas ou inferior a 2.500 gramas - baixo peso - WORLD HEALTH ORGANIZATION ${ }^{124}$, 1980, ALEGRÍA et al. ${ }^{2}$, 2002);

> Idade na época da coleta de dados, ao realizar a TN, receber o diagnóstico e iniciar o tratamento para o $\mathrm{HC}$;

> Nível de TSH analisado na amostra de sangue da TN;

$>$ Dose de levotiroxina no início do tratamento;

> Realização do diagnóstico etiológico;

> Nível socioeconômico (avaliação do serviço social)

> Desempenho na EPBD (avaliação psicológica); 
Resultado da avaliação endocrinológica (níveis hormonais durante o tratamento para o $\mathrm{HC}$ );

- Preenchimento da Ficha de Dados Gerais (Anexo 5) mediante relatos dos responsáveis legais pelas crianças durante entrevista estruturada, com o objetivo coletar as seguintes informações:

Consangüinidade entre pais;

Realização do pré-natal (adequada quando iniciada até o terceiro mês de gestação);

$>$ Ocorrência de problemas gestacionais;

> Tipo de nascimento (a termo para as crianças nascidas após a $37^{a}$ semana de gestação e prematuro para as crianças nascidas antes deste período - WORLD HEALTH ORGANIZATION ${ }^{124}$, 1980, ALEGRÍA et al. ${ }^{2}$, 2002);

$>$ Tipo de parto (natural ou cesariana);

> Suspeita do HC pelo obstetra;

> Condições de saúde na época da coleta de dados, após o nascimento e durante a primeira infância;

$>$ Crescimento físico (adequado quando as avaliações do ganho de altura e peso, realizadas durante o acompanhamento do $\mathrm{HC}$, encontravam-se dentro do esperado para a idade cronológica da criança);

> Desenvolvimento do controle de esfíncteres (diurno adequado quando presente após o $18^{\circ}$ mês de idade e noturno adequado quando presente após o $24^{\circ}$ mês de idade, segundo critérios apresentados por GESELL e AMATRUDA - KNOBLOCK; PASSAMANICK $\left.{ }^{61}, 2000\right)$;

Alimentação (adequado na ausência de engasgos e sucção fraca, considerando o tipo e consistência do alimento de acordo com a idade cronológica da criança);

> Qualidade do sono (adequada na presença de rotina nos horários de dormir e de sono tranqüilo); 
Freqüência em instituições de ensino (creche, pré-escola ou instituições);

Comportamento (julgamento dos responsáveis legais pelas crianças);

Desenvolvimento comunicativo (julgamento dos responsáveis legais pelas crianças);

> Realização de avaliações auditivas e visuais anteriores;

> Ocorrência de otites de repetição;

> Presença de outros fatores de risco para alterações do desenvolvimento além do HC (ocorrência de problemas gestacionais e/ou nascimento prematuro e/ou baixo peso no nascimento e/ou problemas de saúde da criança após o parto);

Presença de antecedentes familiares.

Para a análise da influência das variáveis da história clínica nas habilidades do desenvolvimento das crianças com HC foi realizada correlação dos resultados obtidos na Escala ELM e no IPO com os seguintes dados da história clínica:

$>$ Idade na época da coleta de dados;

$>$ Peso ao nascimento;

> Idade ao realizar a TN, receber o diagnóstico e iniciar o tratamento para o $\mathrm{HC}$;

> Nível de TSH obtido na TN;

$>$ Dosagem de levotiroxina no início do tratamento do HC;

$>$ Nível socioeconômico;

> Gênero;

$>$ Presença de outros fatores de risco para alterações do desenvolvimento além do $\mathrm{HC}$;

$>$ Níveis hormonais durante o tratamento do $\mathrm{HC}$;

> Desempenho na EPBD (avaliação psicológica);

$>$ Desenvolvimento comunicativo (julgamento dos responsáveis legais pelas crianças). 
Além desta análise, foi verificado o grau de concordância entre os resultados obtidos na Escala ELM e os resultados obtidos na área de linguagem do IPO. Utilizou-se apenas a área de linguagem do IPO pelo fato da Escala ELM ser uma triagem para a aquisição inicial de linguagem, não abordando, no entanto, os aspectos motores, cognitivos, sociais e de autocuidados abordados pelo IPO. Também foi analisado o grau de concordância entre o julgamento dos responsáveis legais pelas crianças a respeito do desenvolvimento comunicativo e os resultados obtidos na Escala ELM e na área de linguagem do IPO.

Foram oferecidos procedimentos de avaliação Audiológica na Clínica Fonoaudiológica do Departamento de Fonoaudiologia da FOB/USP para todas as crianças, entretanto, nenhuma família demonstrou interesse. Esta falta de interesse decorreu da realização de triagem auditiva ao nascimento com resultados dentro de parâmetros de normalidade; da ausência de queixas quanto à audição e das dificuldades em agendar o exame em outro horário, uma vez que estas crianças, em sua grande maioria, procediam de várias cidades da região Centro Oeste Paulista e, portanto, dependiam de transporte público.

\section{3 - Critérios de classificação dos resultados}

Com o objetivo de uniformizar a análise dos resultados e sua compreensão, o desempenho global e o desempenho isolado em cada função da Escala ELM e em cada área do IPO foram denominados de adequado ou alterado.

$\mathrm{Na}$ Escala ELM, para a criança obter desempenho global adequado, o valor do teto nas três funções avaliadas ( $A E, A R$ e $V$ ) deveria corresponder a sua idade cronológica. $O$ mesmo foi considerado para as três funções separadamente. Assim, foi possível determinar o desempenho das crianças em relação à função auditiva expressiva, auditiva receptiva e visual. 
Para o IPO, o desempenho global e os desempenhos nas áreas motoras, lingüísticas, cognitivas, sociais, autocuidados e estimulação infantil foram considerados adequados quando a pontuação obtida correspondeu à idade cronológica da criança.

\section{4 - Método estatístico}

Para a apresentação dos resultados referentes ao perfil das habilidades do desenvolvimento utilizou-se estatística descritiva com valores de freqüência absoluta e relativa. Para a descrição dos dados referentes à história clínica utilizou-se estatística descritiva com valores de freqüência absoluta e relativa, e valores de média, mediana, desvio padrão, valor mínimo e valor máximo.

Para a análise da influência das variáveis da história clínica nas habilidades do desenvolvimento utilizou-se:

> Teste de Mann Whitney para comparação da média de variáveis não paramétricas entre dois grupos independentes $\left(\mathrm{ZAR}^{125}\right.$, 1996);

Estatística kappa para verificar a concordância entre os dois procedimentos de avaliação (ZAR $\left.{ }^{125}, 1996\right)$;

> Teste de Fisher e do qui-quadrado de contingência para verificar a associação entre duas variáveis qualitativas independentes $\left(\right.$ ZAR $\left.^{125}, 1996\right)$;

> Coeficiente de Correlação de Pearson para verificar correlação entre duas variáveis quantitativas $\left(Z^{2} R^{125}, 1996\right)$.

Em todas as análises, o nível de significância fixado foi de $p<0,05$. Para a análise dos resultados da Estatística kappa, utilizou-se a proposta de LANDIS; $\mathrm{KOCH}^{66}, 1977$, (Anexo 6). 

6 - RESULTADOS 



\section{6 - RESULTADOS}

Foram avaliadas 35 crianças com $\mathrm{HC}$ diagnosticado e tratado no Laboratório do Teste do Pezinho da APAE-Bauru. A Tabela 1 apresenta a distribuição da casuística quanto à idade (meses) na época da coleta de dados e quanto ao gênero.

TABELA 1 - Distribuição da casuística quanto à idade na época da coleta de dados e quanto ao gênero

\begin{tabular}{cccc}
\hline \hline $\begin{array}{c}\text { Idade } \\
\text { (meses) }\end{array}$ & $\begin{array}{c}\text { Feminino } \\
\mathbf{n}(\%)^{*}\end{array}$ & $\begin{array}{c}\text { Masculino } \\
\mathbf{n}(\%)^{*}\end{array}$ & $\begin{array}{c}\text { Total } \\
\mathbf{n}(\%)^{* *}\end{array}$ \\
\cline { 2 - 3 } $\mathbf{2}$ a $\mathbf{1 2}$ & $8(50,00)$ & $8(50,00)$ & $16(45,72)$ \\
$\mathbf{1 3}$ a $\mathbf{2 4}$ & $10(100,00)$ & $0(0,00)$ & $10(28,57)$ \\
$\mathbf{2 5}$ a $\mathbf{3 6}$ & $5(55,56)$ & $4(44,44)$ & $9(25,71)$ \\
\hline Total & $\mathbf{2 3 ( 6 5 , 7 1 )}$ & $\mathbf{1 2 ( 3 4 , 2 9 )}$ & $\mathbf{3 5}(\mathbf{1 0 0 , 0 0 )}$ \\
\hline \hline
\end{tabular}

* Porcentagem calculada do total de crianças por faixa etária.

** Porcentagem calculada do total de 35 crianças.

\section{1 - Perfil das habilidades do desenvolvimento}

O perfil das habilidades do desenvolvimento com enfoque na comunicação das crianças com HC diagnosticado e tratado no Laboratório do Teste do Pezinho da APAE-Bauru foi traçado por meio da aplicação da Early Language Milestone Scale (Escala ELM) e do Inventário Portage 
Operacionalizado (IPO). A seguir serão apresentados os resultados obtidos para os dois instrumentos de avaliação.

A Tabela 2 apresenta a distribuição da casuística quanto ao desempenho global obtido na Escala ELM e no IPO.

TABELA 2 - Distribuição da casuística quanto ao desempenho global obtido na Escala ELM e no IPO

\begin{tabular}{lcc}
\hline $\begin{array}{c}\text { Desempenho } \\
\text { Global }\end{array}$ & $\begin{array}{c}\text { Escala ELM } \\
\mathbf{n}(\%)\end{array}$ & $\begin{array}{c}\text { IPO } \\
\mathbf{n}(\%)\end{array}$ \\
\hline Adequado & $24(68,57)$ & $27(77,14)$ \\
Alterado & $11(31,43)$ & $8(22,86)$ \\
\hline Total & $35(\mathbf{1 0 0 , 0 0 )}$ & $\mathbf{3 5 ( 1 0 0 , 0 0 )}$ \\
\hline
\end{tabular}

A Tabela 3 apresenta a distribuição da casuística quanto ao desempenho nas três funções da Escala ELM (auditiva expressiva, auditiva receptiva e visual).

TABELA 3 - Distribuição da casuística quanto ao desempenho nas funções auditiva expressiva, auditiva receptiva e visual da Escala ELM

\begin{tabular}{lccc}
\hline & \multicolumn{3}{c}{ Funções da Escala ELM } \\
\cline { 2 - 4 } Desempenho & $\begin{array}{c}\text { Auditiva expressiva } \\
\mathbf{n}(\%)\end{array}$ & $\begin{array}{c}\text { Auditiva receptiva } \\
\mathbf{n}(\%)\end{array}$ & $\begin{array}{c}\text { Visual } \\
\mathbf{n}(\%)\end{array}$ \\
\hline Adequado & $24(68,57)$ & $34(97,14)$ & $33(94,29)$ \\
Alterado & $11(31,43)$ & $1(2,86)$ & $2(5,71)$ \\
\hline Total & $35(\mathbf{1 0 0 , 0 0 )}$ & $35(\mathbf{1 0 0 , 0 0 )}$ & $35(100.00)$ \\
\hline \hline
\end{tabular}


A Tabela 4 apresenta a distribuição da casuística quanto aos meses de atraso nas três funções da Escala ELM (auditiva expressiva, auditiva receptiva e visual).

TABELA 4 - Distribuição da casuística quanto aos meses de atraso nas funções auditiva expressiva, auditiva receptiva e visual da Escala ELM

\begin{tabular}{cccc}
\hline \hline $\begin{array}{c}\text { Meses de } \\
\text { atraso }\end{array}$ & \multicolumn{3}{c}{ Funções da Escala ELM } \\
\cline { 2 - 4 } & $\begin{array}{c}\text { Auditiva expressiva } \\
\mathbf{n}(\%)\end{array}$ & $\begin{array}{c}\text { Auditiva receptiva } \\
\mathbf{n}(\%)\end{array}$ & $\begin{array}{c}\text { Visual } \\
\mathbf{n}(\%)\end{array}$ \\
\hline $\mathbf{1}$ & $3(27,27)$ & - & - \\
$\mathbf{2}$ & $1(9,09)$ & - & - \\
$\mathbf{3}$ & $2(18,18)$ & - & $1(50,00)$ \\
$\mathbf{4}$ & $1(9,09)$ & - & - \\
$\mathbf{5}$ & $2(18,18)$ & - & - \\
$\mathbf{6}$ & $1(9,09)$ & - & - \\
$\mathbf{1 9}$ & $1(9,09)$ & - & $1(50,00)$ \\
\hline $\mathbf{2 1}$ & - & $1(100,00)$ & $\mathbf{2 ( 1 0 0 , 0 0 )}$ \\
\hline Total & $\mathbf{1 1 ( 1 0 0 , 0 0 )}$ & $\mathbf{1 ( 1 0 0 , 0 0 )}$ & - \\
\hline
\end{tabular}

A Tabela 5 apresenta a distribuição da casuística quanto ao desempenho nas áreas do desenvolvimento de abrangência do IPO (autocuidados, socialização, motora, linguagem, cognição e estimulação infantil). A distribuição da casuística quanto aos meses de atraso nestas áreas encontra-se descrita na Tabela 6. 
TABELA 5 - Distribuição da casuística quanto ao desempenho nas áreas autocuidados, socialização, motora, cognição, linguagem, e estimulação infantil do IPO

\begin{tabular}{|c|c|c|c|c|c|c|}
\hline \multirow[b]{2}{*}{ Desempenho } & \multicolumn{6}{|c|}{ Áreas do IPO } \\
\hline & $\begin{array}{c}\text { Autocui } \\
n \\
(\%)\end{array}$ & $\begin{array}{c}\text { Sociali } \\
\text { n } \\
(\%)\end{array}$ & $\begin{array}{c}\text { Motora } \\
\mathbf{n} \\
(\%)\end{array}$ & $\begin{array}{c}\text { Cog } \\
n \\
(\%)\end{array}$ & $\begin{array}{c}\text { Lggem } \\
n \\
(\%)\end{array}$ & $\begin{array}{c}\text { El* } \\
n \\
(\%)\end{array}$ \\
\hline Adequado & $\begin{array}{c}32 \\
(91,43)\end{array}$ & $\begin{array}{c}31 \\
(88,57)\end{array}$ & $\begin{array}{c}31 \\
(88,57)\end{array}$ & $\begin{array}{c}30 \\
(85,71)\end{array}$ & $\begin{array}{c}28 \\
(80,00)\end{array}$ & $\begin{array}{c}9 \\
(75,00)\end{array}$ \\
\hline Alterado & $\begin{array}{c}3 \\
(8,57)\end{array}$ & $\begin{array}{c}4 \\
(11,43)\end{array}$ & $\begin{array}{c}4 \\
(11,43)\end{array}$ & $\begin{array}{c}5 \\
(14,29)\end{array}$ & $\begin{array}{c}7 \\
(20,00)\end{array}$ & $\begin{array}{c}3 \\
(25,00)\end{array}$ \\
\hline Total & $\begin{array}{c}35 \\
(100,00)\end{array}$ & $\begin{array}{c}35 \\
(100,00)\end{array}$ & $\begin{array}{c}35 \\
(100,00)\end{array}$ & $\begin{array}{c}35 \\
(100,00)\end{array}$ & $\begin{array}{c}35 \\
(100,00)\end{array}$ & $\begin{array}{c}12 \\
(100,00)\end{array}$ \\
\hline
\end{tabular}

TABELA 6 - Distribuição da casuística quanto aos meses de atraso nas áreas autocuidados, socialização, motora, cognição, linguagem e estimulação infantil do IPO

\begin{tabular}{|c|c|c|c|c|c|c|}
\hline \multirow{2}{*}{$\begin{array}{l}\text { Mês } \\
\text { de } \\
\text { atraso }\end{array}$} & \multicolumn{6}{|c|}{ Áreas do IPO } \\
\hline & $\begin{array}{c}\text { Autocui } \\
\text { n (\%) }\end{array}$ & $\begin{array}{c}\text { Sociali } \\
\text { n (\%) }\end{array}$ & $\begin{array}{c}\text { Motora } \\
\text { n (\%) }\end{array}$ & $\begin{array}{l}\text { Cog } \\
\text { n (\%) }\end{array}$ & $\begin{array}{l}\text { Lggem } \\
\text { n (\%) }\end{array}$ & $\begin{array}{c}\text { El } \\
n(\%)\end{array}$ \\
\hline 1 & $1(33,33)$ & $3(75,00)$ & $2(50,00)$ & $2(40,00)$ & $2(28,57)$ & $1(33,33)$ \\
\hline 2 & $1(33,33)$ & - & $1(25,00)$ & $1(20,00)$ & - & - \\
\hline 3 & - & - & - & $1(20,00)$ & - & $1(33,33)$ \\
\hline 4 & - & - & - & - & $4(57,14)$ & - \\
\hline 20 & - & - & - & - & - & - \\
\hline 22 & $1(33,33)$ & $1(25,00)$ & $1(25,00)$ & $1(20,00)$ & $1(14,29)$ & $1(33,33)$ \\
\hline Total & $3(100,00)$ & $4(100,00)$ & $4(100,00)$ & $5(100,00)$ & $7(100,00)$ & $3(100,00)$ \\
\hline
\end{tabular}


A concordância entre o desempenho da casuística na Escala ELM e o desempenho na área de linguagem do IPO, medida por meio da Estatística kappa, encontra-se descrita na Tabela 7.

TABELA 7 - Concordância entre o desempenho da casuística na Escala ELM e o desempenho na área de linguagem do IPO

\begin{tabular}{|c|c|c|c|}
\hline \multirow{2}{*}{$\begin{array}{l}\text { Desempenho na } \\
\text { Escala ELM }\end{array}$} & \multicolumn{2}{|c|}{$\begin{array}{l}\text { Desempenho na área de linguagem do } \\
\text { IPO }\end{array}$} & \multirow{2}{*}{ kappa } \\
\hline & $\begin{array}{l}\text { Adequado } \\
\text { n (\%) }\end{array}$ & $\begin{array}{l}\text { Alterado } \\
\text { n (\%) }\end{array}$ & \\
\hline \multirow[t]{2}{*}{ Adequado } & $23(65,71)$ & $1(2,86)$ & \\
\hline & & & 0,559 * \\
\hline Alterado & $5(14,29)$ & $6(17,14)$ & \\
\hline
\end{tabular}

* Concordância moderada.

\section{2 - Dados da história clínica}

A seguir, serão descritos os dados coletados por meio da análise de prontuário e aplicação da Ficha de Dados Gerais com os responsáveis pelas crianças, referentes à história clínica das crianças com HC diagnosticado e tratado no Laboratório do Teste do Pezinho da APAE-Bauru.

A Tabela 8 apresenta a média $(\bar{x})$, mediana (Med), desvio padrão (dp), valor mínimo e valor máximo referentes à idade (meses) na época da coleta de dados, ao peso (gramas) no nascimento, às idades (dias) ao realizar a triagem neonatal (TN), receber o diagnóstico e iniciar o tratamento para o $\mathrm{HC}$, ao valor de $\mathrm{TSH}(\mu \mathrm{Ul} / \mathrm{ml})$ obtido na $\mathrm{TN}$ e à dosagem $(\mathrm{mg} / \mathrm{dia})$ de levotiroxina no início do tratamento medicamentoso. 
TABELA 8 - Caracterização da casuística quanto à idade na coleta de dados, ao peso no nascimento, às idades ao realizar a $\mathrm{TN}$, receber $\mathrm{o}$ diagnóstico e iniciar o tratamento para o $\mathrm{HC}$, ao nível de $\mathrm{TSH}$ obtido na $\mathrm{TN}$ e à dosagem de levotiroxina no início do tratamento

\begin{tabular}{lccccc}
\hline \hline \multicolumn{1}{c}{$\begin{array}{c}\text { Caracterização da } \\
\text { casuística }\end{array}$} & $\bar{X}$ & Med & dp & $\begin{array}{c}\text { Valor } \\
\text { mínimo }\end{array}$ & $\begin{array}{c}\text { Valor } \\
\text { máximo }\end{array}$ \\
\hline $\begin{array}{l}\text { Idade na coleta de } \\
\text { dados (meses) }\end{array}$ & 15,7 & 15,0 & 12,00 & 2 & 36 \\
$\begin{array}{l}\text { Peso ao nascimento } \\
\text { (gramas) }\end{array}$ & 2858,7 & 2935,0 & 680,9 & 860 & 3900 \\
$\begin{array}{l}\text { Idade na TN (dias) } \\
\text { Idade no diagnóstico }\end{array}$ & 18,8 & 8,0 & 36,8 & 2 & 210 \\
(dias) & 40,3 & 30,0 & 37,7 & 12 & 230 \\
$\begin{array}{l}\text { Idade no início do } \\
\text { tratamento (dias) }\end{array}$ & 52,3 & 40,0 & 41,7 & 16 & 240 \\
$\begin{array}{l}\text { Nível de TSH na TN } \\
\text { ( } 1 \text { UUl/ml) }\end{array}$ & 57,6 & 22,4 & 82,4 & 6,60 & 368 \\
$\begin{array}{l}\text { Dose inicial de } \\
\text { Levotiroxina } \\
\text { (mg/dia) }\end{array}$ & 29,5 & 25,0 & 15,4 & 6,25 & 75 \\
\hline \hline
\end{tabular}

A Tabela 9 apresenta a distribuição da casuística quanto ao peso no nascimento (gramas).

TABELA 9 - Distribuição da casuística quanto ao peso no nascimento

\begin{tabular}{lcc}
\hline \hline $\begin{array}{c}\text { Peso no nascimento } \\
\text { (gramas) }\end{array}$ & $\mathbf{n}$ & $\%$ \\
\hline Superior a 2500 & 29 & 82,86 \\
Inferior a 2500 & 6 & 17,14 \\
\hline Total & 35 & $\mathbf{1 0 0 , 0 0}$ \\
\hline \hline
\end{tabular}


A Tabela 10 apresenta a distribuição da casuística quanto à idade (dias) ao realizar a $\mathrm{TN}$, à idade (dias) ao receber o diagnóstico e à idade (dias) ao iniciar o tratamento para o $\mathrm{HC}$ com dosagem de levotiroxina.

TABELA 10 - Distribuição da casuística quanto à idade ao realizar a TN, à idade ao receber o diagnóstico e à idade ao iniciar o tratamento para o $\mathrm{HC}$

\begin{tabular}{|c|c|c|c|c|c|c|}
\hline \multirow{2}{*}{$\begin{array}{l}\text { Idade } \\
\text { (dias) }\end{array}$} & \multicolumn{2}{|c|}{ TN } & \multicolumn{2}{|c|}{ Diagnóstico } & \multicolumn{2}{|c|}{$\begin{array}{l}\text { Início do } \\
\text { tratamento }\end{array}$} \\
\hline & n (\%) & $\%$ acum & n (\%) & $\%$ acum & n (\%) & $\%$ acum \\
\hline $0-7$ & $16(45,71)$ & 45,71 & - & - & - & - \\
\hline $8-30$ & $16(45,71)$ & 91,43 & $18(51,43)$ & 51,43 & $12(34,28)$ & 34,29 \\
\hline $31-60$ & $1(2,86)$ & 94,29 & $12(34,28)$ & 85,71 & $17(48,57)$ & 82,86 \\
\hline $61-90$ & $1(2,86)$ & 97,14 & $4(11,43)$ & 97,14 & $3(8,57)$ & 91,43 \\
\hline $91-120$ & - & 97,14 & - & 97,14 & $1(2,86)$ & 94,29 \\
\hline $121-150$ & - & 97,14 & - & 97,14 & $1(2,86)$ & 97,14 \\
\hline $151-240$ & $1(2,86)$ & 100,00 & - & 97,14 & - & 97,14 \\
\hline $240-270$ & - & 100,00 & $1(2,86)$ & 100,00 & $1(2,86)$ & 100,00 \\
\hline
\end{tabular}

\% acum: porcentagem acumulada.

A Tabela 11 apresenta a distribuição da casuística quanto ao nível de $\mathrm{TSH}(\mu \mathrm{Ul} / \mathrm{ml})$ obtido na análise da amostra de sangue coletada na TN. 
TABELA 11 - Distribuição da casuística quanto ao nível de TSH obtido na análise da amostra de sangue coletada na TN

\begin{tabular}{ccc}
\hline $\begin{array}{c}\text { Nível de TSH } \\
(\boldsymbol{\mu U} \mathrm{U} / \mathrm{ml})\end{array}$ & $\mathbf{n}(\%)$ & \% acumulada \\
\hline $\mathbf{6}-\mathbf{9}$ & $5(14,29)$ & 14,29 \\
$\mathbf{1 0 - 2 0}$ & $11(31,43)$ & 45,72 \\
$\mathbf{2 1 - 6 0}$ & $9(25,70)$ & 71,42 \\
$\mathbf{6 1 - 1 6 0}$ & $5(14,29)$ & 85,71 \\
$\mathbf{1 6 1 - 3 6 8}$ & $5(14,29)$ & 100,00 \\
\hline \hline
\end{tabular}

A Tabela 12 apresenta a distribuição da casuística quanto à dosagem de levotiroxina (mg/dia) no início do tratamento medicamentoso para o HC.

TABELA 12 - Distribuição da casuística quanto à dosagem de levotiroxina no início do tratamento medicamentoso para o $\mathrm{HC}$

\begin{tabular}{ccc}
\hline \hline $\begin{array}{c}\text { Dosagem de levotiroxina } \\
\text { (mg/dia) }\end{array}$ & $\mathbf{n}(\%)$ & \% acumulada \\
\hline $\mathbf{6 , 5 0}$ & $1(2,86)$ & 2,86 \\
$\mathbf{1 2 , 5 0}$ & $6(17,14)$ & 20,00 \\
$\mathbf{2 5 , 0 0}$ & $16(45,71)$ & 65,71 \\
$\mathbf{3 7 , 5 0}$ & $5(14,29)$ & 80,00 \\
$\mathbf{5 0 , 0 0}$ & $6(17,14)$ & 97,14 \\
$\mathbf{7 5 , 0 0}$ & $1(2,86)$ & 100,00 \\
\hline
\end{tabular}


A Tabela 13 apresenta a distribuição da casuística quanto à realização do diagnóstico etiológico, ao nível socioeconômico, ao desempenho na Escala Passos Básicos do Desenvolvimento (EPBD) e ao controle dos níveis hormonais durante o tratamento com levotiroxina.

TABELA 13 - Distribuição da casuística quanto à realização do diagnóstico etiológico, ao nível socioeconômico, ao desempenho na EPBD e ao controle dos níveis hormonais durante o tratamento com levotiroxina

\begin{tabular}{llll}
\hline & Avaliações & $\mathbf{n}$ & $\%$ \\
\hline $\begin{array}{l}\text { Diagnóstico } \\
\text { etiológico }\end{array}$ & Sim & 0 & 0,00 \\
\hline & Bão & 35 & 100,00 \\
$\begin{array}{llll}\text { Nível } \\
\text { socioeconômico }\end{array}$ & Baixo-superior & 9 & 25,71 \\
& Médio-inferior & 25 & 71,43 \\
$\begin{array}{l}\text { Desempenho na } \\
\text { EPBD }\end{array}$ & Adequado & 1 & 2,86 \\
\hline $\begin{array}{l}\text { Níveis } \\
\text { hormonais }\end{array}$ & Alterado & 33 & 94,29 \\
\hline \hline
\end{tabular}

EPBD: Escala Passos Básicos do Desenvolvimento.

A Tabela 14 apresenta a distribuição da casuística quanto aos dados do período gestacional: existência de consangüinidade entre os pais, realização do pré-natal e ocorrência de problemas gestacionais. 
TABELA 14 - Distribuição da casuística quanto aos dados do período gestacional: existência de consangüinidade entre os pais, realização do pré-natal e ocorrência de problemas gestacionais

\begin{tabular}{|c|c|c|c|}
\hline \multicolumn{2}{|c|}{ Dados do período gestacional } & \multirow{2}{*}{$\frac{\mathbf{n}}{0}$} & \multirow{2}{*}{$\begin{array}{c}\% \\
0,00\end{array}$} \\
\hline Consangüinidade & Sim & & \\
\hline entre os p & Não & 35 & 100,00 \\
\hline \multirow{2}{*}{ Realização do pré-। } & Adequada & 33 & 94,29 \\
\hline & Alterada & 2 & 5,71 \\
\hline \multirow{2}{*}{ Problemas gestaci } & Sim & 11 & 31,43 \\
\hline & Não & 24 & 68,57 \\
\hline
\end{tabular}

A Tabela 15 apresenta a distribuição da casuística quanto aos tipos de problemas de saúde da mãe durante a gestação.

TABELA 15 - Distribuição da casuística quanto aos tipos de problemas de saúde da mãe durante a gestação

\begin{tabular}{lc}
\hline \multicolumn{1}{c}{ Problemas de saúde na gestação } & $\mathbf{n}(\%)$ \\
\hline Analgésicos para dores na coluna & $1(9,09)$ \\
Hipertensão arterial & $1(9,09)$ \\
Hipertensão arterial / ameaça de aborto & $1(9,09)$ \\
Infecção geniturinária / ameaça de aborto & $1(9,09)$ \\
Início de contrações no 70 mês de gestação & $1(9,09)$ \\
Ameaça de aborto & $2(18,18)$ \\
Anemia & $2(18,18)$ \\
Infecção geniturinária & $2(18,18)$ \\
\hline Total & $\mathbf{1 1}(\mathbf{1 0 0 , 0 0})$ \\
\hline \hline
\end{tabular}


A Tabela 16 apresenta a distribuição da casuística quanto aos dados do nascimento: tipo de nascimento, tipo de parto e suspeita do HC pelo obstetra após o parto.

TABELA 16 - Distribuição da casuística quanto aos dados do nascimento: tipo de nascimento, tipo de parto e suspeita do HC após o parto

\begin{tabular}{llcc}
\hline \multicolumn{1}{c}{ Dados do nascimento } & $\mathbf{n}$ & $\%$ \\
\hline $\begin{array}{llcc}\text { Tipo de } \\
\text { nascimento }\end{array}$ & A termo & 27 & 77,14 \\
\hline \multirow{2}{*}{ Tipo de parto } & Prematuro & 8 & 22,86 \\
\hline \multirow{2}{*}{ Suspeita do HC } & Cesariana & 16 & 45,71 \\
& Não & 19 & 54,29 \\
\hline \hline
\end{tabular}

A Tabela 17 apresenta a distribuição da casuística quanto à existência de problemas de saúde na época da coleta, após o parto e durante a primeira infância.

TABELA 17 - Distribuição da casuística quanto à existência de problemas de saúde na época da coleta de dados, após o nascimento e durante a primeira infância

\begin{tabular}{llcc}
\hline \hline \multicolumn{2}{c}{ Problemas de saúde } & $\mathbf{n}$ & $\%$ \\
\hline \multirow{2}{*}{ Na coleta de dados } & Sim & 3 & 8,57 \\
& Não & 32 & 91,43 \\
\hline \multirow{2}{*}{ Após o nascimento } & Sim & 13 & 37,14 \\
& Não & 22 & 62,86 \\
\hline \multirow{2}{*}{ Durante a 1 ${ }^{\text {a infância }}$} & Sim & 12 & 34,29 \\
& Não & 23 & 65,71 \\
\hline \hline
\end{tabular}


A Tabela 18 apresenta a distribuição da casuística quanto aos tipos de problemas de saúde na época da coleta de dados.

TABELA 18 - Distribuição da casuística quanto aos tipos de problemas de saúde na época da coleta de dados

Problemas de saúde na coleta de dados

n (\%)

Bronquite

$1(33,33)$

Rinite alérgica

$2(66,67)$

Total

$3(100,00)$

A Tabela 19 apresenta a distribuição da casuística quanto aos tipos de problemas de saúde ocorridos após o parto.

TABELA 19 - Distribuição da casuística quanto aos tipos de problemas de saúde ocorridos após o parto

\begin{tabular}{lc}
\hline \multicolumn{1}{c}{ Problemas de saúde após o parto } & $\mathbf{n}(\%)$ \\
\hline Icterícia / incubadora & $1(7,69)$ \\
Icterícia / incubadora / Unidade de Terapia Intensiva & $1(7,69)$ \\
Incubadora & $1(7,69)$ \\
Problemas respiratórios & $1(7,69)$ \\
Problemas respiratórios / incubadora & $2(15,38)$ \\
Problemas respiratórios / icterícia / incubadora & $3(23,08)$ \\
Icterícia & $4(30,77)$ \\
\hline Total & $13(100,00)$ \\
\hline \hline
\end{tabular}


A Tabela 20 apresenta a distribuição da casuística quanto aos tipos de problemas de saúde durante a primeira infância.

TABELA 20 - Distribuição da casuística quanto aos tipos de problemas de saúde durante a primeira infância

\begin{tabular}{|c|c|}
\hline Problemas de saúde durante a $1^{\mathrm{a}}$ infância & n (\%) \\
\hline $\begin{array}{l}\text { Dificuldades respiratórias / vômito projétil / dificuldade para } \\
\text { aumentar o peso }\end{array}$ & $1(8,33)$ \\
\hline Pele pálida e descamativa / dificuldade para aumentar o peso & $1(8,33)$ \\
\hline Sonolência / choro rouco / edema / hérnia umbilical & $1(8,33)$ \\
\hline $\begin{array}{l}\text { Sonolência / dificuldade respiratória / bócio / dificuldade para } \\
\text { aumentar o peso }\end{array}$ & $1(8,33)$ \\
\hline $\begin{array}{l}\text { Sonolência I Sucção fraca I choro rouco I problemas } \\
\text { intestinais I hérnia umbilical }\end{array}$ & $1(8,33)$ \\
\hline $\begin{array}{l}\text { Sonolência I dificuldades respiratórias I pele pálida e } \\
\text { descamativa / problemas intestinais / hérnia umbilical }\end{array}$ & $1(8,33)$ \\
\hline $\begin{array}{l}\text { Sonolência I sucção fraca I vômito projétil I olhos } \\
\text { empapuçados I choro rouco I hipotonia I bócio I pele pálida } \\
\text { e descamativa I dificuldade para aumentar o peso I } \\
\text { problemas intestinais I hérnia umbilical }\end{array}$ & $1(8,33)$ \\
\hline $\begin{array}{l}\text { Sucção fracal pele pálida e descamativa l problemas } \\
\text { intestinais / hérnia umbilical }\end{array}$ & $1(8,33)$ \\
\hline Vômito projétil / problemas intestinais / crises convulsivas & $1(8,33)$ \\
\hline Problemas intestinais & $3(25,00)$ \\
\hline Total & $12(100,00)$ \\
\hline
\end{tabular}

A Tabela 21 apresenta a distribuição da casuística quanto aos dados do desenvolvimento: crescimento físico, desenvolvimento do controle de esfíncteres e alimentação. 
TABELA 21 - Distribuição da casuística quanto aos dados do desenvolvimento: crescimento físico, desenvolvimento do controle de esfíncteres e alimentação

\begin{tabular}{llcc}
\hline \hline \multicolumn{2}{c}{ Desenvolvimento } & $\mathbf{n}$ & $\%$ \\
\hline $\begin{array}{l}\text { Crescimento } \\
\text { físico }\end{array}$ & Adequado & 32 & 91,43 \\
\hline $\begin{array}{l}\text { Controle de } \\
\text { esfíncteres* }\end{array}$ & Alterado & 3 & 8,57 \\
\hline & Alterado & 7 & 43,75 \\
Alimentação & Adequada & 9 & 56,25 \\
& Alterada & 33 & 94,29 \\
\hline \hline
\end{tabular}

* Foram consideradas apenas as 16 crianças $(45,71 \%)$ com idade superior a 18 meses.

A Tabela 22 apresenta a distribuição da casuística quanto à qualidade do sono, à freqüência em instituições de ensino e à existência de queixas do comportamento.

TABELA 22 - Distribuição da casuística quanto à qualidade do sono, à freqüência em instituições de ensino e à existência de queixas do comportamento

\begin{tabular}{llll}
\hline \multicolumn{2}{c}{ Relato do responsável } & $\mathbf{n}$ & $\%$ \\
\hline Qualidade do sono & Adequada & 33 & 94,29 \\
& Alterada & 2 & 5,71 \\
\hline $\begin{array}{l}\text { Freqüência em instituições } \\
\text { de ensino }\end{array}$ & Sim & 5 & 14,29 \\
\hline & Não & 30 & 85,71 \\
Queixas do comportamento* & Sim & 6 & 17,14 \\
\hline \hline
\end{tabular}

* Julgamento dos responsáveis legais pelas crianças com $\mathrm{HC}$. 
A Tabela 23 apresenta a distribuição da casuística quanto ao desenvolvimento comunicativo, à realização de avaliações auditivas e visuais anteriores e à ocorrência de otites de repetição.

TABELA 23 - Distribuição da casuística quanto ao desenvolvimento comunicativo, à realização de avaliações auditivas e visuais anteriores e à ocorrência de otites de repetição

\begin{tabular}{|c|c|c|c|}
\hline \multicolumn{2}{|c|}{ Relato do responsável } & \multirow{2}{*}{$\begin{array}{c}\mathbf{n} \\
32\end{array}$} & \multirow{2}{*}{$\begin{array}{c}\% \\
91,43\end{array}$} \\
\hline Desenvolvimento & Adequado & & \\
\hline comunicativo* $^{*}$ & Alterado & 3 & 8,57 \\
\hline \multirow{2}{*}{$\begin{array}{l}\text { Avaliação auditiva } \\
\text { anterior }\end{array}$} & Sim & 14 & 40,00 \\
\hline & Não & 21 & 60,00 \\
\hline \multirow{2}{*}{ Otites de repetição } & Sim & 5 & 14,29 \\
\hline & Não & 30 & 85,71 \\
\hline \multirow{2}{*}{$\begin{array}{l}\text { Avaliação visual } \\
\text { anterior }\end{array}$} & $\operatorname{Sim}$ & 1 & 2,86 \\
\hline & Não & 34 & 97,14 \\
\hline
\end{tabular}

* Julgamento dos responsáveis legais pelas crianças com HC.

A Tabela 24 apresenta a distribuição da casuística quanto aos tipos de problemas de comunicação observados pelos responsáveis legais.

TABELA 24 - Distribuição da casuística quanto aos tipos de problemas de comunicação observados pelos responsáveis legais

\begin{tabular}{lc}
\hline \multicolumn{1}{c}{ Problemas de comunicação } & $\mathbf{n}(\mathbf{\%})$ \\
\hline Disfluência & $1(33,33)$ \\
Atraso para o início da fala & $1(33,33)$ \\
Ausência de oralidade & $1(33,33)$ \\
\hline Total & $\mathbf{3 ( 1 0 0 , 0 0 )}$ \\
\hline \hline
\end{tabular}

* Julgamento dos responsáveis legais pelas crianças com $\mathrm{HC}$. 
A Tabela 25 apresenta a distribuição da casuística quanto à presença de outros fatores de risco para alterações do desenvolvimento além do $\mathrm{HC}$ e quanto à presença de antecedentes familiares.

TABELA 25 - Distribuição da casuística quanto à presença de outros fatores de risco para alterações do desenvolvimento além do $\mathrm{HC}$ e quanto à presença de antecedentes familiares

\begin{tabular}{llll}
\hline \multicolumn{1}{c}{ Presença } & & $\mathbf{n}$ & $\%$ \\
\hline \multirow{2}{*}{ Outros fatores de risco } & Sim & 23 & 65,71 \\
& Não & 12 & 34,29 \\
\hline \multirow{2}{*}{ Antecedentes familiares } & Sim & 19 & 54,29 \\
& Não & 16 & 45,71 \\
\hline \hline
\end{tabular}

A Tabela 26 apresenta a distribuição da casuística quanto aos antecedentes familiares.

TABELA 26 - Distribuição da casuística quanto aos antecedentes familiares

\begin{tabular}{lc}
\hline \multicolumn{1}{c}{ Antecedentes familiares } & $\mathbf{n}(\%)$ \\
\hline $\begin{array}{l}\text { Alterações na glândula tireóide / atraso de linguagem I } \\
\text { Doença de Alzeihmer }\end{array}$ & $1(5,26)$ \\
$\begin{array}{l}\text { Alterações na glândula tireóide I retardo mental I } \\
\text { crises epitéticas }\end{array}$ & $1(5,26)$ \\
Alterações na glândula tireóide / Síndrome de Down & $1(5,26)$ \\
Problemas respiratórios crônicos & $1(5,26)$ \\
Retardo mental & $3(15,79)$ \\
Síndrome de Down & $3(15,79)$ \\
Alterações na glândula tireóide & $9(47,37)$ \\
\hline Total & $\mathbf{1 9}(\mathbf{1 0 0 , 0 0 )}$ \\
\hline \hline
\end{tabular}




\section{3 - Análise da influência da história clínica no perfil das habilidades do desenvolvimento}

A seguir, será apresentada a análise da influência das variáveis da história clínica no perfil das habilidades do desenvolvimento das crianças com HC diagnosticado e tratado no Laboratório do Teste do Pezinho da APAEBauru. A Tabela 27 apresenta a comparação, realizada por meio do Teste de Mann Whitney, da idade (meses) na época da coleta de dados e do peso (gramas) no nascimento entre as crianças com desempenho adequado $\mathrm{e}$ alterado na Escala ELM e IPO.

TABELA 27 - Comparação da idade na época da coleta de dados e do peso no nascimento entre as crianças com desempenho adequado e alterado na Escala ELM e IPO

\begin{tabular}{|c|c|c|c|c|c|}
\hline \multicolumn{2}{|c|}{ Desempenho } & \multicolumn{2}{|c|}{$\begin{array}{l}\text { Idade } \\
\text { (meses) }\end{array}$} & \multicolumn{2}{|l|}{$\begin{array}{c}\text { Peso } \\
\text { (gramas) }\end{array}$} \\
\hline & & $\bar{x}$ (Med) & $\mathbf{p}$ & $\bar{x}($ Med) & p \\
\hline \multirow{2}{*}{$\begin{array}{l}\text { Escala } \\
\text { ELM }\end{array}$} & Adequado & $15,2(19,0)$ & \multirow{2}{*}{$0,487^{\mathrm{ns}}$} & $2894,6(3087,5)$ & \multirow{2}{*}{$0,606^{n s}$} \\
\hline & Alterado & $15,9(14,5)$ & & $2780,4(2930,0)$ & \\
\hline \multirow{2}{*}{ IPO } & Adequado & $16,5(15,0)$ & \multirow{2}{*}{$0,608^{\mathrm{ns}}$} & $2898,0(3060,0)$ & \multirow{2}{*}{$0,542^{\mathrm{ns}}$} \\
\hline & Alterado & $11,7(9,0)$ & & $2726,2(2855,0)$ & \\
\hline
\end{tabular}

${ }^{\text {ns }}$ diferença estatisticamente não significante.

A Tabela 28 apresenta a comparação, realizada por meio do Teste de Mann Whitney, das idades (dias) ao realizar a TN, receber o diagnóstico e iniciar o tratamento para $\mathrm{o} \mathrm{HC}$ entre as crianças com desempenho adequado e alterado na Escala ELM e IPO. 
TABELA 28 - Comparação das idades ao realizar a TN, receber o diagnóstico e iniciar o tratamento para o $\mathrm{HC}$ entre as crianças com desempenho adequado e alterado na Escala ELM e IPO

\begin{tabular}{|c|c|c|c|c|c|c|c|}
\hline \multicolumn{2}{|c|}{ Desempenho } & \multicolumn{2}{|c|}{$\begin{array}{l}\text { Idade na TN } \\
\text { (dias) }\end{array}$} & \multicolumn{2}{|c|}{$\begin{array}{c}\text { Idade no } \\
\text { diagnóstico } \\
\text { (dias) } \\
\end{array}$} & \multicolumn{2}{|c|}{$\begin{array}{c}\text { Idade no início } \\
\text { do tratamento } \\
\text { (dias) } \\
\end{array}$} \\
\hline & & $\begin{array}{c}\bar{x} \\
\text { (Med) }\end{array}$ & p & $\begin{array}{c}\bar{x} \\
\text { (Med) }\end{array}$ & p & $\underset{\text { (Med) }}{\bar{x}}$ & p \\
\hline \multirow{2}{*}{$\begin{array}{l}\text { Escala } \\
\text { ELM }\end{array}$} & Adequado & $\begin{array}{l}13,7 \\
(7,0)\end{array}$ & \multirow{2}{*}{$0,291^{\text {ns }}$} & $\begin{array}{c}33,8 \\
(26,0)\end{array}$ & \multirow{2}{*}{$0,109^{\text {ns }}$} & $\begin{array}{c}47,3 \\
(39,0)\end{array}$ & \multirow{2}{*}{$0,285^{\text {ns }}$} \\
\hline & Alterado & $\begin{array}{c}29,9 \\
(10,0)\end{array}$ & & $\begin{array}{c}54,4 \\
(35,0)\end{array}$ & & $\begin{array}{c}63,0 \\
(45,0)\end{array}$ & \\
\hline \multirow{2}{*}{ IPO } & Adequado & $\begin{array}{l}13,0 \\
(7,0)\end{array}$ & \multirow{2}{*}{$0,133^{\mathrm{ns}}$} & $\begin{array}{c}34,8 \\
(27,0)\end{array}$ & \multirow{2}{*}{$0,246^{\mathrm{ns}}$} & $\begin{array}{c}48,4 \\
(39,0)\end{array}$ & \multirow{2}{*}{$0,665^{\text {ns }}$} \\
\hline & Alterado & $\begin{array}{c}38,2 \\
(12,0)\end{array}$ & & $\begin{array}{c}58,9 \\
(35,5)\end{array}$ & & $\begin{array}{c}65,2 \\
(43,5)\end{array}$ & \\
\hline
\end{tabular}

${ }^{\text {ns }}$ diferença estatisticamente não significante.

A Tabela 29 apresenta a comparação, por meio do Teste de Mann Whitney, do nível de TSH C $(\mu \mathrm{Ul} / \mathrm{ml})$ obtido na análise da amostra de sangue coletada na TN e da dosagem ( $\mathrm{mg} / \mathrm{dia}$ ) de levotiroxina no início do tratamento entre as crianças com desempenho adequado e alterado na Escala ELM e IPO.

TABELA 29 - Comparação do nível de TSH obtido na análise da amostra de sangue coletada na TN e da dosagem de levotiroxina no início do tratamento entre as crianças com desempenho adequado e alterado na Escala ELM e IPO

\begin{tabular}{|c|c|c|c|c|c|}
\hline \multicolumn{2}{|c|}{ Desempenho } & \multicolumn{2}{|c|}{$\begin{array}{l}\text { Nível de TSH na TN } \\
(\mu \mathrm{Ul} / \mathrm{ml})\end{array}$} & \multicolumn{2}{|c|}{$\begin{array}{c}\text { Dosagem de levotiroxina } \\
\text { (mg/dia) }\end{array}$} \\
\hline & & $\bar{x}$ Med & $\mathbf{p}$ & $\bar{x}$ Med & $\mathbf{p}$ \\
\hline \multirow{2}{*}{$\begin{array}{l}\text { Escala } \\
\text { ELM }\end{array}$} & Adequado & $64,6(27,9)$ & \multirow{2}{*}{$0,570^{\text {ns }}$} & $31,5(25,0)$ & \multirow{2}{*}{$0,091^{\mathrm{ns}}$} \\
\hline & Alterado & $42,5(15,0)$ & & $25,0(25,0)$ & \\
\hline \multirow[t]{2}{*}{ IPO } & Adequado & $66,9(22,4)$ & \multirow{2}{*}{$0,479^{\text {ns }}$} & $31,2(25,0)$ & \multirow{2}{*}{$0,198^{\mathrm{ns}}$} \\
\hline & Alterado & $26,4(18,8)$ & & $23,5(25,5)$ & \\
\hline
\end{tabular}

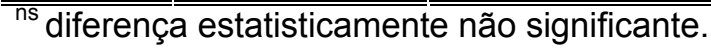


A Tabela 30 apresenta a correlação, realizada por meio da Correlação de Pearson, entre a idade ao realizar a TN e a idade ao receber o diagnóstico de $\mathrm{HC}$, entre a idade ao receber o diagnóstico e a idade ao iniciar o tratamento e entre o nível de TSH obtido na análise da amostra de sangue coletada na TN e a dosagem de levotiroxina no início do tratamento.

TABELA 30 - Correlação entre a idade ao realizar a TN e a idade ao receber o diagnóstico de $\mathrm{HC}$, entre a idade ao receber o diagnóstico e a idade ao iniciar o tratamento e entre o nível de TSH obtido na análise da amostra de sangue coletada na TN e a dosagem de levotiroxina no início do tratamento

\begin{tabular}{lcc}
\hline \multicolumn{1}{c}{ Correlações } & $\mathbf{p}$ \\
\hline Idade na TN e idade no diagnóstico & 0,908 & $<0,001^{*}$ \\
$\begin{array}{l}\text { Idade no diagnóstico e idade no } \\
\text { início do tratamento }\end{array}$ & 0,921 & $<0,001^{*}$ \\
$\begin{array}{l}\text { Nível de TSH na TN e dosagem } \\
\text { inicial de levotiroxina }\end{array}$ & 0,477 & $0,004^{*}$ \\
\hline \hline
\end{tabular}

${ }^{*}$ Correlação estatisticamente significante $(p<0,05)$.

A Tabela 31 apresenta a associação, por meio do Teste do quiquadrado de contingência, entre o nível socioeconômico e o desempenho na Escala ELM e IPO. 
TABELA 31 - Associação entre o nível socioeconômico e o desempenho na Escala ELM e IPO

\begin{tabular}{llcccc}
\hline \hline & & \multicolumn{4}{c}{ Nível socioeconômico } \\
\cline { 3 - 6 } Desempenho & $\begin{array}{c}\text { Baixo-inferior } \\
\mathbf{n}(\%)\end{array}$ & $\begin{array}{c}\text { Baixo-superior } \\
\mathbf{n}(\%)\end{array}$ & $\begin{array}{c}\text { Médio-inferior } \\
\mathbf{n}(\%)\end{array}$ & $\mathbf{p}$ \\
\hline Escala & Adequado & $6(17,14)$ & $17(48,57)$ & $1(2,86)$ & $0,788^{\mathrm{ns}}$ \\
ELM & Alterado & $3(8,57)$ & $8(22,86)$ & $0(0,00)$ & \\
\hline IPO & Adequado & $6(17,14)$ & $20(57,14)$ & $1(2,86)$ & $0,615^{\mathrm{ns}}$ \\
& Alterado & $3(8,57)$ & $5(14,29)$ & $0(0,00)$ & \\
\hline \hline
\end{tabular}

$\overline{{ }^{\text {ns }} \text { diferença estatisticamente não significante. }} \overline{\overline{ }} \overline{\overline{\text {. }}}$

A Tabela 32 apresenta a associação, por meio do Teste de Fisher, entre o gênero e o desempenho na Escala ELM e IPO e entre a presença de outros fatores de risco para alterações do desenvolvimento além do $\mathrm{HC}$ e $\mathrm{o}$ desempenho na Escala ELM e IPO.

TABELA 32 - Associação entre o gênero e o desempenho na Escala ELM e IPO e entre a presença de outros fatores de risco para alterações do desenvolvimento além do HC e o desempenho na Escala ELM e IPO

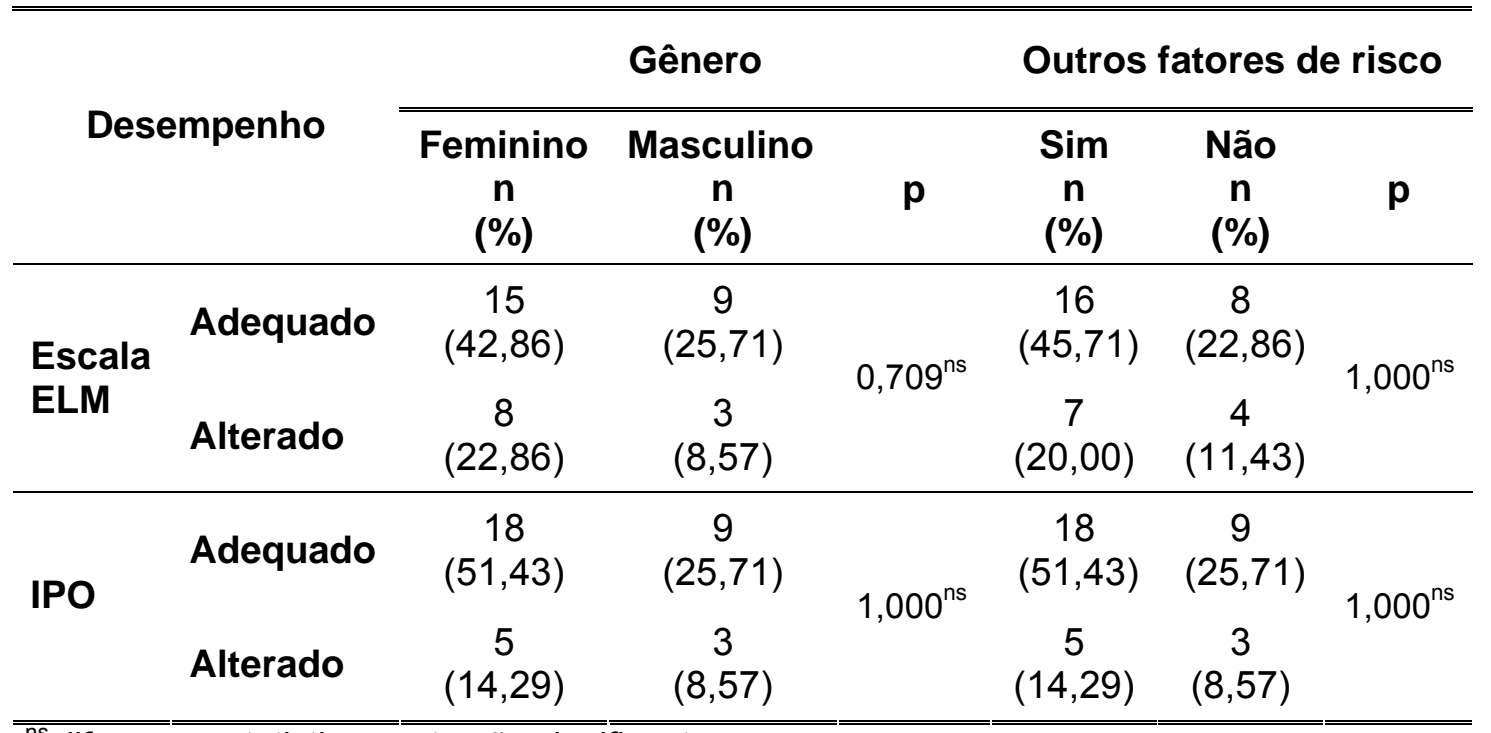

$\overline{{ }^{\text {ns }} \text { diferença estatisticamente não significante. }}$ 
A Tabela 33 apresenta a associação, por meio do Teste de Fisher, entre a condição dos níveis hormonais durante o tratamento para o $\mathrm{HC}$ e o desempenho na Escala ELM e IPO.

TABELA 33 - Associação entre a condição dos níveis hormonais durante o tratamento para o HC e o desempenho na Escala ELM e IPO

\begin{tabular}{llccc}
\hline \hline & & \multicolumn{3}{c}{ Níveis hormonais } \\
\cline { 3 - 5 } & Desempenho & $\begin{array}{c}\text { Controlados } \\
\mathbf{n}(\%)\end{array}$ & $\begin{array}{c}\text { Momentos de } \\
\text { descontrole } \\
\mathbf{n}(\%)\end{array}$ & $\mathbf{p}$ \\
\hline $\begin{array}{l}\text { Escala } \\
\text { ELM }\end{array}$ & Adequado & $21(60,00)$ & $3(8,57)$ & $0,536^{\text {ns }}$ \\
\hline IPO & Alterado & $11(31,43)$ & $0(0,00)$ & $1,000^{\text {ns }}$ \\
& Adequado & $24(68,57)$ & $3(8,57)$ & \\
\hline \hline
\end{tabular}

$\overline{{ }^{n s} \text { diferença estatisticamente não significante. }}$

A Tabela 34 apresenta a concordância, por meio da Estatística kappa, entre o desempenho na EPBD e o desempenho na Escala ELM e IPO.

TABELA 34 - Concordância entre o desempenho para a EPBD e o desempenho na Escala ELM e IPO

\begin{tabular}{llccl}
\hline \hline & & \multicolumn{3}{c}{ Desempenho na EPBD } \\
\cline { 3 - 5 } Desempenho & $\begin{array}{c}\text { Adequado } \\
\mathbf{n}(\%)\end{array}$ & $\begin{array}{c}\text { Alterado } \\
\mathbf{n}(\%)\end{array}$ & kappa \\
\hline Escala & Adequado & $24(68,57)$ & $0(0,00)$ & $0,224^{*}$ \\
ELM & Alterado & $9(25,71)$ & $2(5,71)$ & $0,340^{*}$ \\
IPO & Adequado & $27(77,14)$ & $0(0,00)$ & \\
\hline \hline
\end{tabular}

EPBD: Escala Passos Básicos do Desenvolvimento.

* Concordância mediana. 
A Tabela 35 apresenta a concordância, por meio da Estatística kappa, entre o julgamento dos responsáveis legais a respeito do desenvolvimento comunicativo das crianças e o desempenho na Escala ELM e área de linguagem do IPO.

TABELA 35 - Concordância entre o julgamento dos responsáveis legais a respeito do desenvolvimento comunicativo das crianças e o desempenho na Escala ELM e área de linguagem do IPO

\begin{tabular}{llccc}
\hline \hline & & \multicolumn{2}{c}{ Desenvolvimento Comunicativo } & \\
\cline { 3 - 5 } Desempenho & $\begin{array}{c}\text { Adequado } \\
\mathbf{n}(\%)\end{array}$ & $\begin{array}{c}\text { Alterado } \\
\mathbf{n}(\%)\end{array}$ & kappa \\
\hline $\begin{array}{l}\text { Escala } \\
\text { ELM }\end{array}$ & Adequado & $23(65,71)$ & $1(2,86)$ & $0,174^{*}$ \\
\hline $\begin{array}{l}\text { Linguagem } \\
\text { do IPO }\end{array}$ & Alterado & $9(25,71)$ & $2(5,71)$ & \\
\hline
\end{tabular}

* Concordância leve.

** Concordância mediana. 
7 - DISCUSSÃO 



\section{7 - DISCUSSÃO}

Com o objetivo de traçar o perfil das habilidades do desenvolvimento (motoras, cognitivas, lingüísticas, sociais e autocuidados) enfocando a comunicação, foram avaliadas todas as crianças de 2 a 36 meses de idade, com HC diagnosticado e tratado de maneira adequada pelo Laboratório do Teste do Pezinho da APAE-Bauru, seguindo os critérios do PNTN (BRASIL. MINISTÉRIO DA SAÚDE $\left.{ }^{18}, 2002\right)$.

A casuística foi constituída por 16 crianças $(45,72 \%)$ na faixa etária de 2 a 12 meses, 10 crianças $(28,57 \%)$ na faixa etária de 13 a 24 meses e 9 crianças $(25,71 \%)$ na faixa etária de 25 a 36 meses (Tabela 1). Observou-se maior freqüência do gênero feminino (23 crianças - 65,71\%) em relação ao masculino (12 crianças - 34,29\%). Estudos apontaram a proporção de 2:1 (LAFRANCHI ${ }^{64}, 1999$, ALMACHE $\left.^{3}, 2003\right)$ e até de 4:1 para o gênero feminino (CAMPOS; CAMPOS ${ }^{22}$, 2003) e o consideraram fator de risco para o HC (MEDDA et al. $\left.{ }^{76}, 2005\right)$.

As crianças foram avaliadas (Tabela 2) por meio da aplicação da Escala ELM e do Inventário Portage Operacionalizado (IPO). Para a escala ELM, 24 crianças $(68,57 \%)$ apresentaram desempenho global da linguagem típico para a idade cronológica (adequado) e 11 crianças (31,43\%) desempenho alterado. Na avaliação realizada por meio do IPO, obteve-se 27 crianças $(77,14 \%)$ com desempenho global nas habilidades do desenvolvimento típico para a idade cronológica e 8 crianças $(22,86 \%)$ com desempenho alterado.

Dentre as funções avaliadas na Escala ELM (Tabela 3), observou-se maior déficit no desempenho da função $A E(11$ crianças - 31,43\%) em relação às funções $A R$ (1 criança - 2,86\%) e V (2 crianças - 5,71\%). Quanto ao déficit observado nas 3 funções da Escala ELM (Tabela 4), apenas uma criança 
apresentou maior atraso no desempenho das funções $V$ e AR (21 meses de atraso) em relação à função $\operatorname{AE}$ (19 meses de atraso), o que pode ser justificado pela menor exigência do controle motor para a realização dos itens correspondentes ao valor referente ao teto alcançado na função AE por esta criança (habilidades correspondentes ao primeiro trimestre). Uma criança apresentou atraso de 4 meses no desempenho das funções $A E$ e $V$ e para as outras 9 crianças, observou-se atraso de 1 a 6 meses no desempenho apenas da função $A E$.

Das habilidades avaliadas no IPO (Tabela 5), a área de linguagem apresentou maior número de crianças com desempenho alterado (7 crianças $20,00 \%$ ), seguida da área de cognição (5 crianças - 14,29\%), da área motora e de socialização (4 crianças - 11,43\%) e por fim, da área de autocuidados (3 crianças - 8,57\%). Doze crianças foram avaliadas também por meio da área de estimulação infantil conforme os critérios adotados neste estudo. Das 3 crianças $(25,00 \%)$ com atraso no desempenho na área de estimulação infantil, 2 foram avaliadas quanto ao funcionamento do desenvolvimento apresentado, por possuírem idade cronológica superior à faixa de aplicação desta área (0 a 4 meses). O atraso observado no desempenho das crianças para as áreas cognitivas, motoras, sociais e de autocuidados do IPO (Tabela 6) variou de 1 a 22 meses, concentrando-se em 1 e 2 meses. Para a área de linguagem, observou-se maior concentração de crianças com mais de 4 meses de atraso e, para a área de estimulação infantil, as crianças apresentaram 1, 3 e 22 meses de atraso no desempenho das habilidades avaliadas.

Como o HC pode acarretar alterações nas habilidades do desenvolvimento mesmo quando tratado de maneira adequada e precoce (ROVET ${ }^{101}$, 1999, ALMACHE $\left.{ }^{3}, 2003\right)$, a literatura têm apresentado a importância do acompanhamento longitudinal do desenvolvimento de crianças com esta alteração metabólica (ROVET ${ }^{98}$, 1990, HEYERDAHL; KASE; LIE $^{50}$, 1991, GLORIEUX; DUSSAULT; VAN VLIET ${ }^{43}$, 1992, GOTTSCHALK; RICHMAN; LEWANDOWSKI ${ }^{44}$, 1994, KOOISTRA et al. ${ }^{62}$, 1994, ROVET; EHRLICH ${ }^{99}$, 1995, ROVET; ALVAREZ ${ }^{100}$, 1996, MANRÍQUEZ; NAGEL; VIVANCO ${ }^{48}, 1998$, ROVET $^{101}, 1999$, BARGAGNA et al. ${ }^{7}, 2000$, BONGERS- 
SCHOKKING et al. $^{12}$, 2000, BONGERS-SCHOKKING; DE MUINCK KEIZERSCHRAMA $^{13}, 2005$, PNIEWSKA-SIARK et al. $\left.{ }^{91}, 2006\right)$.

As habilidades do desenvolvimento mais defasadas neste estudo pertenciam à área de linguagem, reforçando a afirmação de BARGAGNA et al. $^{7}, 2000$, de que as crianças com HC são de risco para alterações no desenvolvimento lingüístico. A literatura refere que crianças e adolescentes com HC apresentam com mais freqüência atraso para o início da linguagem oral, dificuldades de compreensão da linguagem, alterações articulatórias, fonológicas e morfossintáticas, vocabulário reduzido e dificuldade para nomeação (GLEISNER et al. ${ }^{42}$, 1986, ROVET; EHRLICH; SORBARA ${ }^{97}, 1987$, GOTTSCHALK; RICHMAN; LEWANDOWSKI ${ }^{44}$, 1994, KOOISTRA et al. ${ }^{62}$, 1994, ROVET; EHRLICH ${ }^{99}$, 1995, ROVET; ALZAREZ ${ }^{100}$, 1996, ROVET ${ }^{101}$, 1999, BARGAGNA et al. ${ }^{7}, 2000$, OERBECK et al. ${ }^{83}, 2003$, BARGAGNA et al. ${ }^{8}$, 2006).

A concordância estatística observada entre o desempenho das crianças na Escala ELM e na área de linguagem do IPO (Tabela 7) foi moderada $(p=0,559)$, pois das 35 crianças avaliadas, $30 \quad(85,71 \%)$ apresentaram o mesmo desempenho (adequado ou alterado) nos dois procedimentos de avaliação da linguagem. A criança com desempenho adequado para a Escala ELM e alterado para a área de linguagem do IPO encontrava-se na faixa etária de 2 a 12 meses e as crianças com desempenho alterado na Escala ELM e adequado na área de linguagem do IPO encontravam-se na faixa etária de 13 a 24 meses. Embora WALKER et al. ${ }^{119}$, 1989, tenham observado menor sensibilidade e especificidade da Escala ELM para a avaliação de crianças com idade entre 0 e 1 ano em relação às demais faixas etárias, neste estudo, este instrumento de triagem, mostrou-se mais sensível em detectar alterações da linguagem. A alteração no desempenho de uma criança de 7 meses de idade foi identificada pela Escala ELM mas não pelo IPO, mostrando a eficácia da aplicação deste procedimento em crianças mais novas (COPLAN et al. ${ }^{27}$, 1982) e a importância da aplicação de mais de um instrumento de avaliação para complementação dos achados. 
Pelos resultados da Escala ELM, as crianças apresentaram a função AE mais comprometida em relação à função AR. BARGAGNA et al. ${ }^{7}, 2000$, também observaram, em crianças com $\mathrm{HC}$, habilidades de linguagem expressiva inferiores às de linguagem receptiva. Em crianças com alteração do desenvolvimento é esperado que, a expressão da linguagem se encontre defasada em relação à recepção (BORGES; SALOMÃO ${ }^{14}$, 2003). Observou-se também maior comprometimento da função $A E$ em relação à função $V$, mostrando que as crianças apresentaram padrões de comunicação gestuais típicos de crianças com alterações no desenvolvimento, conforme também apontaram WETHERBY; YONCLAS; BRYAN ${ }^{122}, 1989$.

A segunda habilidade com desenvolvimento mais comprometido foi a cognição. A literatura refere grande preocupação no acompanhamento do desenvolvimento desta habilidade, uma vez que a principal seqüela do HC é retardo mental (ABRAMS; ZIMMERMAN ${ }^{1}$, 1997, LUDUEÑA; PRADA; SÂNDI ${ }^{71}$, 2002, ANDROVANDI; NUNES ${ }^{5}$, 2004, ZOELLER ${ }^{126}$, 2004, MANGLIK; CHATTERJEE; $\left.\mathrm{CHOSH}^{73}, 2005\right)$ e que o déficit hormonal nas regiões cerebrais responsáveis por atividades cognitivas acarreta alterações perceptivas (IGLESIAS et al. ${ }^{53}, 1996$, ROVET ${ }^{101}, 1999$ ).

Déficits cognitivos têm sido observados em crianças, adolescentes e adultos com HC, principalmente quando o início do tratamento é tardio e/ou a alteração hormonal é mais grave (KLEIN; MELTZER; KENNY ${ }^{58}$, 1972, FUGGLE et al. $^{39}$, 1991, GLORIEU; DUSSAULT; VAN VLIET ${ }^{43}$, 1992, KOOISTRA et al. ${ }^{62}, 1994$, OERBECK et al. ${ }^{83}, 2003$, OERBECK et al. ${ }^{84}, 2005$, ROVET $^{102}$, 2005, HEPWORTH; PANG; ROVET ${ }^{49}$, 2006, KEMPERS et al. ${ }^{56}$, 2006). No entanto, nos estudos em que os indivíduos realizaram o tratamento para o HC precoce e adequado, não foram observadas alterações cognitivas (ROVET; EHRLICH; SORBARA ${ }^{97}$, 1987, GOTTSCHALK; RICHMAN; LEWANDOWSKI $^{44}$, 1994, KOOISTRA et al. ${ }^{62}$, 1994, CAMPOS et al. ${ }^{21}$, 1995, SALERNO et al. ${ }^{104}, 1995$, SALERNO et al. ${ }^{105}, 1999$, BARGAGNA et al. ${ }^{7}, 2000$, BONGERS-SCHOKKING et al. ${ }^{12}$, 2000, ANDROVANDI; NUNES ${ }^{5}, 2004$, BONGERS-SCHOKKING; DE MUINCK KEIZER-SCHRAMA ${ }^{13}, \quad 2005$, BARGAGNA et al. ${ }^{8}, 2006$, DLUHOLUCKY; HOMOVA; LUKAC ${ }^{33}, 2006$, 
HATIPOGLU et al. ${ }^{48}, 2006$, KEMPERS et al. $\left.{ }^{56}, 2006\right)$. O comprometimento cognitivo observado neste estudo acompanhou o comprometimento lingüístico, porém apresentou-se em menor grau de gravidade. Desta forma, observou-se relação direta entre o desenvolvimento cognitivo e lingüístico. CLARK ${ }^{26}, 2004$, ZORZI $^{128}, 2002$, LAMÔNICA ${ }^{65}, 2004$, também relataram esta correlação.

Alterações nas habilidades motoras também foram observadas nas crianças avaliadas. A literatura relata déficits motores em crianças com HC referentes a atraso na inibição dos reflexos primitivos, alterações do equilíbrio e da coordenação motora grossa e fina, atraso para o início da marcha, movimentos associados e alterações do tônus muscular (GLEISNER et al. ${ }^{42}$, 1986, ROVET; EHRLICH; SORBARA ${ }^{97}$, 1987, BAZÁN; PASTERI; CHAIL $^{10}$, 1990, FUGGLE et al. $^{39}$, 1991, BRAGATTI-WINCKLER; ROTTA ${ }^{17}$, 1994, GOTTSCHALK; RICHMAN; LEWANDOWSKI ${ }^{44}$, 1994, KOOISTRA et al. ${ }^{62}$, 1994, BARGAGNA et al. ${ }^{7}, 2000$, OERBECK et al. ${ }^{83}, 2003$, SIMONS et al. ${ }^{109}$, 2004, BARGAGNA et al. ${ }^{8}, 2006$; HATIPOGLU et al. ${ }^{48}, 2006$, KEMPERS et al. ${ }^{56}$, 2006). As alterações motoras observadas por KEMPERS et al. ${ }^{56}, 2006$, em crianças com $\mathrm{HC}$ persistiram na idade adulta, ressaltando a importância do acompanhamento longitudinal das habilidades do desenvolvimento em indivíduos com HC, uma vez que os hormônios tireoidianos estão envolvidos na maturação neuronal (NUNES ${ }^{81}, 1984$, PORTERFIELD; HENDRICH ${ }^{92}, 1993$, BERNAL; NUNES ${ }^{11}, 1995$, LEONARD; FARWELL ${ }^{69}, 1997$, BOTLER $^{16}, 1996$, ROVET $^{101}, 1999$, CALVO et al. ${ }^{20}, 2002$, LAVADO-AUTRIC et al. ${ }^{67}, 2003$, NUNES $^{82}, 2003$ ) e na regulação das habilidades motoras (BARGAGNA et al. ${ }^{7}$, 2000), principalmente na maturação do cerebelo (TINELLI et al. ${ }^{113}, 2003$ ).

As habilidades de socialização e autocuidados também se mostraram alteradas, porém em menor grau de comprometimento. Alterações nas funções sociais, atraso no controle de esfíncteres e dificuldades de sucção foram observados em crianças com diagnóstico de HC tardio (BRAGATTIWINCKLER; ROTTA ${ }^{17}$, 1994, CORRÊA et al. ${ }^{30}$, 1994, ROVET; EHRLICH ${ }^{99}$, 1995). Segundo MANCINI et al. ${ }^{72}, 2002$, a cultura brasileira tende a ser protecionista em relação aos cuidados da criança com alterações de saúde e no desenvolvimento. Déficits nas habilidades de autocuidados podem ser 
observados devido à falta de prática destas habilidades em tarefas da rotina diária proporcionadas pelas ações familiares nos cuidados para a criança e pela criança. Por interferir na qualidade da exploração ambiental, nas possibilidades interativas e nas relações que a criança estabelece no ambiente, o comprometimento motor observado neste estudo, pode ter influenciado o desenvolvimento global das crianças, incluindo as habilidades lingüísticas, cognitivas, sociais e de autocuidados, (CASTAÑO ${ }^{24}, 2003$, LAMÔNICA ${ }^{65}, 2004$, MENDES; MOURA $\left.{ }^{79}, 2004, \operatorname{KENDAL}^{57}, 2005\right)$. As alterações de linguagem e cognição podem também ter influenciado as atividades cotidianas destas crianças, acarretando prejuízos no desenvolvimento das habilidades sociais e de autocuidados (COPLAN et al. ${ }^{27}$, 1982, DSM.IV ${ }^{34}$, 2006, KNOBLOCK; PASSAMANICK ${ }^{61}, 2000$, LAMÔNICA ${ }^{65}, 2004$, WEBSTER et al. $\left.{ }^{121}, 2005\right)$.

A gravidade das alterações no desenvolvimento depende da etiologia do HC, época de seu início (pré ou pós-natal), gravidade da deficiência hormonal e da idade da criança ao iniciar o tratamento com levotiroxina (CHIOVATO; BARGAGNA ${ }^{25}$, 1999, ROVET ${ }^{101}$, 1999, SALERNO et al. ${ }^{105}$, 1999, ALMACHE $^{3}, 2003$, OERBECK et al. ${ }^{83}, 2003$, ROVET $\left.^{102}, 2005\right)$. Por esta razão, neste estudo foram investigados dados da história clínica a fim de caracterizar a população estudada e analisar sua influência no perfil das habilidades do desenvolvimento traçado, como denota a literatura.

O peso das crianças no nascimento foi em média 2858,7 gramas $(\mathrm{Med}=2935,0 ; \mathrm{dp}=680,9)$ e variou de 860 a 3900 gramas (Tabela 8). Nasceram 29 crianças $(82,86 \%)$ com peso superior a 2500 gramas (Tabela 9) e 6 crianças $(17,14 \%)$ com peso inferior, caracterizando baixo peso (WORLD HEALTH ORGANIZATION ${ }^{124}$, 1980). Apesar de não constituir fator de risco para o HC (MEDDA et al. $\left.{ }^{76}, 2005\right)$, o peso no nascimento quando muito baixo, pode acarretar alterações do desenvolvimento (ALEGRÍA et al. ${ }^{2}, 2002$, PERISSINOTO; ISOTANI ${ }^{87}$, 2003).

A idade das crianças na época da coleta de dados foi em média 15,7 meses $($ Med= 15,0; $d p=12,0)$ e variou de 2 a 36 meses (Tabela 8). Ao realizar a TN as crianças tinham em média 18,8 dias (Med=8,0; $\mathrm{dp}=36,8$ ) variando de 2 a 210 dias. A TN foi realizada até o $7^{\circ}$ dia de vida (Tabela 10), período ideal 
para a realização do exame (BRASIL. MINISTÉRIO DA SAÚDE ${ }^{18}, 2002$, SOCIEDADE BRASILEIRA DE TRIAGEM NEONATAL ${ }^{111}$, 2003), em apenas 16 crianças $(45,71 \%)$ e até o primeiro mês de vida em 32 crianças $(91,43 \%)$. A identificação do HC na primeira semana de vida é essencial para o início do tratamento precoce, uma vez que, mesmo sofrendo as seqüelas do $\mathrm{HC}$, as crianças podem não apresentar as manifestações clínicas nos primeiros meses (FRANÇA; SANDRINI ${ }^{37}$, 1997, WARD et al. ${ }^{120}$, 1998, SOUZA; SCHWARTZ; GIUGLIANI ${ }^{112}$, 2002). ALMEIDA et al. ${ }^{4}, 2006$, observaram idade média na TN entre 8 dias e 1 mês e SIRAGUSA et al. ${ }^{110}$, 1996, RAMALHO; VALIDO; AGUIAR-OLIVEIRA ${ }^{93}$, 2000, NASCIMENTO et al. $^{80}, 2003$, RAMOS et al. ${ }^{95}$, 2003, RAMALHO et al. ${ }^{94}, 2004$ e JONES et al. ${ }^{55}$, 2006, observaram idade média de 32, 30, 17, 18, 12 e 7 dias, respectivamente. Os estudos publicados por RAMALHO; VALIDO; AGUIAR-OLIVEIRA ${ }^{93}, 2000$ e RAMALHO et al. ${ }^{94}$, 2004, mostraram evolução no PTN do Estado de Sergipe ao apontarem a diminuição da média de idade das crianças na TN de 30 dias no ano de 1995 para 12 dias no ano de 2003.

A idade das crianças ao receber o diagnóstico do $\mathrm{HC}$ foi em média 40,3 dias (Med= 30,0; $d p=37,7$ ) e variou de 12 a 230 dias (Tabela 8). Até o primeiro mês de vida (Tabela 10), época em que as crianças já deveriam estar realizando o tratamento medicamentoso (BRASIL. MINISTÉRIO DA SAÚDE ${ }^{18}$, 2002, ALMACHE $\left.{ }^{3}, 2003\right)$, apenas 18 crianças $(51,43 \%)$ haviam recebido o diagnóstico de HC. Até o segundo mês de vida, 30 crianças $(85,71 \%)$ haviam sido diagnosticadas. SIRAGUSA et al. ${ }^{110}$, 1996, RAMALHO; VALIDO; AGUIAROLIVEIRA $^{93}, 2000$, NASCIMENTO et al. ${ }^{80}, 2003$, RAMOS et al. ${ }^{95}$, 2003, RAMALHO et al. ${ }^{94}, 2004$ e JONES et al. ${ }^{55}, 2006$ observaram idade média no diagnóstico de 141, 66, 35, 56, 29, 12 dias.

Ao iniciar o tratamento para o $\mathrm{HC}$ (Tabela 8) as crianças tinham em média 52,3 dias (Med=40,0; $d p=41,7$ ) variando de 16 a 240 dias. O tratamento com levotiroxina foi iniciado dentro do primeiro mês de vida (Tabela 10) para 12 crianças $(34,29 \%)$ e até o segundo mês para 29 crianças $(82,86 \%)$. Quanto antes o tratamento medicamentoso para o $\mathrm{HC}$ é iniciado, menor a possibilidade de ocorrer seqüelas no desenvolvimento da criança (FRANÇA; SANDRINI ${ }^{37}$, 
1997, WARD et al. ${ }^{120}, 1998$; ALMACHE $^{3}, 2003$, ROSE et al. ${ }^{96}, 2006$ ). Foram observaram idade média para o início do tratamento de 15, 14, 25, 20-30, 40, 49, 7, 13 e 28 dias por GOTTSCHALK; RICHMAN; LEWANDOWSKI ${ }^{44}$, 1994, CAMPOS et al. ${ }^{21}, 1995$, SALERNO et al. ${ }^{107}, 2001$, NASCIMENTO et al. ${ }^{80}$, 2003, TINELLI et al. ${ }^{113}, 2003$, RAMALHO et al. ${ }^{94}, 2004$, TORRES et al. ${ }^{114}$, 2004, JONES et al. ${ }^{55}, 2006$ e KEMPERS et al. ${ }^{56}, 2006$, respectivamente.

Com as médias das idades descritas para TN, diagnóstico e início do tratamento para o HC (Tabela 8), observou-se intervalo médio de 21,5 dias entre a realização da TN e a confirmação diagnóstica e de 12,0 dias entre o diagnóstico e o início do tratamento para o HC. Estudos observaram intervalo de 18 e 10 dias entre a TN e o diagnóstico e de 14 e 5 dias entre o diagnóstico e o início do tratamento (RAMALHO; VALIDO; AGUIAR-OLIVEIRA ${ }^{93}, 2000$, NASCIMENTO et al. $\left.{ }^{80}, 2003\right)$. Neste estudo, as famílias não residentes no município de Bauru dependiam do sistema de correios para o recebimento e envio dos resultados dos exames laboratoriais, além do apoio da secretaria de transporte de suas cidades de origem para se deslocarem ao Laboratório do Teste do Pezinho da APAE-Bauru. Dessa forma, em alguns casos o início do tratamento para o $\mathrm{HC}$ pode ter sido atrasado e as chances de alterações no desenvolvimento motor, cognitivo, lingüístico, social e de autocuidados podem ter aumentado, conforme apresenta a literatura (KLEIN; MELTZER; KENNY ${ }^{58}$, 1972, GLEISNER et al. ${ }^{42}, 1986$, BAZÁN; PASTERI; CHAIL ${ }^{10}, 1990$, CORRÊA et al. $^{30}, 1994$, ROVET $\left.{ }^{101}, 1999\right)$. Destaca-se ainda, que para as 6 crianças nascidas prematuras e/ou com baixo peso (Tabela 9), o início do tratamento para $\mathrm{O} \mathrm{HC}$ foi mais demorado devido à necessidade de repetição dos exames laboratoriais para a confirmação diagnóstica. Nas primeiras semanas de vida os níveis de TSH de crianças prematuras, de baixo peso ou doentes podem apresentar-se dentro do intervalo de referência para a normalidade, uma vez que estas crianças podem estar sobre influência dos hormônios transferidos pela mãe durante a gestação (MEIRELLES et al. $^{77}$, 1991, SOUZA; SCHWARTZ; GIUGLIANI ${ }^{112}$, 2002, LAVADO-AUTRIC et al. ${ }^{67}, 2003$, ZOELLER ${ }^{126}$, 2004, TYLEK-LEMÁNSKA; KUMOROWICZ-KOPIEC; STARZYK ${ }^{115}, 2005$, KEMPERS et al. $\left.{ }^{56}, 2006\right)$. 
O nível de TSH obtido na análise da amostra de sangue coletada na TN (Tabela 8) foi em média 57,6 $\mu \mathrm{UI} / \mathrm{ml}(\mathrm{Med}=22,4 ; \mathrm{dp}=82,4$ ) e variou de 6,60 a $368 \mu \mathrm{UI} / \mathrm{ml}$. Valores inferiores a $20 \mu \mathrm{UI} / \mathrm{ml}$ (Tabela 11) foram relatados para 16 crianças $(45,72 \%)$ e valores superiores a esta unidade de referência foram relatados para 19 crianças $(54,28 \%)$. Como a glândula tireóide é estimulada pelo hormônio TSH a produzir seus hormônios (KNOBEL; NOGUEIRA; MEDEIROS-NETO ${ }^{60}$, 2001), níveis elevados de TSH sugerem deficiência da glândula tireóide em produzir os hormônios necessários ao desenvolvimento da criança (LUDUEÑA; PRADA; SÂNDI ${ }^{71}, 2002$, ALMACHE $^{3}, 2003, \mathrm{NUNES}^{82}$, 2003). Assim, quanto mais elevados os níveis de TSH na TN, mais baixos os níveis de $\mathrm{T}_{4}$ e conseqüentemente mais grave o $\mathrm{HC}$ da criança (MANRÍQUEZ; NAGEL; VIVANCO ${ }^{74}, 1998$, SALERNO et al. $\left.{ }^{107}, 2001\right)$.

A dosagem de levotiroxina no início do tratamento para o $\mathrm{HC}$ (Tabela 8) foi em média 29,5 mg/dl (Med= 25,0; dp=15,4) e variou de 6,25 a $75 \mathrm{mg} / \mathrm{dl}$. Foram indicadas para 23 crianças $(65,71 \%)$ dosagens iniciais de levotiroxina inferiores a $25 \mathrm{mg} / \mathrm{dl}$ e a 12 crianças (34,29\%) dosagens superiores a este valor (Tabela 12). Segundo a literatura, existem questionamentos quanto à dosagem ideal para o tratamento medicamentoso do $\mathrm{HC}$, pois não foi comprovado que doses altas de levotiroxina proporcionam melhorias no desenvolvimento destas crianças (HINDMARSH ${ }^{52}$, 2002). Entretanto, ressaltase que o PTN do Laboratório do Teste do Pezinho da APAE-Bauru segue as especificações do PNTN do Ministério da Saúde (BRASIL. MINISTÉRIO DA SAÚDE $\left.^{18}, 2002\right)$.

As crianças avaliadas neste estudo não realizaram o diagnóstico etiológico do HC (Tabela 13). Este tipo de diagnóstico permite a compreensão da fisiopatologia do HC (PERONE et al. ${ }^{88}$, 2004, VONO-TONIOLO; KOPP ${ }^{118}$, 2004) e a determinação do prognóstico e do programa de tratamento de cada criança (KOOISTRA et al. ${ }^{62}$, 1994, HANUKOGLU et al. ${ }^{47}$, 2001, PARK; CHATTERJEE $^{85}$, 2005). O Manual de Normas Técnicas e Rotinas Operacionais do Programa Nacional de Triagem Neonatal (BRASIL. MINISTÉRIO DA SAÚDE $^{18}$, 2002) não contempla o diagnóstico etiológico do $\mathrm{HC}$, embora recomende sua realização. Ressalta-se que o PTN do Laboratório do Teste do 
Pezinho da APAE-Bauru é credenciado pelo Ministério da Saúde e, portanto, segue suas recomendações fundamentais referentes à identificação precoce e tratamento para o $\mathrm{HC}$.

A análise da avaliação do serviço social (Tabela 13) mostrou que 9 crianças $(25,71 \%)$ apresentavam nível socioeconômico baixo-inferior, 25 crianças $(71,43 \%)$ baixo-superior e 1 criança $(2,86 \%)$ médio-inferior. Uma das hipóteses para justificar a ausência de crianças com níveis socioeconômicos médio, médio-superior e alto pode estar relacionada a características da população acompanhada por este PTN. O atendimento oferecido pelo Laboratório do Teste do Pezinho da APAE-Bauru é ligado ao Sistema Único de Saúde e abrange a população de grande parte da região Centro Oeste Paulista. Famílias com melhor nível socioeconômico podem ter optado por realizar o tratamento das crianças com HC por meio de convênios médicos particulares ou mesmo por meio do sistema público de saúde de sua cidade de origem. As crianças com HC avaliadas no estudo de CAMPOS et al. ${ }^{21}, 1995$, apresentaram nível socioeconômico médio e desenvolvimento cognitivo, comportamental e crescimento físico normais. Estudos têm considerado o nível socioeconômico como um parâmetro relevante para o pareamento de crianças com e sem HC (FUGGLE et al. ${ }^{39}$, 1991, KOOISTRA et al. ${ }^{62}$, 1994, KOOISTRA et al. ${ }^{63}, 1996$, BARGAGNA et al. ${ }^{7}, 2000$, SIMONS et al. $\left.{ }^{109}, 2004\right)$.

$\mathrm{Na}$ análise da avaliação psicológica (Tabela 13) realizada por meio da Escala Passos Básicos do Desenvolvimento (EPBD), 33 crianças (94,29\%) apresentaram desempenho adequado e apenas 2 (5,71\%) apresentaram desempenho alterado sugerindo atraso na idade mental calculada em 21 e 6 meses para cada uma. Como o retardo mental, uma das principais seqüelas do HC, é passível de prevenção quando o tratamento com levotiroxina é adequado (ABRAMS; ZIMMERMAN ${ }^{1}$, 1997, LUDUEÑA; PRADA; SÂNDI ${ }^{71}, 2002$, ZOELLER ${ }^{126}$, 2004, MANGLIK; CHATTERJEE; $\mathrm{CHOSH}^{73}$, 2005), a realização de avaliações cognitivas em crianças diagnosticadas com HC é de extrema importância.

Os níveis hormonais acompanhados durante o tratamento para o $\mathrm{HC}$ (Tabela 13) foram mantidos dentro do intervalo de referência (controlados) em 
32 crianças $(91,43 \%)$. Três crianças $(8,57 \%)$ apresentaram, em alguns períodos do tratamento, níveis hormonais fora deste intervalo, entretanto, suas dosagens de levotiroxina foram alteradas tornando seus níveis hormonais adequados de acordo com os valores de referência. Como o objetivo do tratamento com dosagens de levotiroxina é manter os níveis hormonais dentro da normalidade (ROSE et al. ${ }^{96}, 2006$ ), pode-se observar que as dosagens medicamentosas indicadas pelo Laboratório do Teste do Pezinho da APAEBauru às crianças avaliadas neste estudo têm sido eficientes. Vale lembrar que o acompanhamento laboratorial é realizado no máximo trimestralmente, o que permite com que as alterações hormonais sejam corrigidas com a mudança da dosagem medicamentosa.

Não foram obtidos relatos de consangüinidade entre os pais das crianças avaliadas (Tabela 14). Embora a literatura não relate consangüinidade como fator de risco para HC, GHAZI et al. ${ }^{41}, 2005$, descreveram o estudo clínico de uma família com 3 filhos diagnosticados com HC cujos pais eram consangüíneos.

Quanto à realização do acompanhamento pré-natal (Tabela 14) 33 mães $(94,29 \%)$ iniciaram o acompanhamento antes do $3^{\circ}$ mês de gestação e as outras 2 mães $(5,71 \%)$ referiram não ter tido condições de acompanhar a gestação desde seu início. A gestação de 24 crianças $(68,57 \%)$ não apresentou problemas (Tabela 14), entretanto, 11 (31,43\%) responsáveis legais pelas crianças relataram a ocorrência de problemas de saúde da mãe durante a gestação, tais como (Tabela 15): uso de analgésicos para dores fortes na coluna (1 relato $-9,09 \%$ ), hipertensão arterial (1 relato $-9,09 \%$ ), hipertensão arterial e ameaça de aborto (1 relato - 9,09\%), infecção geniturinária com ameaça de aborto (1 relato - 9,09\%), início de contrações no sétimo mês de gestação (1 relato - 9,09\%), ameaça de aborto (2 relato $18,18 \%$ ), anemia (2 relatos - 18,18\%) e infecção geniturinária (2 relatos $18,18 \%)$. Ameaça de abortos espontâneos não constituem fator de risco para o HC (MEDDA et al. ${ }^{76}, 2005$ ), entretanto, podem ser considerados fatores de risco para alterações do desenvolvimento, assim como a hipertensão e quadros infecciosos (DIAMENT $\left.{ }^{32}, 1996\right)$. A anemia durante a gestação, relatadas por 2 
mães, pode sugerir alimentação materna inadequada e/ou subnutrição com deficiência de iodo levando à produção insuficiente dos hormônios tireoidianos pela mãe e ao agravamento do hipotireoidismo no feto (DIAMENT ${ }^{32}$, 1996, DELANGE $^{31}$, 2001).

Quanto ao tipo de nascimento (Tabela 16), foram relatados 27 nascimentos a termo $(77,14 \%)$ e 8 prematuros $(22,86 \%)$ - nascimentos anteriores à $37^{\mathrm{a}}$ semana gestacional (WORLD HEALTH ORGANIZATION ${ }^{124}$, 1980, ALEGRÍA et al. ${ }^{2}$, 2002). A prematuridade não foi considerada fator de risco para o $\mathrm{HC}$ como os nascimentos ocorridos após a $40^{\mathrm{a}}$ semana gestacional (MEDDA et al. ${ }^{76}$, 2005). Entretanto, crianças prematuras deixam de receber o hormônio tireoidiano materno quando este ainda é necessário para a maturação do sistema hipotálamo-hipofisiário-tireóideo e, portanto, para o metabolismo dos hormônios da tireóide (VAN WASSENAER et al. ${ }^{117}$, 2002). Devido à alta possibilidade de instabilidade hemodinâmica e respiratória à maior susceptibilidade a doenças, a prematuridade é considerada importante fator de risco para atrasos no desenvolvimento global das crianças (WORLD HEALTH ORGANIZATION ${ }^{124}$, 1980, ALEGRÍA et al. ${ }^{2}$, 2002, PERISSINOTO; ISOTANI $^{87}$, 2003). Quanto ao tipo de parto (Tabela 16), foram relatados 19 partos $(54,29 \%)$ por cesariana e 16 partos $(45,71 \%)$ naturais. MEDDA et al. ${ }^{76}$, 2005, observaram que o tipo de parto não constituiu fator de risco para o HC. Nenhuma criança teve o HC suspeitado pelo médico obstetra após o parto (Tabela 16), demonstrando a dificuldade em se realizar o diagnóstico clínico do $\mathrm{HC}$ embora, já se possa esperar seqüelas decorrentes da deficiência hormonal (MENABÓ et al. $^{78}, 1990$, SETIAN $^{108}$, 1996, SOUZA; SCHWARTZ; GIUGLIANI $^{112}$, 2002, UNIVERSIDADE FEDERAL DE MINAS GERAIS ${ }^{116}$, 2005).

Ao ser investigada a saúde das crianças (Tabela 17), obteve-se relato de 3 crianças $(8,57 \%)$ com problemas de saúde na época da coleta de dados, 13 crianças $(37,14 \%)$ com problemas de saúde após o nascimento e 12 crianças $(34,29 \%)$ com problemas de saúde na $1^{\text {a }}$ infância. Os problemas de saúde na época da coleta de dados (Tabela 18) referiam-se a problemas 
respiratórios como bronquite (1 relato - 33,33\%) e rinite alérgica (2 relatos $66,67 \%)$.

Quanto aos problemas de saúde após o parto relatados (Tabela 19), 1 criança $(7,69 \%)$ apresentou icterícia e necessidade de incubadora, 1 criança apresentou $(7,69 \%)$ icterícia e necessidade de incubadora e Unidade de Terapia Intensiva, 1 criança $(7,69 \%)$ apresentou necessidade de incubadora isolada, 1 criança $(7,69 \%)$ apresentou problemas respiratórios isolados, 1 criança $(7,69 \%)$ apresentou problemas respiratórios e necessidade de incubadora, 3 crianças $(23,08 \%)$ apresentaram problemas respiratórios, icterícia e necessidade de incubadora e 4 crianças $(30,77 \%)$ apresentaram icterícia isolada. Mais de um problema de saúde foram relatados para 7 das 13 crianças. A icterícia, necessidade de incubadora, problemas respiratórios e choro fraco são características clínicas de criança com HC nos primeiros meses de vida $\left(\right.$ FALEN $^{35}$, 1992, LUDUEÑA; PRADA; SÂNDI ${ }^{71}, 2002$, UNIVERSIDADE FEDERAL DE MINAS GERAIS ${ }^{116}, 2005$, HATIPOGLU et al. ${ }^{48}$, 2006).

Os relatos de problemas de saúde ocorridos durante a primeira infância (Tabela 20) foram: 1 criança (8,33\%) com dificuldades respiratórias, vômito projétil e dificuldade para aumentar o peso, 1 criança $(8,33 \%)$ com pele pálida e descamativa e dificuldade para aumentar o peso, 1 criança $(8,33 \%)$ com sonolência, choro rouco, edema e hérnia umbilical, 1 criança $(8,33 \%)$ com sonolência, dificuldade respiratória, bócio e dificuldade para aumentar o peso, 1 criança $(8,33 \%)$ com sonolência, sucção fraca, choro rouco, problemas intestinais e hérnia umbilical, 1 criança $(8,33 \%)$ com sonolência, dificuldades respiratórias, pele pálida e descamativa, problemas intestinais e hérnia umbilical, 1 criança $(8,33 \%)$ com sonolência, sucção fraca, vômito projétil, olhos empapuçados, choro rouco, hipotonia, bócio, pele pálida e descamativa, dificuldade para aumentar o peso, problemas intestinais e hérnia umbilical, 1 criança $(8,33 \%)$ com sucção fraca, pele pálida e descamativa, problemas intestinais e hérnia umbilical, 1 criança $(8,33 \%)$ com vômito projétil, problemas intestinais e crises convulsivas e 3 crianças $(25,00 \%)$ com problemas intestinais. Problemas intestinais, hérnia umbilical, sonolência, choro rouco, 
edema, bócio, olhos empapuçados, pele seca e descamativa e hipotonia são sinais clínicos do HC nos três primeiros meses de vida (FALEN ${ }^{35}, 1992$, CORRÊA et al. ${ }^{30}$, 1994, MANRÍQUEZ; NAGEL; VIVANCO ${ }^{74}$, 1998, LUDUEÑA; PRADA, SÂNDI ${ }^{71}, 2002$, UNIVERSIDADE FEDERAL DE MINAS GERAIS ${ }^{116}$, 2005, HATIPOGLU et al. ${ }^{48}$, 2006).

Quanto ao crescimento físico (Tabela 21), 32 crianças $(91.43 \%$ ) apresentaram percentis de altura e peso esperados para a idade cronológica e 3 crianças $(8,57 \%)$ apresentaram percentis abaixo do esperado. A realização do diagnóstico e o início do tratamento para o HC das 3 crianças com crescimento físico alterado ocorreu após o primeiro mês de vida. A literatura relata que em crianças com início do tratamento precoce não foram observadas alterações do crescimento (CAMPOS et al. ${ }^{21}$, 1995, SALERNO et al. ${ }^{107}, 2001$, PNIEWSKA-SIARK et al. $\left.{ }^{91}, 2006\right)$. Porém, em crianças com diagnóstico e tratamento para o HC tardio e deficiência grave do hormônio tireoidiano, foram observadas alterações no crescimento físico quanto à altura, peso, perímetro cefálico e idade óssea (ARASON et al. ${ }^{6}$, 1990, BAZÁN; PASTERI; CHAIL ${ }^{10}$, 1990, CORRÊA et al. ${ }^{30}, 1994$, GRANT ${ }^{45}$, 1994, SIRAGUSA et al. ${ }^{110}, 1996$, HEYERDAHL et al. ${ }^{51}$, 1997). Desenvolvimento puberal alterado também tem sido observado em crianças com HC diagnosticado tardiamente (PIZARRO; PASKULIN; OLIVEIRA ${ }^{90}$, 1994, RUIBAL-FRANCISCO et al. ${ }^{103}$, 2001). Entretanto, crianças diagnosticadas na TN apresentaram desenvolvimento puberal adequado (SALERNO et al. ${ }^{106}, 2000$ ), mostrando que a reposição hormonal adequada pode proporcionar crescimento físico normal às crianças com HC. Estudos também têm relatado que crianças com idade óssea aquém da idade cronológica apresentaram pior desempenho quanto às habilidades cognitivas, motoras e lingüísticas (ROVET; EHRLICH; SORBARA ${ }^{97}$, 1987, GLORIEUX; DUSSAULT; VAN VLIET ${ }^{43}$, 1992, CORRÊA et al. ${ }^{30}$, 1994, GOTTSCHALK; RICHMAN; LEWANDOWSKI ${ }^{44}$, 1994, PIZARRO; PASKULIN; OLIVEIRA $^{90}$, 1994, ROVET ${ }^{101}$, 1999). Segundo BARROS-FILHO ${ }^{9}, 2006$, a determinação da idade óssea antes dos dois anos não tem valor, uma vez que a criança ainda apresenta poucos pontos de ossificação para estabelecer idade óssea confiável, todavia, ela é importante em conjunto com a idade cronológica, idade atual e história de alteração hormonal. 
Das 35 crianças avaliadas, 16 (45,71\%) encontravam-se em idade de desenvolvimento do controle de esfíncteres diurno a partir do $18^{\circ}$ mês ou noturno a partir do $24^{\circ}$ mês, conforme os critérios apresentados por GESSEL e AMATRUDA - KNOBLOCK; PASSAMANICK ${ }^{61}$, 2000. Considerando estas 16 crianças, o desenvolvimento do controle de esfíncteres (Tabela 21) ocorreu em idade adequada para 7 crianças $(43,75 \%)$ e foi tardio para 9 crianças $(56,25 \%)$. Quanto à alimentação (Tabela 21), obteve-se relato de 33 crianças (94,29\%) sem dificuldades para se alimentar e de 2 crianças $(5,71 \%)$ com engasgos durante as refeições e dificuldades em deglutir alimentos sólidos como carnes e pães. A literatura relata atraso no controle de esfíncteres (BRAGATTIWINCKLER; ROTTA ${ }^{17}$, 1994), dificuldade de sucção e refluxo gastroesofágico (CORRÊA et al. ${ }^{30}, 1994$ ) em crianças com diagnóstico do HC tardio.

Quanto à qualidade do sono (Tabela 22) obteve-se relato de 33 crianças (94.29\%) com rotina para dormir e sono tranqüilo (qualidade do sono adequada) e de 2 crianças (5,71\%) com dificuldades em manter rotina nos horários de dormir e inquietação durante o sono (qualidade do sono alterada). Com relação à educação (Tabela 22), apenas 5 crianças $(14,29 \%)$ freqüentavam instituições educacionais. Os responsáveis legais pelas outras 30 crianças $(85,71 \%)$ atribuíram a ausência em instituições de ensino a pouca idade e a dificuldade em adaptar-se a ambientes com muitas crianças na ausência da mãe. Considerando as leis brasileiras do Ministério da Educação, todas as crianças com 4 a 6 anos de idade devem estar inseridas em programas educacionais e, é dever do Estado, direito da criança e opção da família o atendimento gratuito em instituições de Educação Infantil às crianças de 0 a 6 anos. (BRASIL. MINISTÉRIO DA EDUCAÇÃO ${ }^{19}$, 2006). A idade das crianças avaliadas foi inferior a 3 anos e, portanto, a permanência nas modalidades de maternal e pré-escola é eletiva e de responsabilidade somente da família. OERBECK et al. ${ }^{83}, 2003$, relataram que adultos com HC que não haviam terminado o ensino médio receberam doses baixas de levotiroxina no início do tratamento. A este respeito, SIMONS et al. ${ }^{109}, 2004$, observaram dificuldade no desempenho de habilidades matemáticas em crianças que iniciaram tratamento com levotiroxina com dosagens menores. A literatura relata a ocorrência de alterações nas habilidades visoespaciais, visomotoras, 
de memória, de atenção, de raciocínio lógico e de leitura em crianças com HC, as quais podem influenciar negativamente nas atividades escolares (ROVET; EHRLICH ${ }^{99}$, 1995, KOOISTRA et al. ${ }^{63}$, 1996, ROVET; ALVAREZ ${ }^{100}$, 1996, ROVET $^{101}$, 1999, TORRES et al. $^{114}$, 2004, DLUHOLUCKY; HOMOVA; LUKAC $\left.^{33}, 2006\right)$.

Quanto à presença de queixas do comportamento (Tabela 22), não foram obtidos relatos de problemas comportamentais para 29 crianças $(82,86 \%)$, entretanto, 6 responsáveis legais pelas crianças $(17,14 \%)$ relataram queixas quanto ao comportamento, referente a comportamentos de birra e agressividade freqüentes. Segundo inferência dos profissionais que acompanhavam estas crianças, estes comportamentos considerados maladaptativos são comuns, mas não constituem um traço secundário ao HC. A literatura apresenta que, de maneira geral, ao acreditar que os filhos apresentam problemas de saúde, os pais tendem a superproteção e a dificuldade para impor limites (CHIOVATO; BARGAGNA ${ }^{25}$, 1999, MANCINI et al. $^{72}$, 2002, TINELLI et al. ${ }^{113}$, 2003, SIMONS et al. ${ }^{109}$, 2004). Estudos observaram a ocorrência de comportamentos delinqüentes, de birra, agressividade, hiperatividade, ansiedade, reclusão social, depressão e perda da orientação espacial em indivíduos com HC (FUGGLE et al. ${ }^{39}$, 1991, BRAGATTI-WINCKLER; ROTA ${ }^{17}$, 1994, ROVET; EHRLICH ${ }^{99}$, 1995, TINELLI et al. ${ }^{113}, 2003$, SIMONS et al. ${ }^{109}, 2004$, OERBECK et al. $\left.{ }^{84}, 2005\right)$. Entretanto, crianças que realizaram tratamento medicamentoso para o $\mathrm{HC}$ de maneira precoce e adequada não apresentaram alterações do comportamento (ROVET; EHRLICH; SORBARA ${ }^{97}$, 1987, CAMPOS et al. ${ }^{21}$, 1995, FIGUEIREDO; SCHERMANN $\left.{ }^{36}, 2001\right)$.

O desenvolvimento comunicativo (Tabela 23) de 32 crianças $(91,43 \%)$ foi julgado adequado pelos responsáveis legais. Os relatos de queixas quanto ao desenvolvimento da comunicação (Tabela 24) para 3 crianças $(8,57 \%)$ referiam-se a disfluência (1 relato - 33,33), atraso para o início da fala (1 relato - 33,33) e ausência de oralidade (1 relato - 33,33). Quanto à habilidade auditiva (Tabela 23 ), obteve-se relato de que 14 crianças $(40,00 \%)$ haviam realizado avaliações auditivas anteriores, todas com resultados 
referentes à normalidade. Os $21(60,00 \%)$ responsáveis legais pelas crianças que não haviam sido avaliadas quanto à audição, não demonstraram interesse na avaliação desta habilidade. Otites de repetição foram relatadas para 5 crianças $(14,29 \%)$, todas tratadas em clínicas particulares ou Unidade Básica de Saúde de suas cidades de origem. Um dos sinais clínicos do HC, principalmente quando não tratado nos primeiros meses de vida, é a ocorrência de icterícia prolongada (FALEN ${ }^{35}$, 1992, MANRÍQUEZ; NAGEL; VIVANCO ${ }^{74}$, 1998, UNIVERSIDADE FEDERAL DE MINAS GERAIS ${ }^{116}, 2005$, HATIPOGLU et al. ${ }^{48}$, 2006). Neste estudo, foram obtidos 9 relatos de icterícia ao nascimento (Tabela 19) com duração máxima de 5 dias, o que pode constituir importante fator de risco para alterações auditivas (JOINT COMMITTEE OF INFANT HEARING ${ }^{54}$, 1994). A literatura relata tanto perda auditiva em criança com HC tratado tardiamente, como limiares auditivos semelhantes aos de crianças sadias (BRAGATTI-WINCKLER; ROTTA ${ }^{17}$, 1994, FRANÇÓIS et al. ${ }^{38}$, 1994). MARTI et al. ${ }^{75}, 2006$, observaram maior latência da onda N200 durante a avaliação dos potenciais evocados auditivos em crianças com tratamento inadequado para o $\mathrm{HC}$.

Quanto à habilidade visual (Tabela 23), obteve-se apenas 1 relato $(2,86 \%)$ de avaliação visual anterior, na qual foi diagnosticado lesão de fundo de olhos e estrabismo no olho direito. Embora a literatura não considere alterações visuais como conseqüência do HC, ALEGRÍA et al. ${ }^{2}, 2002$, observaram alta probabilidade de ocorrência de problemas visuais em crianças prematuras. A criança com alterações visuais neste estudo apresentou no nascimento importantes fatores de risco para alterações do desenvolvimento como falta de oxigenação, prematuridade e baixo peso. Para as 34 crianças (97.14\%) que não realizaram avaliações visuais anteriores, não foram obtidos relatos de queixas visuais.

Ocorrência de outros fatores de risco para alterações do desenvolvimento além do HC (Tabela 25), como intercorrências gestacionais e/ou nascimento prematuro e/ou baixo peso no nascimento e/ou problemas de saúde após o parto, foram relatadas para 23 crianças $(65,71 \%)$, mas não para as outras 12 crianças (34,29\%). WORLD HEALTH ORGANIZATION ${ }^{124}, 1980$, 
JOINT COMMITTEE OF INFANT HEARING ${ }^{54}$, 1994, DIAMENT ${ }^{32}, 1996$ e ALEGRÍA et al. $^{2}$, 2002, afirmaram que todos estes aspectos constituem importantes fatores de risco para alterações no desenvolvimento da criança. A existência de antecedentes familiares foi negada para 16 crianças $(45,71 \%)$. Os antecedentes familiares relatados para as outras 19 crianças $(54,29 \%)$ foram (Tabela 26): para 1 criança $(5,26 \%)$ alterações na glândula tireóide, atraso de linguagem e Doença de Alzeihmer; para 1 criança $(5,26 \%)$ alterações na glândula tireóide, retardo mental e crises epitéticas; para 1 criança alterações na glândula tireóide e Síndrome de Down; para 1 criança (5,26\%) problemas respiratórios crônicos; para 3 crianças $(15,79 \%)$ retardo mental; para 3 crianças $(15,79 \%)$ Síndrome de Down e para 9 crianças $(47,37 \%)$ alterações na glândula tireóide. Das 12 crianças com histórico familiar de problemas tireoidianos, 6 relataram alterações da glândula tireóide em mais de um parente. MEDDA et al. $^{76}, 2005$, afirmaram que embora a ocorrência de alterações da glândula tireóide na família não tenha se mostrado fator de risco significante para $\circ \mathrm{HC}$, foi observado uma tendência para o aumento do risco de HC. Neste estudo, 2 crianças da casuística eram irmãs de pais diferentes e possuíam ainda um irmão de 7 anos de idade com $\mathrm{HC}$ diagnosticado na TN e a mãe com diagnóstico realizado aos 27 anos. Quanto ao retardo mental, a literatura apenas afirma que esta pode ser o grande ônus pago pela falta de diagnóstico precoce do HC (BAZÁN; PASTERI; CHAIL ${ }^{10}$, 1990, SALERMO et al. ${ }^{104}, 1995$, SETIAN ${ }^{108}, 1996$, SALERNO et al. ${ }^{106}, 2000$, DELANGE ${ }^{31}, 2001$ ).

Para a verificação da influência dos dados da histórica clínica no perfil das habilidades do desenvolvimento traçado, variáveis relevantes foram correlacionadas com o desempenho das crianças na Escala ELM e no IPO.

A diferença no peso ao nascimento entre as crianças com desempenho adequado e alterado para a Escala $\operatorname{ELM}(p=0,606)$ e para o IPO $(p=0,542)$ não foi significante (Tabela 27). Apesar de não ser um importante fator de risco para o HC (MEDDA et al. $\left.{ }^{76}, 2005\right)$, o baixo peso ao nascimento pode interferir no desenvolvimento neuropsicomotor (ALEGRÍA et al. ${ }^{2}, 2002$ ). Tentou-se verificar se as crianças das diferentes faixas etárias se comportariam de modo diferente nos procedimentos de avaliação, considerando que as 
crianças mais velhas teriam um tempo maior de tratamento e, portanto, hipoteticamente, maiores condições de melhor desempenho nos aspectos do desenvolvimento. Entretanto, a diferença na idade da época da coleta de dados entre as crianças com desempenho adequado e alterado para a Escala ELM $(p=0,487)$ e para o IPO $(p=0,608)$ também não foi significante. BARGAGNA et al. $^{7}, \quad 2000$, observou melhora no desempenho das habilidades do desenvolvimento conforme as crianças fossem ficando mais velhas e no transcorrer do tratamento para o HC. Ao acompanhar longitudinalmente crianças com HC, ROVET; EHRLICH; SORBARA ${ }^{97}$, 1987, BARGAGNA et al. ${ }^{7}$, 2000, e DLUHOLUCKY; HOMOVA; LUKAC ${ }^{33}$, 2006, observaram que as crianças com HC podem superar as alterações nas habilidades do desenvolvimento, desde que acompanhadas com tratamento adequado.

Embora a média da idade na TN, no diagnóstico e no inicio do tratamento para o HC (Tabela 28) das crianças com desempenho adequando tenha sido inferior à média das crianças com desempenho alterado para a Escala ELM $(p=0,291 ; p=0,109$ e $p=0,285)$ e para o IPO $(p=0,133 ; p=0,246$ e $p=0,665)$, essas diferenças não foram significantes. Este resultado sugere que a idade no início do tratamento para o $\mathrm{HC}$ destas crianças permitiu que seqüelas no desenvolvimento fossem prevenidas. No entanto, observou-se tendência para desempenho adequado nas habilidades avaliadas, entre as crianças que realizaram a $\mathrm{TN}$, receberam $\mathrm{o}$ diagnóstico e iniciaram $\mathrm{O}$ tratamento para o HC mais precocemente. CAMPOS et al. ${ }^{21}$, 1995, SALERNO et al. ${ }^{104}, 1995$, KOOISTRA et al. ${ }^{63}$, 1996, SALERNO, et al. ${ }^{107}, 2001$, ROVET $^{102}$, 2005 e KEMPERS et al. ${ }^{56}$, 2006, não observaram correlação entre a idade no início do tratamento para o $\mathrm{HC}$ e o desempenho de crianças com $\mathrm{HC}$ nas habilidades cognitivas, uma vez que nestes estudos, a idade do início do tratamento também foi precoce. Entretanto, a literatura relata correlações positivas entre o desempenho nas habilidades cognitivas, motoras, lingüísticas e a idade do diagnóstico e do início do tratamento para o HC (KLEIN; MELTZER; KENNY58, 1972, BAZÁN; PASTERI; CHAIL ${ }^{10}$, 1990, ROVET $^{101}$, 1999). Ressalta-se que por definição, o HC é uma das poucas causas em que o retardo mental pode ser prevenido, quando tratada precocemente 
(MANRIQUEZ; NAGEL; VIVANCO ${ }^{74}, \quad 1998, \quad$ MANGLIK; CHATTERJEE; $\left.\mathrm{CHOSH}^{73}, 2005\right)$.

Neste estudo, quanto mais precoce a realização da TN (Tabela 30) mais cedo foi efetuado o diagnóstico $(r=0,908)$ e iniciado o tratamento para o $\mathrm{HC}(r=0,921)$. Conforme a literatura, quanto mais precoce a identificação e o tratamento para o HC maior a possibilidade de prevenção dos distúrbios do desenvolvimento e do retardo mental (KLEIN; MELTZER; KENNY58, 1972, GLEISNER et al. $^{42}$, 1986, FRANÇA; SANDRINI' ${ }^{37}$, 1997, MANRÍQUEZ; NAGEL; VIVANCO $^{74}$, 1998, ROVET ${ }^{101}$, 1999, SOUZA; SCHWARTZ; GIUGLIANI ${ }^{12}$, 2002, TORRES et al. ${ }^{114}, 2004$, PERONE et al. ${ }^{88}, 2004$, GEELHOED et al. ${ }^{40}$, 2005, CARROLL; DOWNS ${ }^{23}, 2006$, ROSE et al. $\left.{ }^{96}, 2006\right)$.

Embora a média dos níveis de TSH $(\mu \mathrm{Ul} / \mathrm{ml})$ obtidos na TN das crianças com desempenho adequado (Tabela 29) tenha sido superior à média dos níveis de TSH das crianças com desempenho alterado para a Escala ELM $(p=0,570)$ e para o IPO $(p=0,479)$, essa diferença não foi significante. SALERNO et al. ${ }^{107}$, 2001, também não observaram correlação entre a gravidade do HC e desenvolvimento. Entretanto, estudos têm observado relação inversa entre a gravidade do $\mathrm{HC}$ no diagnóstico e o desempenho nas habilidades cognitivas, lingüísticas e motoras de crianças com HC (FUGGLE et al. $^{39}$, 1991, GLORIEUX; DUSSAULT; VAN VLIET ${ }^{43}, 1992$, KOOISTRA et al. ${ }^{62}$, 1994, SALERNO et al. $^{104}$, 1995, KOOISTRA et al. ${ }^{63}$, 1996, MANRÍQUEZ; NAGEL; VIVANCO ${ }^{74}$, 1998, ROVET ${ }^{101}$, 1999, SALERNO et al. ${ }^{105}$, 1999, BARGAGNA et al. ${ }^{7}, 2000$, BONGERS-SCHOKKING et al. ${ }^{12}, 2000$, OERBECK et al. ${ }^{83}, 2003$, SIMONS et al. ${ }^{109}, 2004$, BARGAGNA et al. ${ }^{8}, 2006$, KEMPERS et al. ${ }^{56}$, 2006). Embora a média da dosagem inicial de levotiroxina (mg/dia) prescrita para as crianças com desempenho adequado (Tabela 29) tenha sido superior à média da dosagem das crianças com desempenho alterado para a Escala ELM $(p=0,091)$ e para o IPO $(p=0,198)$, essa diferença não foi significante. No entanto, observou-se tendência para desempenho adequado nas habilidades avaliadas entre as crianças que receberam dosagem de levotiroxina mais elevada no início do tratamento para o HC. A ausência de significância estatística ocorreu, muito provavelmente, pelo fato das crianças 
terem iniciado o tratamento em idades precoces e com dosagens consideradas adequadas para prevenir alterações decorrentes da falta dos hormônios tireoideanos no organismo. Portanto, pode-se inferir que mesmo desconhecendo a etiologia do HC, o Laboratório do Teste do Pezinho da APAE-Bauru tem conseguido adequar o programa de tratamento às necessidades individuais das crianças. A ausência de correlação entre a dosagem inicial de levotiroxina e o desempenho de crianças com $\mathrm{HC}$ em tarefas cognitivas foi relatada por ROVET; EHRLICH, ${ }^{99} 1995$ e SALERNO et al. $^{104}$, 1995. Entretanto, SALERNO et al. ${ }^{106}$, 2000, OERBECK et al. ${ }^{83}, 2003$, BONGERS-SCHOKKING; DE MUINCK KEIZER-SCHRAMA ${ }^{13}$, 2005, OERBECK et al. ${ }^{84}, 2005$ e ROVET ${ }^{102}, 2005$, observaram correlação entre a dosagem de levotiroxina e o desempenho das crianças em habilidades cognitivas, motoras e de aprendizagem. As crianças que apresentaram níveis mais elevados de TSH na TN (Tabela 30) receberam dosagem inicial de levotiroxina também mais elevada $(r=0,477)$, ou seja, quanto maior a gravidade do $\mathrm{HC}$, maior a dosagem de levotiroxina no início do tratamento para o $\mathrm{HC}$ (MANRÍQUEZ; NAGEL; VIVANCO ${ }^{74}, 1998$, SALERNO et al. ${ }^{107}, 2001$ ).

O desempenho das crianças de diferentes níveis socioeconômicos (Tabela 31) não se diferenciou significantemente para a Escala ELM $(p=0,788)$ e para o IPO ( $p=0,615)$. O fato de haver apenas uma criança na condição socioeconômica média-inferior pode ter contribuído para essa ausência de associação entre as variáveis. CHIOVATO; BARGAGNA ${ }^{25}$, 1999, afirmaram que o nível socioeconômico pode ser um fator de risco para alterações do desenvolvimento em crianças com HC. BONGERS-SCHOKKING et al. ${ }^{12}, 2000$, ANDROVANDI; NUNES ${ }^{5}$, 2004, BARGANA et al. $^{8}, 2006$, observaram correlação entre o nível socioeconômico e o desempenho de crianças com HC nas habilidades motoras, cognitivas e lingüísticas. Embora não tenham realizado esta associação, FIGUEIREDO; SCHERMANN ${ }^{36}$, 2001, afirmaram que o nível socioeconômico médio pode ter servido como fator preventivo para o não aparecimento de alterações sociais e comportamentais.

O desempenho das crianças do gênero feminino (Tabela 32) não se diferenciou significantemente do desempenho das crianças do gênero 
masculino para a Escala ELM $(p=0,719)$ e para o IPO $(p=1,000)$. HEYERDAHL; KASE; LIE ${ }^{50}$, 1991, observaram que as crianças do gênero masculino apresentaram desempenho em tarefas cognitivas inferior às crianças do gênero feminino. O desempenho das crianças com outros fatores de risco para alterações do desenvolvimento além do $\mathrm{HC}$, não se diferenciou significantemente do desempenho das crianças que não apresentaram outros fatores de risco. Essa associação negativa foi observada tanto para a Escala ELM $(p=1,000)$ e como para o IPO $(p=1,000)$. A literatura não relata a investigação da associação entre estas variáveis.

Não foi observada associação entre as condições hormonais (hormônios controlados ou momentos de descontrole hormonal) durante o tratamento para o $\mathrm{HC}$ (Tabela 33) e o desempenho das crianças na Escala ELM $(p=0,536)$ e no IPO $(p=1,000)$. Níveis de $T_{4}$ Livre e TSH mantidos no intervalo de referência durante $\mathrm{O}$ tratamento para $\mathrm{O} \mathrm{HC}$ favorecem $\mathrm{O}$ desenvolvimento adequado da criança (LAFRANCHI $\left.{ }^{64}, 1999\right)$, entretanto, mesmo com início precoce do tratamento para o $\mathrm{HC}$, é possível observar demora na normalização dos níveis hormonais (ROVET ${ }^{98}$, 1990). A este respeito, SALERNO et al. ${ }^{104}$, 1995, observaram normalização da concentração de TSH após 2 meses de tratamento medicamentoso em apenas 50\% das crianças com HC. HEYERDAHL; KASE; LIE ${ }^{50}$, 1991, verificaram melhor desempenho cognitivo para as crianças que apresentaram melhor controle dos níveis hormonais durante o tratamento com levotiroxina.

A concordância (Tabela 34) entre o desempenho das crianças na EPBD e nos procedimentos de avaliação deste estudo foi mediana (Escala ELM - kappa= 0,224; e IPO - kappa=0,340). Este grau de concordância pode ser justificado pelo fato das crianças identificadas com desempenho alterado para a Escala ELM e IPO e não para a EPBD, terem apresentado atraso de pouco meses, de acordo com a idade cronológica, no desempenho das habilidades avaliadas. As 2 crianças que apresentaram desempenho alterado na EPBD também apresentaram desempenho alterado nos procedimentos aplicados neste estudo, entretanto, seus desempenhos foram inferiores aos 
desempenhos apresentados pelas crianças não identificadas pela EPBD, principalmente no que diz respeito às habilidades de linguagem.

Observou-se concordância leve entre o julgamento dos responsáveis pelas crianças quanto ao desenvolvimento comunicativo (Tabela 35) e o desempenho obtido para a Escala $\operatorname{ELM}(p=0,174)$. A concordância entre $o$ julgamento dos responsáveis quanto ao desenvolvimento comunicativo das crianças e desempenho obtido para a área de linguagem do IPO $(p=0,273)$ foi mediana. Com este resultado, foi constatada a dificuldade dos familiares em identificar alterações no processo de desenvolvimento da linguagem destas crianças. A este respeito, WETHERBY; YONCLAS; BRYAN ${ }^{122}$, 1989, consideraram que atrasos da linguagem podem ser identificados apenas quando as crianças estão em idade escolar e seu desempenho lingüístico é mais cobrado. Justifica-se então, o fato das crianças com desempenho alterado para as habilidades lingüísticas serem consideradas boas comunicadoras pelos familiares. A idade das crianças avaliadas representou fator importante nesta análise, pois as crianças foram consideradas "pequenas" pelos familiares, o que reduziu a expectativa quanto ao desempenho das habilidades comunicativas. O conceito dos familiares de que as crianças apresentavam "problemas" como o HC, também contribuiu para a baixa expectativa quanto ao desempenho comunicativo, pois conforme afirmaram FIGUEIREDO; SCHERMANN ${ }^{36}, 2001$, as reações familiares frente à doença interferem nas interações e expectativas quanto ao futuro do filho.

\section{Considerações Finais}

Considerando a cobertura do PTN do Laboratório do Teste do Pezinho da APAE Bauru (98,66\% em 2005 - Figura 1), pode-se inferir que este programa tem cumprido tanto a Lei Federal $n^{\circ}$. 8069/90, que regulamenta a obrigatoriedade da TN para todos RNs, quanto as normas estabelecidas pelo PNTN (BRASIL. MINISTÉRIO DA SAÚDE ${ }^{18}$, 2002) que visam à identificação de alterações metabólicas e a prevenção de seqüelas no desenvolvimento infantil. 
Os resultados obtidos sugerem que o Laboratório do Teste do Pezinho da APAE-Bauru, mesmo não realizando o estudo etiológico do $\mathrm{HC}$ das crianças diagnosticadas, tem estabelecido programas individuais de tratamento e acompanhamento eficazes na prevenção das seqüelas previstas nesta alteração metabólica.

Neste estudo observou-se que a minoria das crianças avaliadas apresentou desempenho alterado nas habilidades do desenvolvimento. Mesmo com resultados otimistas, ressalta-se a importância do acompanhamento longitudinal destas crianças, uma vez que a literatura relata alterações em habilidades específicas de indivíduos em idade escolar (KOOISTRA et al. ${ }^{63}$, 1996, ROVET; ALVAREZ ${ }^{100}$, 1996, ROVET ${ }^{101}$, 1999, BARGAGNA et al. ${ }^{7}, 2000$, OERBECK et al. ${ }^{83}, 2003$, SIMONS et al. ${ }^{109}$, 2004, TORRES et al. ${ }^{114}, 2004$, DLUHOLUCKY; HOMOVA; LUKAC ${ }^{33}, 2006$, KEMPERS et al. ${ }^{56}, 2006$ ).

As alterações nas habilidades de linguagem observadas neste estudo e concordantes com a literatura (GLEISNER et al. ${ }^{42}$, 1986, ROVET; EHRLICH; SORBARA ${ }^{97}$, 1987, GOTTSCHALK; RICHMAN; LEWANDOWSKI ${ }^{44}$, 1994, KOOISTRA et al. $^{62}$, 1994, ROVET; EHRLICH ${ }^{99}$, 1995, ROVET; ALZAREZ ${ }^{100}, 1996$, ROVET $^{101}, 1999$, BARGAGNA et al. ${ }^{7}, 2000$, OERBECK et al. $^{83}, 2003$, BARGAGNA et al. $\left.{ }^{8}, 2006\right)$ mostram que as crianças com HC são de risco para alterações no desenvolvimento lingüístico e, portanto, necessitam do acompanhamento longitudinal do desenvolvimento comunicativo (BARGAGNA et al. ${ }^{7}$, 2000). Considerando os padrões de normalidade para 0 desenvolvimento da linguagem (COPLAN ${ }^{28}, 1985$, COPLAN $^{29}, 1993$, ZORZI $^{127}$, 1994, BORNSTEIN et al. ${ }^{15}, 1999$, ZORZI $\left.^{128}, 2002\right)$, crianças com alterações no desenvolvimento desta habilidade podem ser identificadas precocemente e acompanhadas por meio de procedimentos de estimulação (PIOVESANA ${ }^{89}$, 2001, HAHNE; ECKSTEIN; FRIEDERIC ${ }^{46}$, 2004).

Diante do exposto, os achados deste estudo sugerem a necessidade da inserção do fonoaudiólogo na equipe de profissionais dos PTNs que realizam o acompanhamento longitudinal do desenvolvimento de indivíduos diagnosticados com $\mathrm{HC}$. 



\section{8 - CONCLUSÃO}

A maioria das crianças avaliadas neste estudo apresentou desempenho adequado para as habilidades motoras, cognitivas, lingüísticas, sociais e de autocuidados. Paras as crianças com desempenho alterado nas habilidades do desenvolvimento, observou-se maior déficit nas habilidades de linguagem, principalmente no que diz respeito aos aspectos expressivos e, nas habilidades cognitivas. Não ficou comprovada a influência dos dados da história clínica no perfil traçado para as habilidades do desenvolvimento das crianças com HC deste estudo. Entretanto, observou-se tendência para desempenho adequado nas habilidades avaliadas entre as crianças que realizaram a $\mathrm{TN}$, receberam o diagnóstico e iniciaram o tratamento para o $\mathrm{HC}$ mais precocemente e que receberam dosagem de levotiroxina mais elevada no início do tratamento medicamentoso do HC. 

ANEXOS 



\title{
ANEXO 1: Termo de Consentimento Livre e Esclarecido
}

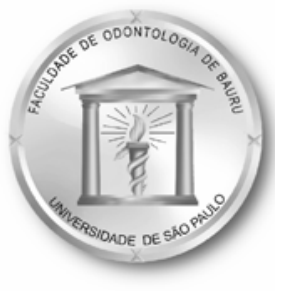

\author{
Universidade de São Paulo \\ Faculdade de Odontologia de Bauru
}

Al. Dr. Octávio Pinheiro Brisolla, 9-75 - Bauru-SP - CEP 17012-901 - C.P. 73

PABX (0XX14)3235-8000 - FAX (0XX14)3223-4679

\section{TERMO DE CONSENTIMENTO LIVRE E ESCLARECIDO}

Pelo presente instrumento que atende às exigências legais, o Sr. (a)

portador da cédula de identidade , após leitura minuciosa

da CARTA DE INFORMAÇÃO AO SUJEITO DA PESQUISA, devidamente explicada pelos profissionais em seus mínimos detalhes, ciente dos serviços e procedimentos aos quais será submetido, não restando quaisquer dúvidas a respeito do lido e explicado, firma seu CONSENTIMENTO LIVRE E ESCLARECIDO concordando em participar da pesquisa proposta.

Fica claro que o sujeito da pesquisa ou seu representante legal pode a qualquer momento retirar seu CONSENTIMENTO LIVRE E ESCLARECIDO e deixar de participar desta pesquisa e ciente de que todas as informações prestadas tornaram-se confidenciais e guardadas por força de sigilo profissional (Art. $9^{\circ}$ do Código de Ética Odontológica ou Art. $29^{\circ}$ do Código de Ética do Fonoaudiólogo).

Por estarem de acordo assinam o presente termo.

Bauru-SP de de 200 . 


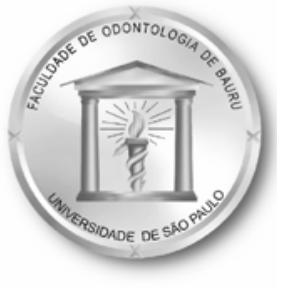

\author{
Universidade de São Paulo \\ Faculdade de Odontologia de Bauru
}

Al. Dr. Octávio Pinheiro Brisolla, 9-75 - Bauru-SP - CEP 17012-901 - C.P. 73

PABX (0XX14)3235-8000 - FAX (0XX14)3223-4679

\title{
Carta de Informação ao Sujeito da Pesquisa
}

O estudo chamando "Habilidades do desenvolvimento em crianças com hipotireoidismo congênito: enfoque na comunicação" é importante porque a deficiência do hormônio da tireóide, no bebê mesmo na gravidez, pode resultar em atraso no desenvolvimento físico e mental da criança. Diante disso, queremos caracterizar as condições de desenvolvimento da comunicação das crianças com Hipotireoidismo Congênito. Para isso, será realizada entrevista com os pais ou responsáveis pelos pacientes e aplicação de testes que verifiquem o desenvolvimento do paciente, como a Escala de Aquisições Iniciais de Linguagem (Escala ELM), e o Inventário Portage Operacionalizado.

Garantimos que o paciente não passará por desconforto ou correrá risco durante a realização das avaliações, e se benificiará com a obtenção de diagnóstico definido, informações sobre os aspectos avaliados e sobre expectativas do desenvolvimento comunicativo, orientações para as instituições que atendem tais pacientes, e encaminhamentos necessários. Garantimos ainda, seu direito de receber respostas a qualquer pergunta ou esclarecimento a qualquer dúvida sobre os procedimentos, riscos, benefícios e outros assuntos relacionados com a pesquisa, e informações atualizadas sobre 0 hipotireoidismo congênito.

Você tem a total liberdade de retirar seu consentimento a qualquer momento e deixar de participar do estudo. Os dados de identificação pessoal da criança, como nome, cidade, nome dos pais, não serão divulgados.

Caso o sujeito da pesquisa queira apresentar reclamações em relação a sua participação na pesquisa, poderá entrar em contato com o Comitê de Ética em Pesquisa em Seres Humanos, da FOB-USP, pelo endereço da Al. Dr. Octávio Pinheiro Brisolla, 9-75 (sala no prédio da Biblioteca, FOB/USP) ou pelo telefone (14)3235-8356.

Para esclarecimento de possíveis dúvidas, os responsáveis pelo paciente poderão entrar em contato com a pesquisadora Mariana Germano Gejão na Clínica de Fonoaudiologia da Faculdade de Odontologia de Bauru USP, pelo telefone (14) 3235-8460. 
ANEXO 2: Escala ELM - "Early Language Milestone Scale"

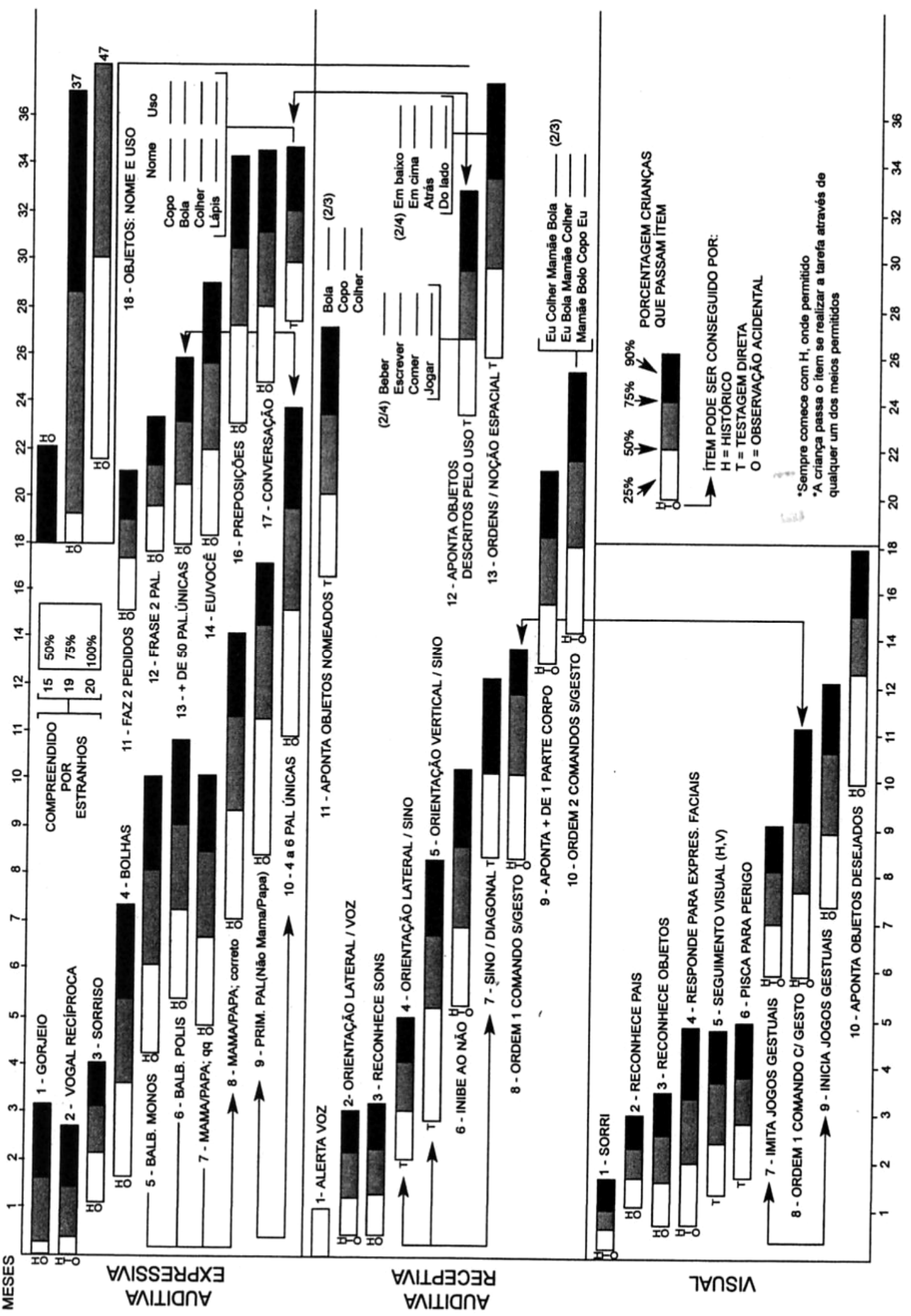


ANEXO 3: Inventário Portage Operacionalizado (IPO)

Nome:

Aplicador
Data de nascimento:

Data de aplicação:

\section{Estimulação Infantil}

\begin{tabular}{|c|c|c|c|c|}
\hline 1 & 10 & 19 & 28 & 37 \\
\hline 2 & 11 & 20 & 29 & 38 \\
\hline 3 & 12 & 21 & 30 & 39 \\
\hline 4 & 13 & 22 & 31 & 40 \\
\hline 5 & 14 & 23 & 32 & 41 \\
\hline 6 & 15 & 24 & 33 & 42 \\
\hline 7 & 16 & 25 & 34 & 43 \\
\hline 8 & 17 & 26 & 35 & 44 \\
\hline 9 & 18 & 27 & 36 & 45 \\
\hline
\end{tabular}

Desenvolvimento Motor

Faixa etária

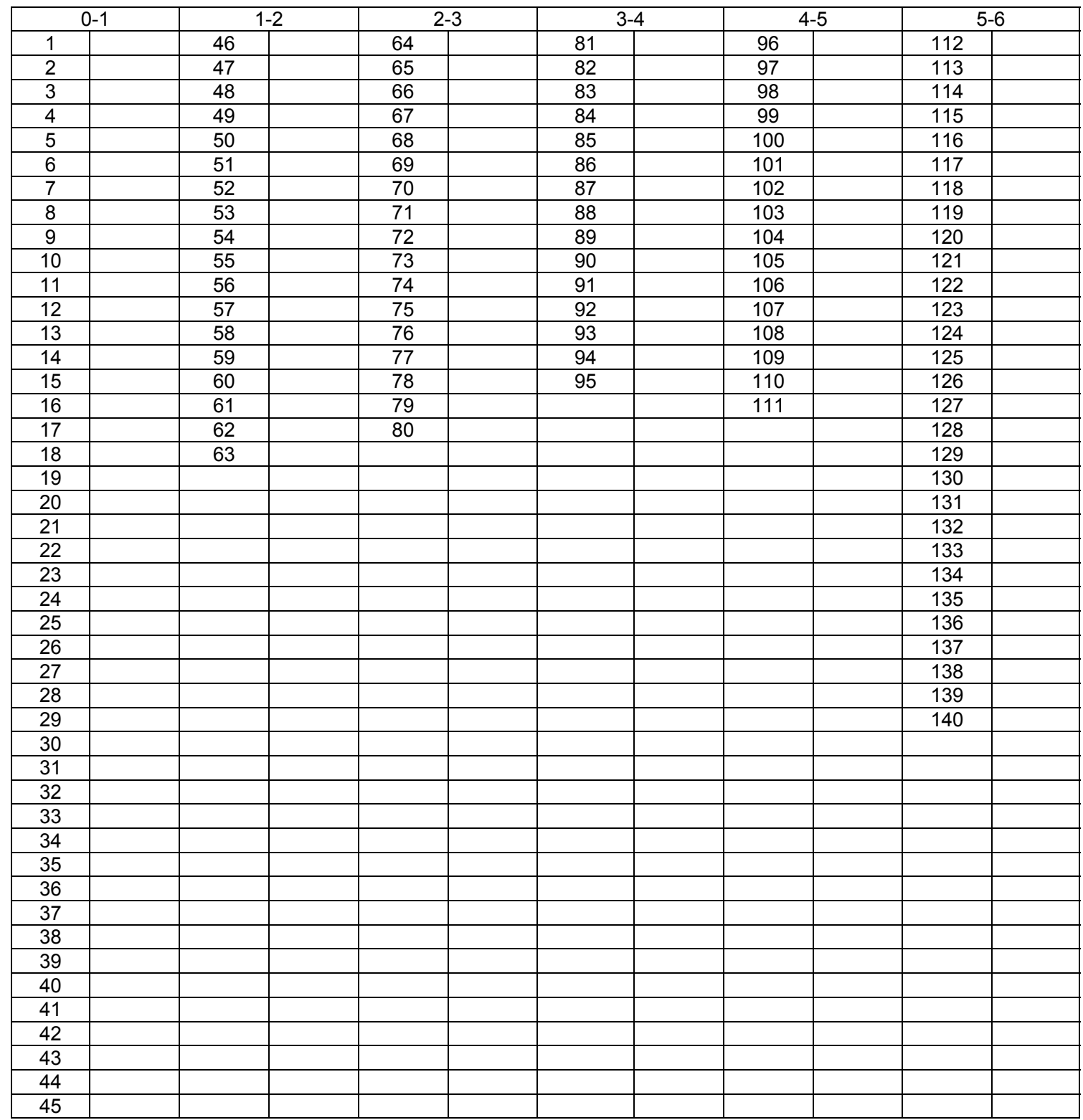


ANEXO

\section{Linguagem}

Faixa etária

\begin{tabular}{|c|c|c|c|c|c|c|}
\hline $0-1$ & $1-2$ & $2-3$ & $3-4$ & $4-5$ & \multicolumn{2}{|c|}{$5-6$} \\
\hline 1 & 11 & 29 & 59 & 71 & 86 & \\
\hline 2 & 12 & 30 & 60 & 72 & 87 & \\
\hline 3 & 13 & 31 & 61 & 73 & 88 & \\
\hline 4 & 14 & 32 & 62 & 74 & 89 & \\
\hline 5 & 15 & 33 & 63 & 75 & 90 & \\
\hline 6 & 16 & 34 & 64 & 76 & 91 & \\
\hline 7 & 17 & 35 & 65 & 77 & 92 & \\
\hline 8 & 18 & 36 & 66 & 78 & 93 & \\
\hline 9 & 19 & 37 & 67 & 79 & 94 & \\
\hline 10 & 20 & 38 & 68 & 80 & 95 & \\
\hline & 21 & 39 & 69 & 81 & 96 & \\
\hline & 22 & 40 & 70 & 82 & 97 & \\
\hline & 23 & 41 & & 83 & 98 & \\
\hline & 24 & 42 & & 84 & 99 & \\
\hline & 25 & 43 & & 85 & & \\
\hline & 26 & 44 & & & & \\
\hline & 27 & 45 & & & & \\
\hline & 28 & 46 & & & & \\
\hline & & 47 & & & & \\
\hline & & 48 & & & & \\
\hline & & 49 & & & & \\
\hline & & 50 & & & & \\
\hline & & 51 & & & & \\
\hline & & 52 & & & & \\
\hline & & 53 & & & & \\
\hline & & 54 & & & & \\
\hline & & 55 & & & & \\
\hline & & 56 & & & & \\
\hline & & 57 & & & & \\
\hline & & 58 & & & & \\
\hline
\end{tabular}

Socialização

Faixa etária

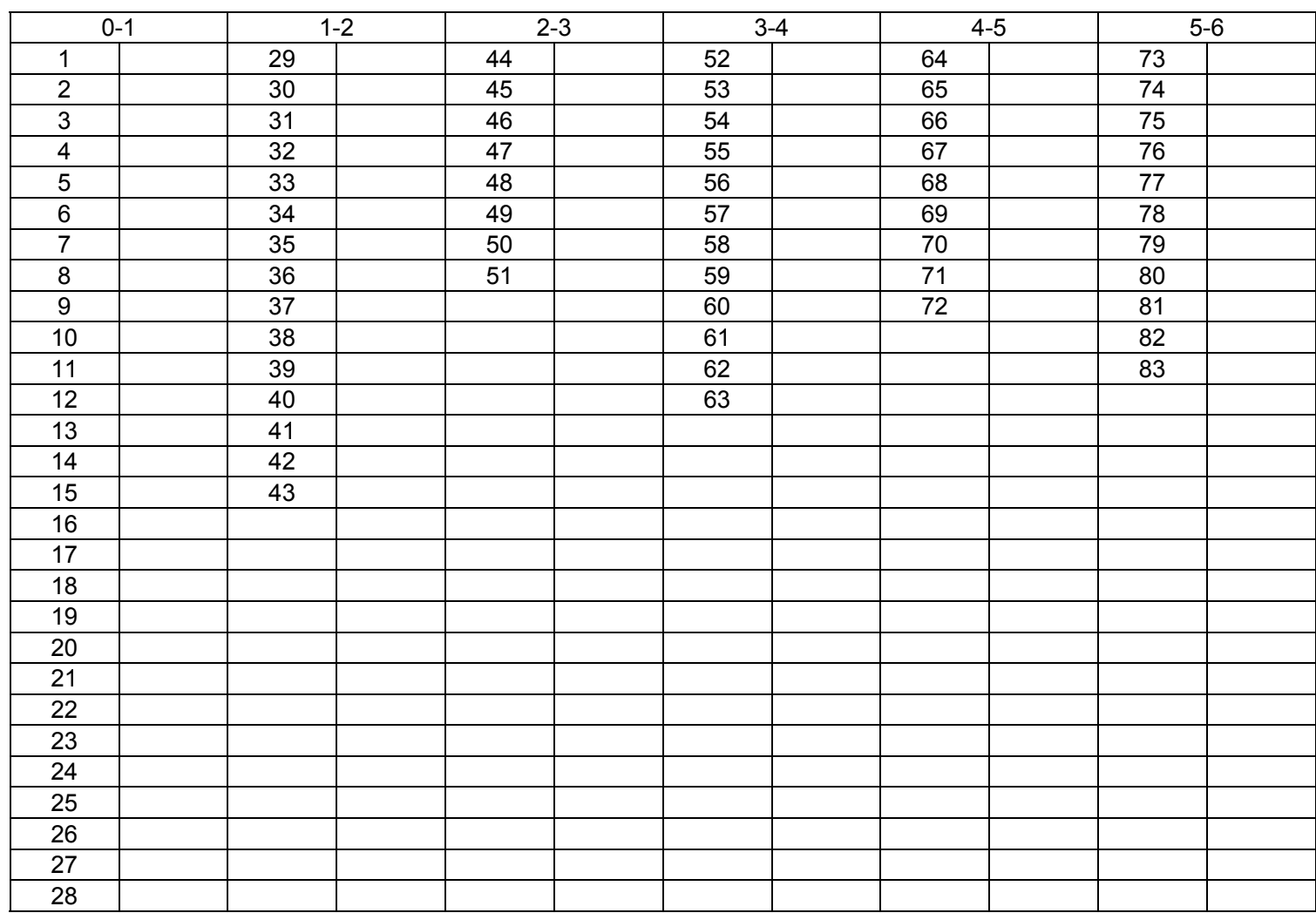


ANEXO

\section{Autocuidados}

Faixa etária

\begin{tabular}{|c|c|c|c|c|c|c|}
\hline $0-1$ & $1-2$ & $2-3$ & $3-4$ & $4-5$ & \multicolumn{2}{|c|}{$5-6$} \\
\hline 1 & 11 & 26 & 53 & 68 & 91 & \\
\hline 2 & 12 & 27 & 54 & 69 & 92 & \\
\hline 3 & 13 & 28 & 55 & 70 & 93 & \\
\hline 4 & 14 & 29 & 56 & 71 & 94 & \\
\hline 5 & 15 & 30 & 57 & 72 & 95 & \\
\hline 6 & 16 & 31 & 58 & 73 & 96 & \\
\hline 7 & 17 & 32 & 59 & 74 & 97 & \\
\hline 8 & 18 & 33 & 60 & 75 & 98 & \\
\hline 9 & 19 & 34 & 61 & 76 & 99 & \\
\hline 10 & 20 & 35 & 62 & 77 & 10 & \\
\hline 11 & 21 & 36 & 63 & 78 & 101 & \\
\hline 12 & 22 & 37 & 64 & 79 & 102 & \\
\hline 13 & 23 & 38 & 65 & 80 & 103 & \\
\hline & 24 & 39 & 66 & 81 & 104 & \\
\hline & 25 & 40 & 67 & 82 & 105 & \\
\hline & & 41 & & 83 & & \\
\hline & & 42 & & 84 & & \\
\hline & & 43 & & 85 & & \\
\hline & & 44 & & 86 & & \\
\hline & & 45 & & 87 & & \\
\hline & & 46 & & 88 & & \\
\hline & & 47 & & 89 & & \\
\hline & & 48 & & 90 & & \\
\hline & & 49 & & & & \\
\hline & & 50 & & & & \\
\hline & & 51 & & & & \\
\hline & & 52 & & & & \\
\hline
\end{tabular}

Cognição

Faixa etária

\begin{tabular}{|c|c|c|c|c|c|c|}
\hline $0-1$ & $1-2$ & $2-3$ & $3-4$ & $4-5$ & \multicolumn{2}{|c|}{$5-6$} \\
\hline 1 & 15 & 25 & 41 & 65 & 87 & \\
\hline 2 & 16 & 26 & 42 & 66 & 88 & \\
\hline 3 & 17 & 27 & 43 & 67 & 89 & \\
\hline 4 & 18 & 28 & 44 & 68 & 90 & \\
\hline 5 & 19 & 29 & 45 & 69 & 91 & \\
\hline 6 & 20 & 30 & 46 & 70 & 92 & \\
\hline 7 & 21 & 31 & 47 & 71 & 93 & \\
\hline 8 & 22 & 32 & 48 & 72 & 94 & \\
\hline 9 & 23 & 33 & 49 & 73 & 95 & \\
\hline 10 & 24 & 34 & 50 & 74 & 96 & \\
\hline 11 & & 35 & 51 & 75 & 97 & \\
\hline 12 & & 36 & 52 & 76 & 98 & \\
\hline 13 & & 37 & 53 & 77 & 99 & \\
\hline 14 & & 38 & 54 & 78 & 100 & \\
\hline & & 39 & 55 & 79 & 101 & \\
\hline & & 40 & 56 & 80 & 102 & \\
\hline & & & 57 & 81 & 103 & \\
\hline & & & 58 & 82 & 104 & \\
\hline & & & 59 & 83 & 105 & \\
\hline & & & 60 & 84 & 106 & \\
\hline & & & 61 & 85 & 107 & \\
\hline & & & 62 & 86 & 108 & \\
\hline & & & 63 & & & \\
\hline & & & 64 & & & \\
\hline
\end{tabular}




\section{Anexo 4: Pontuação do Inventário Portage Operacionalizado}

$\mathrm{Na}$ área denominada "estimulação infantil", avaliada em crianças com até quatro meses de idade, a criança deve realizar 11,25 itens por mês. 0 número de itens que a criança deve realizar por mês nas demais áreas do desenvolvimento encontra-se na Figura 2.

\begin{tabular}{|cccccc|}
\hline Faixa & \multicolumn{5}{c|}{$\mathrm{n}$ de itens realizados por mês } \\
etária & \multicolumn{5}{c|}{} \\
\cline { 2 - 6 } (anos) & Motor & Linguagem & Cognição & Socialização & Autocuidados \\
\hline $0-1$ & 3,75 & 0,83 & 1,16 & 2,33 & 1,08 \\
$1-2$ & 1,5 & 1,5 & 0,83 & 1,25 & 1,00 \\
$2-3$ & 1,41 & 2,5 & 1,33 & 0,66 & 2,25 \\
\hline
\end{tabular}

FIGURA 2 - Número de itens do IPO a serem realizados por mês em cada área de avaliação de acordo com a faixa etária 


\title{
Anexo 5: Ficha de Dados Gerais
}

\author{
Universidade de São Paulo \\ Faculdade de Odontologia de Bauru \\ Mestrado em Fonoaudiologia
}

Ficha de Dados Gerais

Dados Pessoais:

Nome:

D.N.: $1 / 1$ Escolaridade:

Pai:

Escolaridade:

Ocupação:

Escolaridade:

Mãe:

Ocupação: $\mathrm{N}^{\circ}$ :

Rua:

Bairro:

Cidade:

$\mathrm{N}^{\mathrm{O}}:$

Telefone:

Falar com:

Composição familiar:

Queixa:

\section{Gravidez}

Idade mãe:

Idade pai:

Mãe tinha boa saúde ( ) sim ( ) não

HC ou adquirido materno ( ) sim ( ) não Tratamento:

Pré-natal ( ) sim ( ) não A partir do mês:

\section{Nascimento}

Tipo de nascimento: ( ) a termo ( ) prematuro Quantos meses?

Motivo:

Tipo de parto: ( ) natural ( ) cesariana Nascimento individual ( ) $\operatorname{sim}($ ) não

Peso: Comprimento: Perímetro cefálico: Apgar:

Problemas de saúde no nascimento ( ) sim ( ) não
( ) choro fraco ao nascer
( ) batimentos cardíacos alterados
( ) incubadora
( )mole e inativo
( ) transfusão de sangue
( ) icterícia
( ) problema respiratório
( ) defeito congênito
( ) fezes no líquido amniótico
( ) bebê azul
Outros:

Pediatra suspeitou de HC ( ) sim ( )não

Realizou a triagem neonatal? ( ) sim ( ) não Onde Idade na TN:

Diagnóstico etiológico ( ) sim ( ) não Idade no diagnóstico:

Idade no início do tratamento:

Nível de TSH na TN: Dose inicial:

\section{Primeira Infância}

Problemas de saúde na primeira infância ( ) sim ( ) não
( ) dificuldades respiratórias
( ) sucção fraca
( ) dificuldade para mamar
( ) hipotonia
( ) choro rouco
( ) problemas intestinais
( ) hérnia umbilical
( ) hipotermia
( ) dificuldade em aumentar o peso
( ) icterícia prolongada
( ) macroglossia
( ) problemas cardíacos
( ) sonolência
( ) edema
( ) pele pálida e descamativa
( ) convulsões
( ) frontanelas amplas
( ) vômito projétil

Reações de susto ou espanto com estímulos auditivos ou visuais ( ) sim ( ) não 
Criança afetuosa ( ) sim ( ) não Sorria para pessoas da família ( ) sim ( ) não

Movimentos repetitivos ( ) sim ( ) não Maneirismos ( ) sim ( ) não

Dificuldades para imita ( ) sim ( ) não

Foi amamentado no peito ( ) sim ( ) não Idade do desmame:

Crescimento físico ( ) sim ( ) não

\section{Estágios de Desenvolvimento}

Chorava de modo diferente quando tinha fome ou dor ( ) sim ( ) não

Reconhecia a mãe ou cuidador ( ) sim ( ) não Respondia a sons ( ) sim ( ) não Idades dos desenvolvimentos:

Equilíbrio de pescoço:

Sentar com apoio:

Sentar sem apoio:

Engatinhar: Ficar em pé:

Primeiros Passos:

Anda nas pontas dos pés ( ) sim ( ) não

Transfere o peso de um lado à outro ( ) sim ( ) não

Cai com freqüência ( ) sim ( ) não

Primeiras palavras:

Gestos significativos ( ) sim ( ) não

Desenvolvimento da comunicação ( ) adequado ( ) alterado

Exposição a mais línguas ( ) sim ( ) não

Como chama a atenção das pessoas

Apresenta dificuldades para perceber perigos reais ( ) sim ( ) não

Reage a mudança na rotina ( ) sim ( ) não

Problemas de comportamento ( ) sim ( ) não

Queixas da audição da criança ( ) sim ( ) não

Avaliação anterior ( ) sim ( ) não Idade:

Resultado:

Otites de repetição ( ) sim ( ) não

Queixas visuais ( ) sim ( ) não

Avaliação anterior ( ) sim ( ) não Idade:

Resultado:

Controle de esfíncteres diurno ( ) sim ( ) não Idade que completou:

Controle de esfíncteres noturno ( ) sim ( ) não Idade que completou:

Dificuldades para se alimentar ( ) sim ( ) não

Come nas consistências: ( ) pastosa ( ) líquida

Dificuldades para aceitar mudança no cardápio? ( ) sim ( ) não

Veste-se sozinha ( ) sim ( ) não ( ) com ajuda
Problemas com:
( ) equilíbrio
( ) andar
( ) cortar com tesoura
( ) segurar talher
Dominância manual: ( ) destra ( ) canhota ( ) ambidestra
( ) correr
( ) segurar lápis

Hábitos parafuncionais ( ) sim ( ) não

Faz amigos ( ) sim ( ) não ( ) da mesma idade ( ) mais jovens ( ) mais velhos

Qualidade do sono ( ) adequada ( ) alterada

Freqüenta instituição de ensino ( ) sim ( ) não

Queixas escolares ( ) sim ( ) não

Reprovou de ano ( ) sim ( ) não

\section{Informações Médicas}

Problemas de saúde ( ) sim ( ) não

É alérgica a algum medicamento ( ) sim ( ) não

Acidente significativo ( ) sim ( ) não

Internações ( ) sim ( ) não 


\section{Anexo 6: Análise do Resultado da Estatística kappa}

\begin{tabular}{|lll|}
\hline Valor de kappa & $\begin{array}{l}\text { Strength of } \\
\text { Agreement }\end{array}$ & $\begin{array}{c}\text { Nível de } \\
\text { concordância }\end{array}$ \\
$0,0,00$ & poor & pobre \\
$0,00-0,20$ & slight & leve \\
$0,21-0,40$ & fair & mediano \\
$0,41-0,60$ & moderate & moderado \\
$0,61-0,80$ & substantial & significante \\
$0,81-1,00$ & almost perfect & quase perfeito \\
\hline
\end{tabular}

FIGURA 3 - Proposta de LANDIS e $\mathrm{KOCH}^{66}$, 1977, para a análise dos resultados da Estatística kappa 
REFERÊNCIAS 



\section{REFERÊNCIAS}

1. Abrams GM, Zimmerman EA. Doenças sistêmicas e medicina geral. In.: Rowland, L. Merritt Tratado de Neurologia. 9th ed. Ganabara Koogan S.A., 1997. p. 698-712.

2. Alegría A, Pittaluga E, Mena P, Schlack L, Dias MM, Vergara SD, et al. Evolución neurosensorial en recién nacido de muy bajo peso de nacimiento a los 2 años de edad corregida. Rev Chil Pediatr. 2002;37(4):348-56.

3. Almache ON. Hipotiroidismo congénito. Paediatr. 2003;5(2):93-9.

4. Almeida AM, Godinho TM, Teles MS, Rehem APP, Jalil HM, Fukuda TG, et al. Avaliação do programa de triagem neonatal na Bahia no ano de 2003. Rev Bras Saúde Matern Infant. 2006;6(1):85-91.

5. Androvandi C, Nunes MLT. Avaliação intelectual de escolares com hipotireoidismo congêntio. Aletheia. 2004(20):55-64.

6. Arason R, Ehrlich RM, Bailey D, Rovet JF. Growth in children with congenital hypothyroidism detected by neonatal screening. J Pediatr. 1990;116(1):33-7.

7. Bargagna S, Canepa G, Costagli C, Dinetti D, Marcheschi M, Millepiedi $S$, et al. Neuropsychological follow-up in early-treated congenital hypothyroism: a problem-oriented approach. Thyroid. 2000;10(3):243-9.

8. Bargagna S, Astrea G, Perelli V, Rafanelii V. Neurophychiatric outcome in patients with congenital hypothyroidism precautiously treated: risk factors analysis in a grup of patients from Tuscany. Minerva Pediatr. 2006;58(3):279-87.

9. Barros-Filho AA. Crescimento e desenvolvimento. In: Moura-Ribeiro MUL, Gonçalves VMG. Neurologia do desenvolvimento da criança. Rio de Janeiro: Revinter; 2006, p. 162-81.

10. Bazán MC, Pasteri S L., Chail A Z. Hipotiroidismo congenito y desarrollo mental. Cienc Méd (San Miguel de Tucuman). 1990; 5(6):189-96.

11. Bernal J, Nunes J. Thyroid hormones and brain development. Eur J Endocrinol. 1995;133:390-8.

12. Bongers-Schokking JJ, Koot HM, Wiersma D, Vernek PH, de Muinck Keizer-Schrama SMPF. Influence of timing and dose of thyroid hormone replacement on development in infants with congenital hypothyroidism. J Pediatr. 2000;136(3):292-297.

13. Bongers-Schokking JJ, de Muinck Keizer-Schrama SM. Influence of timing and dose of thyroid hormone replacement on mental, psycomotor, and behavioral development in children with congenital hypothyroidism. J 
Pediatr. 2005;147(6):768-74.

14. Borges IV, Salomão NMR. Aquisição da linguagem: considerações da perspectiva da interação social. Psicol Ref Crít. 2003;16(2):327-36.

15. Bornstein $\mathrm{MH}$, Haynes OM, Pacaual KN, Galperin CZ. Play in two societies: pervasiveness of process, specificity of structure. Child Dev. 1999;70(2):317-31.

16. Botler J. Repercussões neurológicas do hipotireoidismo congênito. Arq Bras Endocrinol Metab. 1996;40(4):264-70.

17. Bragatti-Winckler MI, Rotta NT. Hormônios tireóideos na sintomatologia de doenças neuropsiquiátricas. Arq Neuropsiquiatr. 1994;52(3):427-30.

18. Brasil. Ministério da Saúde. Manual de normas técnicas e rotinas operacionais do programa nacional de triagem neonatal. Brasília: Ministério da Saúde; 2002. [Acesso em 25 de jul de 2006]. Disponível em URL: http:/www.saude.gov.br/sas

19. Brasil. Ministério da Educação. Política Nacional de Educação Infantil: pelo direito das crianças de zero a seis anos à educação. Brasília : MEC/SEB, 2006. 32 p. [Acesso em 21 de out de 2006]. Disponível em URL:

http:/www.portal.mec.gov.br/seb/arquivos/pdf/Educinf/eduinfpolit2006.pdf

20. Calvo RM, Jauniaux E, Gulbis B, Asunción M, Gervy C, Contempré B, et al. Fetal tissues are exposed to biologically relevant free thyroxine concentrations during early phases of development. J Clin Endocrinol Metab. 2002;87(4):1768-77.

21. Campos SP, Sandberg DE, Barrick C, Voorhess ML, MacGillivray MH. Outcome of lower I-thyroxine dose for treatment of congenital hypothyroidism. Clin Pediatr. 1995;34(10):14-20.

22. Campos MV, Campos B. Disfunção tireoidiana no recém-nascido. Acta Med Port. 2003;16:348-50.

23. Carroll AE, Downs SM. Comprehensive cost-utility analysis of newborn screening strategies. Pediatrics. 2006;117(5):S287-94.

24. Castaño J. Bases neurobiológicas del lenguaje y sus alteraciones. Rev Neurol. 2003;36(8):781-5.

25. Chiovato L, Bargagna S. Congenital hypothyroidism: treated chidren but dont't forget their parents. Eur J Endocrinol. 1999;141:101-4.

26. Clark EV. How language acquisition build on cognitive development. Trends Cogn Sci. 2004;8(10):472-8.

27. Coplan J, Gleason JR, Ryan R, Burke MG, Williams ML. Validation of an early language milestone scale in a high-risk population. Pediatr. 
1982;70:81-94.

28. Coplan, J. Evaluation of the child delayed speech or language. Pediatr Ann. 1985;14:203-8.

29. Coplan J. Early language milestone scale. 2nd ed. Texas: Pro-ed; 1993.

30. Corrêa AL, Breda DJ, Pereira GM, Schotkis MV, Feijó RB. Hipotireoidismo congênito: relato de caso. Rev Pesq Med. 1994;28(1):33-7.

31. Delange F. lodine deficiency as a cause of brain damage. Postgrad Med J. 2001;77:217-20.

32. Diament A. Deficiência mental. In: Diament A, Cyper S. Neurologia Infantil. 3rd ed. São Paulo: Editora Atheneu, 1996. p. 779-814.

33. Dluholucky S, Homova V, Lukac P. Congenital hypothyroidism in one of monozygotic twins: comparations of their long-term psychosomatic development. Neuro Endocrinol Lett. 2006;27(1-2):203-8.

34. DSM.IV. Diagnostic and statistical manual of mental disorders. [Acesso em: 24 out. 2006]. Disponível em URL: http://www.virtualpsy.locaweb.com.br/dsm

35. Falen J. Hipotireoidismo neonatal. Diagnostico (Peru). 1992;30(3-6):6171.

36. Figueiredo CKB, Schermann L. Interação mãe-criança e problemas de comportamento infantil em crianças com hipotireoidismo congênito. Psicol Reflex Crit. 2001;14(3):487-95.

37. França SN, Sandrini R. Rastreamento neonatal do hipotireoidismo congênito. Arq Bras Endocrinol Metab. 1997;41(1):III-IV.

38. Françóis $M$, Bonfils $P$, Leger $J$, Czernichow $P$, Narcy $P$. Role of congenital hypothyroisism in hearing loss in children. $\mathrm{J}$ Pediatr. 1994;124(3):444-6.

39. Fuggle PW, Grant DB, Smith I, Murphy G. Intelligence, motor skills and behaviour at 5 years in early-treated congenital hypothyroidism. Eur $\mathrm{J}$ Pediatr. 1991;150:570-4.

40. Geelhoed EA, Lewis B, Hounsome D, O'Leary P. Ecomonic evaluation of neonatal screeinig for phenylketonúria and congenital hypothyroidism. J Paediatr Child Health. 2005;41:575-9.

41. Ghazi AM, Ordookhani A, Pourafkari M, Fallahian M, Bahar A, Hedayati $M$, et al. Intrauterine diagnosis and management of fetal goitrous hypothyroidism: a report of an iranian family with three consecutive pregnancies complicated by fetal goiter. Thyroid. 2005;15(12):1341-7. 
42. Gleisner AA, Torres CB, Wilhelm VP, Asenjo SM, Adriazola AM, Cafati IK, et al. Hipotiroidismo congênito: evaluación neurológica y sincométrica. Rev Chil Pediatr. 1986;57(6):524-7.

43. Glorieux J, Dussault J, Van Vliet G. Intellectual developmente at age 12 years of children with congenital hypothyroidism diagnosed by neonatal screening. J Pediatr. 1992;121(4);581-4.

44. Gottschalk B, Richman RA, Lewandowski L. Subtle speech and motor deficits of children with cogenital hupothyroidism treated early. Dev Med Child Neurol. 1994;36:216-20.

45. Grant DB. Growth in early treated congenital hypothyroidism. Arch Dis Child. 1994;70:464-8.

46. Hahne $A$, Eckstein $\mathrm{K}$, Friederic $A D$. Brain signature and semantic process during children's language development. J Cogn Neurosci. 2004;16(7):1302-18.

47. Hanukoglu A, Perlman K, Shamis I, Brnjac L, Rovet J, Daneman D. Relationship of etiology to treatment in congenital hypothyroidism. J Clin Endocrinol Metab. 2001;86(1):186-91.

48. Hatipoglu N, Kurtoglu S, Keskin M, Kendrici M. An occasional side effect in the treatment of congenital hypothyroidism: hair loss. Eur J Pediatr. 2006;165:500-1.

49. Hepworth SL, Pang, EW, Rovet JF. Word and face recognitions in children with congenital hypothyroidism: an evente-related potencial study. J Clin Exp Neuropsychol. 2006;28(4):509-27.

50. Heyerdahl S, Kase BF, Lie SO. Intelectual developmente in children with congenital hypothyroisidm in relation to recommended thyroxine treatment. J Pediatr. 1991;118(6):850-7.

51. Heyerdahl S, Ilicki A, Karlberg J, Kase BF, Larsson A. Linear growth in early treated children with congenital hypothyroidism. Acta Paediatr. 1997;86(5):479-83.

52. Hindmarsh PC. Optimisation of thyroxine dose in congenital hypothyroidism. Arch Dis Child. 2002;86:73-5.

53. Iglesias T, Caubín J, Stunnenberg HG, Zaballos A, Bernal J, Muñoz A. Thyroid hormone-dependent transcription repression of neural cell adhesion molecule during brain maturation. EMBO J. 1996;15:4307-16.

54. Joint Committee of Infant Hearing - American Academy of Pediatrics. Position Statement. Audiology Today. 1994;6:6-9.

55. Jones JH, Mackenzie J, Croft GA, Beaton S, Young D, Donaldson MD. Improvement in scrrening performance and diagnosis of congenital hypothyroidism in Scotland 1979-2003. Arch Dis Child. 2006;91(8):680- 
5.

56. Kempers MJE, Van der Sluijs Veer L, Nijhuis-Van ser Sander MWG, Kooistra L, Wiedijl BM, Faber I, et al. Intellectual and motor development of young adults with congenital hypothyroidism diagnosed by neonatal screening. J Clin Endocrinol Metab. 2006;91(2):418-24.

57. Kendal L. Social, economic and environmental influences on disorders of hearing, language and speech. J Communic Disord. 2005;38(1):261-2.

58. Klein $\mathrm{AH}$, Meltzer S, Kenny F. Improved prognosis in congenital hypothyroidism treated before age three months. J Pediatr. 1972;81(5):912-7.

59. Klein S K. Evaluation for suspected language disorders in preschool children. Pediatr Clin North Am. 1991;38:1455-67.

60. Knobel M, Nogueira CR, Medeiros-Neto G. Genética Molecular do Hipotireoidismo Congênito. Arq Bras Endocrinol Metab. 2001;45(1):2431.

61. Knoblock H, Passamanick B (Ed). Gesell e Amatruda: psicologia do desenvolvimento do lactente e da criança pequena: bases neuropsicológicas e comportamentais. [Trad de Vera Lúcia Ribeiro]. São Paulo: Editora Ateneu; 2000.

62. Kooistra L, Laane C, Vulsma T, Schellekens JMH, Van der Meere JJ, Kalverboer AF. Motor and cognitive developmente in children with congenital hypothyroidism: a long-term evaluation of the effects of neonatal treatment. J Pediatr. 1994;124(6):903-9.

63. Kooistra L, Van der Meere JJ, Vulsma T, Kalverboer AF. Sustained attention problems in children with early treated congenital hypothyroidism. Acta Paediatr. 1996;85:425-9.

64. LaFranchi S. Congenital hypothyroidism: etiologies, diagnosis, and management. Thyroid. 1999;9(7):732-40.

65. Lamônica DAC. Linguagem na paralisia cerebral. In: Ferreira LP, BefiLopes DM, Limonge SCO. Tratado de Fonoaudiologia. São Paulo: Roca; 2004. p. 967-976.

66. Landis JR, Koch GG. The measurement of observer agreement for categorical data. Biometrics. 1977;33:159-74.

67. Lavado-Autric R, Ausó E, García-Velasco V, Arufe MC, Rey FE, Berbel $P$, et al. Early maternal hypothyroxinemia alters histogenesis and cerebral córtex cytoarchitecture of th progeny. J Clin Invest. 2003;11(7):1073-82.

68. Leirião VHV. Estudo comparativo em crianças com sem fissura labiopalatina através do protocolo de triagem do desenvolvimento de 
linguagem até os 3 anos de idade [Tese]. Bauru (SP): Hospital de Reabilitação de Anomalias Craniofaciais, Universidade de São Paulo; 2003.

69. Leonard JL, Farwell AP. Thyroid hormone-regulated actin polimerization in brain. Thyroid. 1997;7(1):174-51.

70. Lima MCMP. Avaliação de fala de lactentes no período pré-lingüístico: uma proposta para triagem de problemas auditivos [Tese]. Campinas (SP): Faculdade de Ciências Médicas, Universidade Estadual de Campinas; 1997.

71. Ludueña MP, Prada EMG, Sândi KP. Hipotiroidismo congênito: a propósito de um caso. Rev Soc Bol Ped. 2002;41(1):11-4.

72. Mancini MC, Fiúza PM, Rebelo JM, Magalhães LC, Coelho ZAC, Paixão $\mathrm{ML}$, et al. Comparação do desempenho de atividades funcionais em crianças com desenvolvimento normal e paralisia cerebral. Arq Neuropsiquiatr. 2002;60(2-B):446-52.

73. Manglik AK, Chatterjee N, Chosh G. Umbilical cord blood TSH levels in term neonatal: a screening tool for congenital hypothyroidism. Indian Pediatr. 2005;42(17):1029-31.

74. Manríquez MO, Nagel LB, Vivanco XW. Evaluación neurológica em pacientes com hipotiroidismo congênito diagnosticado por rastreo neonatal. Rev Chil Pediatr. 1998;69(2):56-9.

75. Marti S, Alvarez M, Simoneau-Roy J, Leroux S, Van Vilet G, Robaey P. Effects of early high-dose levothyroxine treatment on auditory brain evente-related potentials at school entry in children with congenital hypothyroisdism. Horm Res. 2006;66(5):240-8.

76. Medda E, Olivier A, Stazi MA, Grandolfo ME, Fazzini C, Baserga M, et al. Risk factors for congenital hypothyroidism: results of a population case-control study (1997-2003). Eur J Endocrinol. 2005;153(6):765-73.

77. Meirelles RMR, Maciel RMB, Machado Filho A, Castro AS. Subsídios para a regulamentação das leis que estabelecem a obrigatoriedade do diagnóstico do hipotiroidismo congênito e fenilcetonúria. Arq Bras Endocrinol Metabol. 1991;35(1):12-4.

78. Menabó E, Vieira JGH, Russo EMK, Kunii IS, Miranda WL, Maciel RMB. Determinação da tirotrofina (TSH) em sangue total seco colhido em papel de filtro: desenvolvimento da metodologia e aplicação em programas de detecção precoce de hipotireoidismo congênito. Arq Bras Endocrinol Metabol. 1990;34(2):17-22.

79. Mendes DMLF, Moura MLS. Desenvolvimento da brincadeira e linguagem em bebês de 20 meses. Psicol Teoria Pesq. 2004;20(3):21522. 
80. Nascimento ML, Pires MMS, Nassar SM, Ruhland L. Avaliação do programa de rastreamento neonatal para hipotireoidismo congênito da Secretaria de Saúde do Estado de Santa Catarina. Arq Bras Endocrinol Metab. 2003;47(1):75-81.

81. Nunes J. Effects of thyroid hormones during brain differentiation. Molec Cel Endocr. 1984;37:125-32.

82. Nunes MT. Hormônios tireoidianos: mecanismo de ação e importância biológica. Arq Bras Encodrinol Metab. 2003;47(6):639-43.

83. Oerbeck B, Sunder K, Kase BF, Heyerdahl S. Congenital hypothyroism: influence of disease severity and I-thyroxine treatment on intellectual, motor, and school-associated outcomes in young adults. Pediatrics. 2003;112(4):923-30.

84. Oerbeck B, Sunder K, Kase BF, Heyerdahl S. Congenital hypothyroism: no adverse effects of high dose throxine treatment on adult memory, attention, and behaviour. Arch Dis Child. 2005;90:132-7.

85. Park SM, Chatterjee VKK. Genetics of congenital hypothyroidism. J Med Genet. 2005;42:379-89.

86. Pérez-Ramos AMQ. Estimulação precoce: informações básicas aos pais e aos professores. Projeto especial multinacional de educação. Brasília: MEC/OEA; 1975. p. 10-12.

87. Perissinoto J, Isotani S M. Desenvolvimento da linguagem: programa de acompanhamento de recém-nascidos de risco. In: Hernandez AM. Conhecimentos essenciais para atender bem o neonato. São José dos Campos: Pulso; 2003.

88. Perone D, Teixeira SS, Clara SA, Santos DC, Nogueira CR. Aspectos genéticos do hipotireoidismo congênito. Arq Bras Endocrinol Metab. 2004;48(1):62-9.

89. Piovesana AMSG. Hemiparetic cerebral palsy: etiological risk factors and neuroimaging. Arq Neuropsiquiatr. 2001;59(1):29-34.

90. Pizarro CB, Paskulin GA, Oliveira MC. Hipotireoidismo primário associado à puberdade precoce: um caso com apresentação incomum. Rev AMRIGS. 1994;38(4):312-4.

91. Pniewska-Siark B, Jeziorowska A, Bobeff I, Lewinski A. Analysis of physical and mental development of children with aplasia, hypoplasia and ectopy oth thyroid gland. Endocr Regul. 2006;40(1):7-14.

92. Porterfield SP, Hendrich CE. The role of thyroid hormones in prenatal and neonatal neurological development: current perspectives. Endocr Rev. 1993;14(1):94-106. 
93. Ramalho RJR, Valido DP, Aguiar-Oliveira MH. Avaliação do programa de triagem para hipotireoidismo congênito no Estado de Sergipe. Arq Bras Endocrinol Metab. 2000;44(2):157-61.

94. Ramalho RJR, Ramalho ARO, Oliveira CRP, Aguiar-Oliveira MH. Evolução do programa de triagem neonatal para hipotireoidismo congênito e fenilcetonúria no Estado de Sergipe de 1995 a 2003. Arq Bras Endocrinol Metab. 2004;48(6):890-6.

95. Ramos AJS, Rocha AM, Costa ADM, Benicio AV, Ramos ALC, Silva $\mathrm{CRA}$, et al. Avaliação do programa de rastreamento de doenças congênitas em Campina Grande PB, Brasil. Arq Bras Endocrinol Metab. 2003;47(3):280-4.

96. Rose SR, Browm RS, Foley T, Kaplowitz PB, Kaye Cl, Sundararajan S, et al. Update of newborn screening and therapy for congenital hypothyroidism. Pediatr. 2006;177(6):2290-303.

97. Rovet J, Ehrlich R, Sorbara D. Intellectual outcome in children with fetal hypothyroidism. J Pediatr. 1987;110(5):700-4.

98. Rovet JF. Does Breast-feeding protect the hypothyroid infant whose condition is diagnosed by newborn screening? Am $\mathrm{J}$ Dis Child. 1990;144(3):319-23.

99. Rovet JF, Ehrlich RM. Long-term effects of I-thyroxine therapy for congenital hypothyroidism. J Pediatr. 1995;126(3):380-6.

100. Rovet J, Alvarez M. Throid hormones and attention in congenital hypothyroidism. J Pediatric Endocrinol Metab. 1996;9(1):63-6.

101. Rovet JF. Congenital hypothyroidism: long-term outcome. Thyroid. 1999;9(7):741-8.

102. Rovet JF. Children with congenital hypothyroidism and their siblings: do they really differ? Pediatr. 2005;115(1):52-7.

103. Ruibal-Francisco J L, Pérez-Rodriguez O, Dorado-Moles MJ, PiñeiroMartínez, Jiménez-Alamo ML, Bueno-Lozano G. Estudio longitudinal y restrospectivo del desarrollo puberal en mujeres con hipotiroidismo congénito primario. An Esp Pediatr. 2001;54(1):13-7.

104. Salerno M, Di-Maio S, Militerni R, Argenziano A, Valerio G, Tenore A. Prognostic factors in the intellectual development at 7 years of age in children with congenital hypothyroidism. J Endocrinol Invest. 1995;18:774-9.

105 Salerno M, Militerni R, Di Maio S, Bravaccio C, Gasparini N, Tenore A. Intellectual outcome at 12 years of age in congenital hypothyroidsm. Eur J Endocrinol. 1999;141:105-10. 
106. Salerno $M$, Di-Maio $S$, Micillo $M$, Officioso $A$, Ferri $P$, Lettiero $T$, et al. Effect of different starting doses of I-thyroxine on intellectual outcome in congenital hypothyroidism. Horm Res. 2000;53(2 suppl.):16.

107. Salerno M, Micilo M, Di-Maio S, Capallo D, Ferri P, Lettiero T, et al. Longitudinal growth, sexual maturation and final height in patients with congenital hypothyroidism detected by neonatal screening. Eur J Endocrinol. 2001;145(4):377-83.

108. Setian N. Correlações neuroendócrinas na criança. In: Diament A, Cyper S. Neurologia Infantil. 3rd ed. São Paulo: Editora Atheneu; 1996. p. 1215-25.

109. Simons WF, Fuggle PW, Grant DB, Smith I. Educational progress, behavior, and motor skills at 10 years in early treated congenital hypothyroidism. Arch Dis Child. 2004;77:219-22.

110. Siragusa V, Terenghi A, Rondanini GF, Vigone MC, Galli L, Weber G, et al. Congenital hypothyroidism: auxological retrospective study during the first six years of age. J Endocrinol Invest. 1996(19):224-9.

111. Sociedade Brasileira de Triagem Neonatal. Levantamento epidemiológico brasileiro da triagem neonatal; 2003. [Acesso em: 26 jul. 2006]. Disponível em URLL: http://www.sbtn.org.br

112. Souza CFM, Schwartz IV, Giugliani R. Triagem neonatal de distúrbios metabólicos. Ciênc Saúde Colet. 2002;7(1):129-37.

113. Tinelli F, Costagli C, Bargagna S, Marcheschi M, Parrini B, Perelli V. Behavioural disorders in adolescents with early-treated congenital hypothyroidism. Funct Neurol. 2003:18(3):161-4.

114. Torres AO, Pías NC, Rodríguez CM, Gesen CP, Martinez FC, et al. Atención sostenida em niños em edad escolar com hipotiroidismo congênito. Rev Cuba Encobrinol. 2004;15(2).

115. Tylek-Lemánska D, Kumorowicz-Kopiec M, Starzyk J. Screening for congenital hypothyroidism: the value of retesting after four weeks in neonates with low and very low birth eight. J Med Screen. 2005;12(4):166-9.

116 Universidade Federal de Minas Gerais. Núcleo de Pesquisa em Apoio Diagnóstico. [Acesso em: 25 set. 2005]. Disponível em URL: http:/www.medicina.ufmg.br/nupad/triagem/hipointroducao.htm

117. Van Wassenaer AG, Briët JM, Van Baar A, Smit BJ, Tamminga P, Vijlder JJM, et al. Free thyroxine levels during the first weeks of life and neurodevelopmental outcome until the age of 5 years in very preterm infants. Pediatr. 2002;109(3):534-9.

118. Vono-Toniolo J, Kopp P. Thyroglobulin gene mutations and other genetic 
defects associated with congenital hypothyroidism. Arq Bras Endocrinol Metab. 2004;48(1):70-82.

119. Walker D, Gugenhein S, Downs MP, Northern JL. Early language Milestone scale and language screening of young children. Pediatr. 1989;83:284-8.

120. Ward LS, Maciel RMB, Magalhães RF, Kunii IS, Kurazawa GK e Matsumura LK, et al. Comparação entre duas estratégias para a detecção precoce do hipotiroidismo congênito. Rev Assoc Med Bras. 1998;44(2):81-6.

121. Webster RIMBS, Fracp MSC, Majnemer A, Plat OT, Shevell MS. Motor function at school age in children with a Preschool diagnosis of development impairment. J Pediatr. 2005;46(1):80-5.

122. Wetherby AM, Yonclas DG, Bryan AA. Communicative profiles of preschool children with handcaps: implications for early identification. J Speech Hear Disord. 1989;54:148-58.

123. Williams LCA, Aiello ALR. O Inventário Portage Operacionalizado: intervenção com famílias. São Paulo: Memnon Edições Científicas; 2001.

124. World Health Organization. International Classification of impairments, disabilities and handicaps. Geneva: World Health Organization; 1980.

125. Zar JH. Biostatistical analysis. 3rd ed. New Jersey: Prentice-Hall; 1996.

126. Zoeller T. Editorial: local control of the timing of thyroid hormone action in the developing human brain. $J$ Clin Endocrinol Metabol. 2004;89(7):3114-6.

127. Zorzi JL. Linguagem e desenvolvimento cognitivo: a evolução do simbolismo na criança. São Paulo: Pancast; 1994.

128. Zorzi JL. A intervenção fonoaudiológica nas alterações da linguagem infantil. 2nd ed. Rio de Janeiro: Revinter; 2002. 
ABSTRACT 



\section{ABSTRACT}

\section{DEVELOPMENT SKILLS IN CHILDREN WITH CONGENITAL HYPOTHYROIDISM: FOCUS ON COMMUNICATION}

The congenital hypothyroidism, one of the metabolism alterations detected through the neonatal screening, may cause alterations in the individual's global development. The objective of this study was to draw the profile of the development skills in children with congenital hypothyroidism and verify possible influences of the clinical history data in the drawn profile. It had assessed, through Early Languagem Milestone Scale and Inventário Portage Operacionalizado, 35 children (23 of the feminine gender and 12 of the masculine) with congenital hypothyroidism detected by the neonatal screening. The children belonged to the age group from 2 to 36 months and accomplished treatment with hormonal replacement for at least one month. The clinical history data were obtained through interview with the legal responsible for the children and handbooks analysis. In assessement through Early Languagem Milestone Scale, 11 children presented altered performance in auditory expressive function, 2 in visual function and 1 in auditory receptive function. In assessement through the Inventário Portage Operacionalizado, 7 children presented altered performance in the language area, 5 in cognitive area, 4 in motor and social areas and 3 in self-care area. Influences of the clinical history data were not observed in the obtained result. It was concluded that most of the assessed children in this study presented adequate performance for the evaluated skills. For the children with altered performance, larger deficit was observed in language area, mainly in expressive aspects and cognitive area. The influence of the clinical history data was not proven in the profile drawn for the development skills. However, tendency for appropriate performance in the assessed skills was observed among the children that accomplished the neonatal screening, received the diagnosis and began the treatment for the 
congenital hypothyroidism earlier and that received higher dose of thyroxine in the beginning of the treatment.

Keeywords: Congenital hypothyroidism. Child development. Language development. Evaluation. 
